\title{
Antioxidant, antibacterial and antifungal electrospun nanofibers for food packaging applications
}

\author{
Fuat Topuz $^{\mathrm{a}, *}$, Tamer Uyar ${ }^{\mathrm{b}, *}$ \\ ${ }^{a}$ Advanced Membranes \& Porous Materials Center, Physical Sciences and Engineering Division, King Abdullah University of Science and Technology (KAUST), Thuwal 23955-6900, Saudi Arabia \\ ${ }^{\mathrm{b}}$ Department of Fiber Science \& Apparel Design, College of Human Ecology, Cornell University, Ithaca, NY 14853, USA
}

\section{A R T I C L E I N F O}

\section{Keywords}

Food packaging

Electrospinning

Antibacterial

Antioxidant

Antifungal

Nanofibers

\begin{abstract}
A B S T R A C T
Food packaging is a multidisciplinary area that encompasses food science and engineering, microbiology, as well as chemistry, and ignited tremendous interest in maintaining the freshness and quality of foods and their raw materials from oxidation and microbial spoilage. With the advances in the packaging industry, they could be engineered as easy-to-open, resealable, active, as well as intelligent with the incorporation of sensory elements while offering desired barrier properties against oxygen and water vapor. In this regard, the use of the electrospinning approach allows producing nanofibrous packaging materials with large surface-to-volume ratios and enables the higher loading of active agents into packaging materials. Electrospun packaging materials have been produced from various polymers (i.e., synthetic and natural) and their (nano)composites, and were mainly exploited for the encapsulation of active agents for their use as active food packaging materials. The electrospinning process was also used for the deposition of electrospun fibers on films to enhance their performance (e.g., as reinforcement material, or to enhance barrier properties). They could be even engineered to provide nutraceuticals to food, or antioxidant, antimicrobial or antifungal protection to the packaged food. In this article, first, introductory descriptions of food packaging, barrier properties, and electrospinning are given. Afterward, active and intelligent food packaging materials are briefly discussed, and the use of electrospinning for the fabrication of active food packaging materials is elaborated. Particular interest has been given to the polymer-type used in the production of electrospun fibers and active properties of the resultant packaging materials (e.g., antioxidant, antibacterial, antifungal). Finally, this review paper concludes with a summary and future outlook towards the development of electrospun food packaging materials.
\end{abstract}

\section{Introduction}

Food packaging comprises an important portion of the packaging industry, and innovation in this field has been motivated mainly by consumer needs and preferences, as well as variations in global trends, including increased population number and the need of long-distance transportation while maintaining the freshness of the packaged food without spoilage symptoms (Marsh \& Bugusu, 2007). The main in-

\footnotetext{
Abbreviations: Ag-NPs, silver nanoparticles; ATBC, acetyl tributyl citrate; AU, Allium ursinum L.; BC, bacterial cellulose; BCNW, bacterial cellulose nanowhiskers; bLF, bovine lacto-

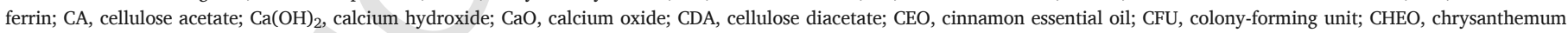

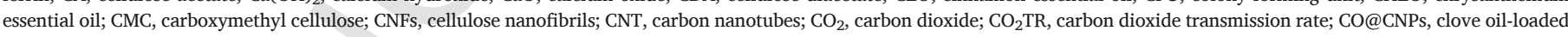

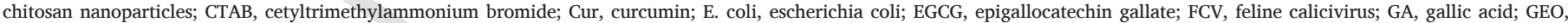

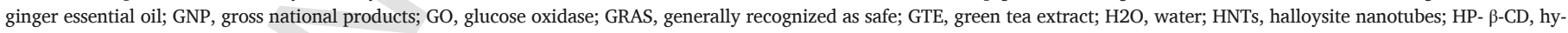

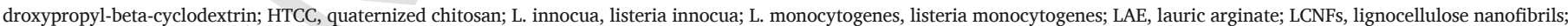

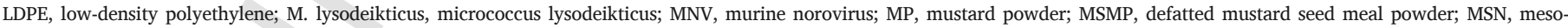

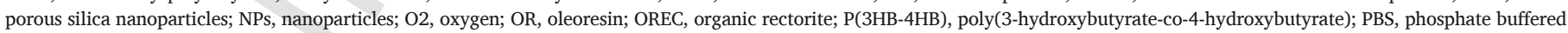

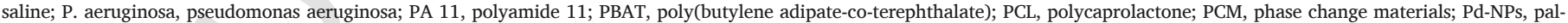

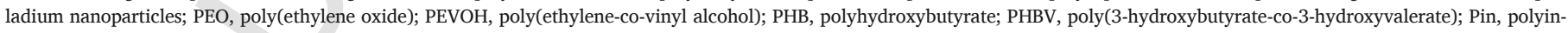

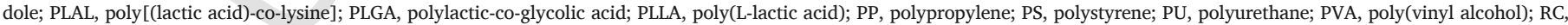

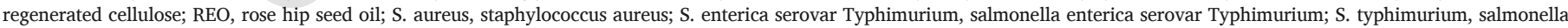

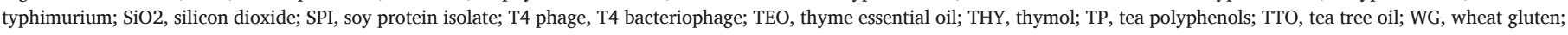

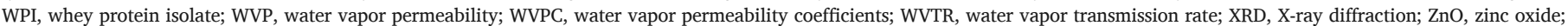
$\beta$-CD, beta-cyclodextrin.

* Corresponding authors.

E-mail addresses: fuat.topuz@rwth-aachen.de (F. Topuz); tu46@cornell.edu (T. Uyar)
} 
tention of food packaging is to prolong the shelf-life of food during storage and transportation. In this context, the definition of the "shelf-life" becomes critical for a better understanding of food preservation. Shelf-life is a term used to refer to the time interval between the packaging after production and the storage of the food with approved specifications (e.g., without spoilage symptoms) under certain storage conditions. Hence, the shelf-life of foods is highly associated with the inherent features of the packaged foods and exposed environmental conditions during their transportation and storage, and most importantly, the quality of the packaging system used (Robertson, 2014).

The packaging sector has become an important part of the global industry and constitutes $2 \%$ of the Gross National Products (GNP) for the developed countries (Robertson, 2006). In this regard, particularly, in the last decade, there has been a growing demand given to the extension of shelf-life of food, product safety, environmental issues, and cost-efficiency. For this purpose, many different material systems have been developed and exploited for the fabrication of high-efficiency food packaging materials. In recent years, special interest has been given to the electrospinning technique for the preparation of nanostructured food packaging materials or the surface functionalization of the packaging materials with functional electrospun nanofibers (Senthil Muthu Kumar et al., 2019a).

Progress in research and development on novel packaging materials has grown drastically to meet the demands of effective food protection against oxidation and the attacks of microorganisms while intelligent food packaging materials with embedded or decorated sensory elements can indicate the instantaneous freshness of food and its characteristics (Müller \& Schmid, 2019). Food packaging materials, beyond the basic necessity of their barrier function against humidity and $\mathrm{O}_{2}$, they can be engineered to be active with the incorporation of active ingredients, such as antimicrobial nanoparticles to keep microbes away from food (Rooney, 1995; Rooney, 2005; Yildirim et al., 2018; Zhong, Oporto, \& Jaczynski, 2017). Such active packaging materials can kill or inhibit pathogenic microorganisms growing on food (Malhotra, Keshwani, \& Kharkwal, 2015). In the last decade, the electrospinning technique has also been exploited for the preparation of packaging materials to extend the shelf-life of the treated and raw food either using the packaging materials produced by electrospinning (Moreira, Morais, Morais, Vaz, \& Costa, 2018) or the deposition of electrospun fibers on the film surface to create bi- or multilayered packaging films (Cherpinski, Torres-Giner, Cabedo, Méndez, \& Lagaron, 2018). Electrospun materials can be produced with desired structural properties by the parameters employed in the electrospinning process and solution properties, and owing to their higher surface-to-volume ratio and structurally tunable properties, electrospun materials can offer many benefits in food packaging (Tang et al., 2019).

Electrospinning is a fiber fabrication technique that produces fibrous non-woven materials by the deposition of an electrically-charged single jet on a negatively charged grounded collector (Xue, Wu, Dai, $\&$ Xia, 2019). It allows the production of electrospun fibers in nanoor micron-sized in diameter, and gives rise to the development of fibrous non-woven materials with a high surface area to mass ratio than their film counterparts and the fibers produced by mechanical extrusion. Owing to the continuity of the process, the electrospinning ends up with an electrospun mat composed of entangled long fibers. Based on the electrospinning system and solution formulation used, the resultant fibers can be porous (Celebioglu \& Uyar, 2011), hollow (Homaeigohar, Davoudpour, Habibi, \& Elbahri, 2017), aligned (Cai et al., 2017), core-shell (Hwang, Lee, Kong, Seo, \& Choi, 2012), and in multilayer coaxial structures (Yang et al., 2019). Furthermore, various (bio)active molecules can be incorporated into the matrix of electrospun nanofibers so they become useful materials in drug delivery (Topuz \& Uyar, 2018a), tissue engineering (Jun, Han, Edwards, \& Jeon, 2018), water treatment (Celebioglu, Topuz, \& Uyar, 2019), textile (Lee \& Obendorf, 2007), food industry (Weiss, Kan- janapongkul, Wongsasulak, \& Yoovidhya, 2012), and food packaging (Torres-Giner, 2011).

Several natural and synthetic polymers, as well as their composites, were exploited for the production of electrospun materials for food packaging. Most studies used zein (Dias Antunes et al., 2017) or gelatin zein (Alp-Erbay, Yeşilsu, \& Türe, 2019) and their combination with other (bio)polymers (Moreno, Orqueda, Gómez-Mascaraque, Isla, \& López-Rubio, 2019). Likewise, cellulose (Azeredo, Barud, Farinas, Vasconcellos, \& Claro, 2019) and chitosan (Díez-Pascual \& Díez-Vicente, 2015) were commonly employed for the fabrication of many bio-based electrospun materials for food packaging applications. Synthetics polymers, such as poly(L-lactic acid) (PLA) (Kara et al., 2016), poly(vinyl alcohol) (PVA) (Lan et al., 2019), and polycaprolactone (PCL) (Salević, Prieto, Cabedo, Nedović, \& Lagaron, 2019) were also used for the development of electrospun food packaging materials. Each of these polymers has its own intrinsic benefits, such as biodegradability, bioactivity, barrier and mechanical properties. The characteristics of electrospun fibers can further be improved with the addition of nanoparticles, particularly for enhancing the barrier and mechanical properties of the resultant packaging materials. In this regard, nanoclays (e.g., montmorillonite) are employed as additives during the preparation of food packaging materials since they can interact physically with polymer chains, resulting in a dense membrane structure (Agarwal, Raheja, Natarajan, \& Chandra, 2014).

In this paper, a comprehensive overview of the use of electrospun nanofibers in food packaging applications was reported. The review first begins with introductory descriptions on active (e.g., antioxidant, antibacterial and antifungal food packaging) and intelligent packaging systems. Afterward, the applications of electrospun food packaging materials are categorized by the polymer-type used in the fabrication of electrospun food packaging materials. Finally, the review concludes with a summary, challenges, and outlook towards the development of electrospun food packaging materials.

\section{Food packaging}

Food packaging plays a critical role in maintaining food freshness and retaining food quality in the period of storage and distribution to the final consumers. The complete goals of the food packaging are to (i) suppress microorganism growth, keep their stability against environmental hazards and resist against oxidation, (ii) mask the unpleasant odors while preserving flavor, (iii) sustained delivery of nutrients, (iv) help the filtration and accumulation of elements, and (v) act as a sensor carrier (Nedovic, Kalusevic, Manojlovic, Levic, \& Bugarski, 2011; Noruzi, 2016). Many different parameters are involved in maximizing food preservation, for example via improving the barrier properties of the packaging materials used. Towards these goals, several materials have been produced to provide an effective barrier against oxygen (Miller \& Krochta, 1997), water vapor (Park \& Chinnan, 1995), and carbon dioxide (Alves et al., 2006; Siracusa, Rocculi, Romani, \& Rosa, 2008). Accordingly, many review papers have been reported on the use of food packaging materials with different barrier properties. Lim et al. (2011) reported a comprehensive book chapter on active and intelligent packaging materials, in which the authors focused on the use of vapor and gas scavengers and the engineering of intelligent packaging materials (Lim, 2011). Maftoonazad et al. (2018) provided an overview of the use of bionanocomposites in food processing (Maftoonazad \& Ramaswamy, 2018).

\section{Active food packaging}

Unlike conventional food packaging materials, active food packaging systems possess oxygen scavengers (Dey \& Neogi, 2019), moisture absorbers (Gaikwad, Singh, \& Ajji, 2019), $\mathrm{CO}_{2}$ absorbers/emitters (Lee, 2016), ethylene absorbers (Bailén et al., 2006), antimicrobial (Mousavi Khaneghah, Hashemi, \& Limbo, 2018) or antifungal agents (Heras-Mozos et al., 2019). In this context, Ozdemir et 
al. (2004) reported a comprehensive review of active food packaging technologies (Ozdemir \& Floros, 2004). Depending on the functional component embedded in the matrix, the packaging material can offer its intrinsic activity, such as antioxidant, antimicrobial and antifungal protection to the packaged food. In this regard, most of the electrospun materials were exploited as active nanostructured food packaging materials with the incorporation of active ingredients into electrospun nanofibers. In the following section, the barrier properties of the food packaging systems are briefly discussed with a particular interest in oxygen $\left(\mathrm{O}_{2}\right)$, water vapor $\left(\mathrm{H}_{2} \mathrm{O}\right)$, and carbon dioxide $\left(\mathrm{CO}_{2}\right)$ permeability.

\subsection{Barrier properties}

The main intention of using packaging materials is to put a barrier between the environment and food. Hence, the use of packaging materials as a barrier against environmental conditions becomes vital to able to prolong the shelf-life of the treated and raw food. In this regard, the low barrier properties of the used packaging materials can affect the nutritional quality and freshness of food. Therefore, ideal packaging materials are expected to have sufficient barriers against $\mathrm{H}_{2} \mathrm{O}$ and $\mathrm{O}_{2}$, whose presence can trigger the development of microbial spoilage on food, resulting in a shorter shelf-life. Particularly, for highly porous packaging materials, such as electrospun materials, the barrier properties of such materials can be improved with the incorporation of active agents to adsorb water vapor and oxygen.

\subsubsection{Water Vapor Permeability (WVP)}

WVP is one of the key parameters in food packaging applications that can directly reduce or extend the shelf-life of the packaged food. It can be expressed over water vapor permeability coefficients (WVPC) that indicate the amount of water vapor permeating per unit of area and time in packaging materials ( $\mathrm{kg} \mathrm{m} \mathrm{m} \mathrm{m} \mathrm{s}^{-1} \mathrm{~Pa}^{-1}$ ) (Siracusa et al., 2008). In addition to the WVPC, another important parameter is the water vapor transmission rate (WVTR), which is expressed in $c c \mathrm{~m}^{-2} \mathrm{~s}^{-1}$ (or $\mathrm{g}$ $\mathrm{m}^{-2} \mathrm{day}^{-1}$ ). Particularly, in bakery and delicatessen, avoiding water permeation is highly crucial, and thus, these parameters become critical in maintaining the quality of the packaged food by protecting the food from the environmental conditions.

\subsubsection{Oxygen permeability}

Oxygen permeability is another critical factor that can affect food freshness, and hence, the engineering of food packaging materials with low oxygen permeability is highly recommended to preserve the freshness and nutritive quality of the foods during their storage. Many treated foods are highly sensitive to the exposure of oxygen, particularly long-term oxygen exposure may lead to worsening in the food quality in terms of variation in taste, odor, the color of the food or enable the growth of microorganisms (Dey \& Neogi, 2019). In this regard, the use of oxygen scavengers can prolong the shelf-life while maintaining original food quality since they can adsorb the dissolved oxygen and oxygen in the air. In this regard, many papers on the use of oxygen scavengers for food packaging applications were reported. Several metals, e.g., palladium (Cherpinski, Gozutok, Sasmazel, Torres-Giner, \& Lagaron, 2018), iron (Foltynowicz, 2019), vitamins (i.e., ascorbic acid (vitamin C) (Lee et al., 2018) and $\alpha$-tocopherol (vitamin E) (Marcos et al., 2014)), unsaturated hydrocarbons (Arvanitoyannis, 2012), and microorganisms have been frequently used as oxygen scavengers.

\subsubsection{Carbon dioxide $\left(\mathrm{CO}_{2}\right)$ permeability}

Similar to the oxygen and water vapor permeability, the $\mathrm{CO}_{2}$ barrier property is significant in the food packaging industry. The presence of $\mathrm{CO}_{2}$ at a properly high concentration can inhibit or mitigate microbial growth on foods (Daniels, Krishnamurthi, \& Rizvi, 1985) and therefore, assists in preserving the food freshness and extending the shelf-life. In addition to its critical role in inhibiting microbial growth, it can act as an antioxidant agent and protect the food from oxidation (Puligundla, Jung, \& Ko, 2012). The $\mathrm{CO}_{2}$ barrier is given over the permeability coefficients of $\mathrm{CO}_{2}$, which denote the amount of $\mathrm{CO}_{2}$ that permeates per unit area and time in the packaging materials and expressed in $\mathrm{kg} \mathrm{m} \mathrm{m}^{-2} \mathrm{~s}^{-1} \mathrm{~Pa}^{-1}$. Likewise, $\mathrm{CO}_{2}$ transmission rate $\left(\mathrm{CO}_{2} \mathrm{TR}\right)$ is given as $\mathrm{cc} \mathrm{m}^{-2} \mathrm{~s}^{-1}$ (or $\mathrm{g} \mathrm{m}^{-2}$ day $^{-1}$ ).

Depending on the storage temperature, unpasteurized fermented foods (e.g., yogurt) can harvest a considerable amount of $\mathrm{CO}_{2}$. During the long-term storage of such foods, excess $\mathrm{CO}_{2}$ can be produced, resulting in detrimental effects on food product quality and packaging integrity. Thus, a moderate concentration of $\mathrm{CO}_{2}$ is most desired for optimal food preservation, and therefore, $\mathrm{CO}_{2}$ absorbers can be incorporated into the packaging of such foods. Among many examples, the most commonly used ones are calcium oxide $(\mathrm{CaO})$, calcium hydroxide $\left(\mathrm{Ca}(\mathrm{OH})_{2}\right)$, and physical absorbers, such as activated carbon and zeolites. In this regard, Lee et al. reported a comprehensive review of $\mathrm{CO}_{2}$ absorbers for food packaging applications (Lee, 2016).

\subsection{Antioxidant food packaging}

The growth of molds, insects, and aerobic bacteria requires oxygen. Therefore, the presence of oxygen absorbers can prevent the growth of bacteria, molds, and insect infestation (Powers \& Berkowitz, 1990). The oxidation of pigments and lipids and the loss of $\mathrm{O}_{2}$ sensitive vitamins (e.g., vitamin $\mathrm{A}, \mathrm{C}$, and $\mathrm{E}$ ) can give rise to alterations in texture, flavor, color and nutritive value (Hernández-López, Rodríguez-Carpena, Lemus-Flores, Galindo-García, \& Estévez, 2016). Such alterations can transform the food into an unacceptable form for human consumption. Most importantly, such chemical transformation can also cause the formation of toxic aldehydes owing to the degradation of polyunsaturated fatty acids (Ayala, Munoz, \& S, 2014; Pizzimenti et al., 2013). As oxygen can easily permeate through most membranes, the exposure of a high level of oxygen in the food packaging can facilitate the growth of microbial species (Kerry, 2008), including aerobic bacteria or insects, the loss of $\mathrm{O}_{2}$ sensitive nutrients (e.g., vitamins), and pigments (Han, Ruiz-Garcia, Qian, \& Yang, 2018). Variations in such values can affect the edibility of food for human consumption. Furthermore, toxic aldehydes can be formed by the degradation of polyunsaturated fatty acids (PUFAs - healthy nutrition for the prevention of cardiovascular diseases) (Gómez-Estaca, López-de-Dicastillo, Hernández-Muñoz, Catalá, \& Gavara, 2014; Realini \& Marcos, 2014). Various oxygen scavenging agents are used to react with oxygen and mitigate $\mathrm{O}_{2}$ abundance. The most common types of oxygen scavenging compounds are ascorbic acid, some nylons, catechol, enzymes (e.g., glucose oxidase), ferrous acid, unsaturated hydrocarbons, and sulfites. In this context, a complete list of oxygen scavengers has been given by Gómez-Estaca et al. (2014), who reported a comprehensive review on antioxidant active food packaging materials (Gómez-Estaca et al., 2014).

\subsection{Antibacterial food packaging}

Antimicrobial packaging contains antimicrobial agents embedded in the packaging system for delaying or inhibiting microbial growth and/ or contamination during storage and transportation (Han, 2005). In this regard, silver ( $\mathrm{Ag}$ ) has been commonly exploited as an antibacterial agent in food storage applications (Echegoyen \& Nerín, 2013). It has a very long history and has been used from ancient societies, who used silver vessels for the storage of wine and water. Antibacterial food packaging materials were produced mainly incorporating the antimicrobial agents (e.g., essential oils (Vergis, Gokulakrishnan, Agarwal, \& Kumar, 2015; Wang et al., 2011), polycations (Fernandez-Saiz, 2011), chitosan (Ignatova, Manolova, \& Rashkov, 2013) 
and nanoparticles (e.g., Ag-NPs (Tavakoli, Rastegar, Taherian, Samadi, \& Rostami, 2017)) to enhance the safety of the packaged food against microbial spoilage.

\subsection{Antifungal food packaging}

Although the presence of several studies on antimicrobial food packaging materials, less attention has been given to the fabrication of antifungal packaging materials. Many antimicrobial food packaging materials are not enough to control fungal spoilage, and therefore, the use of essential oils and preservatives has increased drastically owing to their high activity against the inhibition of mold growth (Paster et al., 1990). As molds mostly develop on the surface of the products, the use of antifungal food packaging materials can mitigate or inhibit their growth (Leyva Salas et al., 2017). As an alternative to the fungicides, the use of essential oils as antifungal agents can affect the organoleptic properties of foods. Natural products (e.g., natamycin) and preservatives (e.g., potassium sorbate) are more acceptable for direct addition to the products. In this regard, a comprehensive review on active packaging with antifungal activities is available for interested readers (Nguyen Van Long, Joly, \& Dantigny, 2016).

\section{Intelligent food packaging}

Smart packaging materials are capable of monitoring the condition of the packaged food, providing instantaneous data on food quality during storage and transportation (Müller \& Schmid, 2019; Vanderroost, Ragaert, Devlieghere, \& De Meulenaer, 2014; Yousefi et al., 2019). Unlike active food packaging, intelligent food packaging systems do not possess any active agents that involve extending the shelf life of food, and indeed, it contains active sensory elements in the packaging materials to monitor characteristics related to the food's quality. In this regard, several external discrete components are incorporated into the packaging materials: these are temperature (Fuertes, Soto, Carrasco, Vargas, Sabattin, \& Lagos, 2016), freshness (Kuswandi, 2017) and gas indicators (Mills, 2009). Electrospun materials were also exploited as carriers for intelligent sensors. Some examples include the detection of cauliflower mosaic virus through DNA-specific sequences of self-doped PANI nanofibers with deposited Au microspheres (Wang, Yang, Li, \& Jiao, 2011), and the visual detection of L-ascorbic acid in juices with the hybrid nanofibers of polyamide and polyaniline (Wen et al., 2015). A comprehensive review of the intelligent food packaging technologies with a focus on sensory elements is available (Ghaani, Cozzolino, Castelli, \& Farris, 2016).

\section{5. Electrospinning}

Electrospinning is an effective technology for the production of ultrathin continuous fibers under an electric field from polymeric and non-polymeric systems or from their composites driven by electrostatic forces to produce a single continuous jet with diameters from $10 \mathrm{~nm}$ to few micrometers and can length up to kilometers (Sundaray et al., 2004). Such a process have been applied to polymer solutions (Topuz \& Uyar, 2017), melted polymers (Dalton, Grafahrend, Klinkhammer, Klee, \& Möller, 2007), polymer-free systems (Topuz \& Uyar, 2018b) and molecule-nanoparticle mixtures (Topuz \& Uyar, 2019) from laboratory-scale production to the industrial-scale. The texture and structural properties of such fibers can be tailored to be porous (Katsogiannis, Vladisavljević, \& Georgiadou, 2015), and hollow (Anka \& Balkus, 2013). Electrospun materials have been exploited in many fields, including tissue engineering (T. Uyar, 2017), water treatment (Celebioglu, Topuz, Yildiz, \& Uyar, 2019), drug delivery (Topuz \& Uyar, 2018a), food industry (Noruzi, 2016), and food packaging (Aytac, Keskin, Tekinay, \& Uyar, 2017). Also, they can be engineered to carry bioactive agents for their use in the food industry. In this context, Lim et al. (2015) reported an overview on the use of electrospraying and electrospinning for the encapsulation of bioactive compounds (Lim, 2015).

Obtaining a bead-free fiber structure from electrospinning solutions is dependent on several parameters, particularly on solution conductivity, viscosity, and surface tension (Haider, Haider, \& Kang, 2018; Xue, Xie, Liu, \& Xia, 2017). Depending on the solution viscosity and conductivity, electrospraying can take place instead of electrospinning, giving rise to the formation of electrosprayed beads (Jaworek, 2007; Topuz, Satilmis, \& Uyar, 2019). However, increasing the polymer concentration or solution conductivity can result in the formation of beaded or bead-free fibers. The resultant fibers can be aligned with the use of a drum collector (Hamsici et al., 2017). Furthermore, the structure of electrospun fibers can be engineered to be core-shell (Aytac \& Uyar, 2018), triaxial (Han \& Steckl, 2013), Janus (Zhou et al., 2015), flat/ribbon (Topuz \& Uyar, 2017) and so-forth using an appropriate spinneret and changing the electrospinning process parameters and solution properties (Fig. 1).

There are different electrospinning methods to produce nanofibrous materials. Principally, the electrospinning systems can be classified into two major categories: (i) solution electrospinning and (ii) melt electrospinning. In addition, there are some other examples of electrospinning systems such as gas jet electrospinning (Lin et al., 2008), magnetic field-assisted electrospinning (Xu et al., 2019), conjugate electrospinning (Wang et al., 2019), bubble electrospinning (Yang, He, $\mathrm{Xu}, \& \mathrm{Yu}, 2009$ ), and centrifugal electrospinning (Peng, Liu, \& Ramakrishna, 2017). In addition to the typical solution electrospinning, melt electrospinning was also used to develop bioactive packaging structure using polycaprolactone and Rosemary (Rosmarinus officinalis L.) plant based extract (Bhullar, Kaya, \& Jun, 2015). Such electrospinning eliminates the necessity of toxic solvents. However, owing to feasibility and versatility, the solution electrospinning system has been commonly employed in the development of fibrous food packaging materials. Furthermore, unlike melt electrospinning, the solution electrospinning does not require any high temperature and does not rely on some specific polymers. Compare to nozzle-based electrospinning systems (Fig. 1), nozzle-less electrospinning systems allow mass production of nanofibers (Wei, Sun, Liu, Xiong, \& Qin, 2019). In this regard, the use of nozzle-less electrospinning yield multiple jets compared to the conventional single nozzle-based electrospinning and therefore produce nanofibrous mats with higher productivity. On the other hand, the electrospinning yield can be enhanced using alternating current electrospinning, which enables an electrostatic field with periodically changing polarity (Balogh et al., 2015). Even though the presence of several electrospinning systems, the literature reports showed that electrospun food packaging materials were mainly produced using the conventional solution electrospinning system as shown in Fig. 1.

\section{Electrospun materials for food packaging}

There is a growing demand for producing food packaging materials with a high loading of active agents and highly responsive nature so that the materials can release active molecules as a response to surrounding conditions. Electrospun materials allow high loading of active agents, and their higher surface area boosts their response to its surrounding conditions with the timely release of active materials. Furthermore, the smaller gaps between the fibers make a barrier against bacterial entry. Moreover, electrospun materials offer many advantages over their film counterparts, such as structural and functional advantages. A high surface-to-volume ratio, intertwined fibrous structure induced porosity, tailored surface texture and other tunable physical properties are the main structural advantages of electrospun fibers. On the other hand, the functional advantages of them are a high-loading capacity, enhanced stability of sensitive bioactive molecules, the sustained and controlled release of the embedded molecules, and the presence of food-grade (bio)polymers (Tian et al., 2019). Even though many advantages of electrospun materials in food packaging, there 


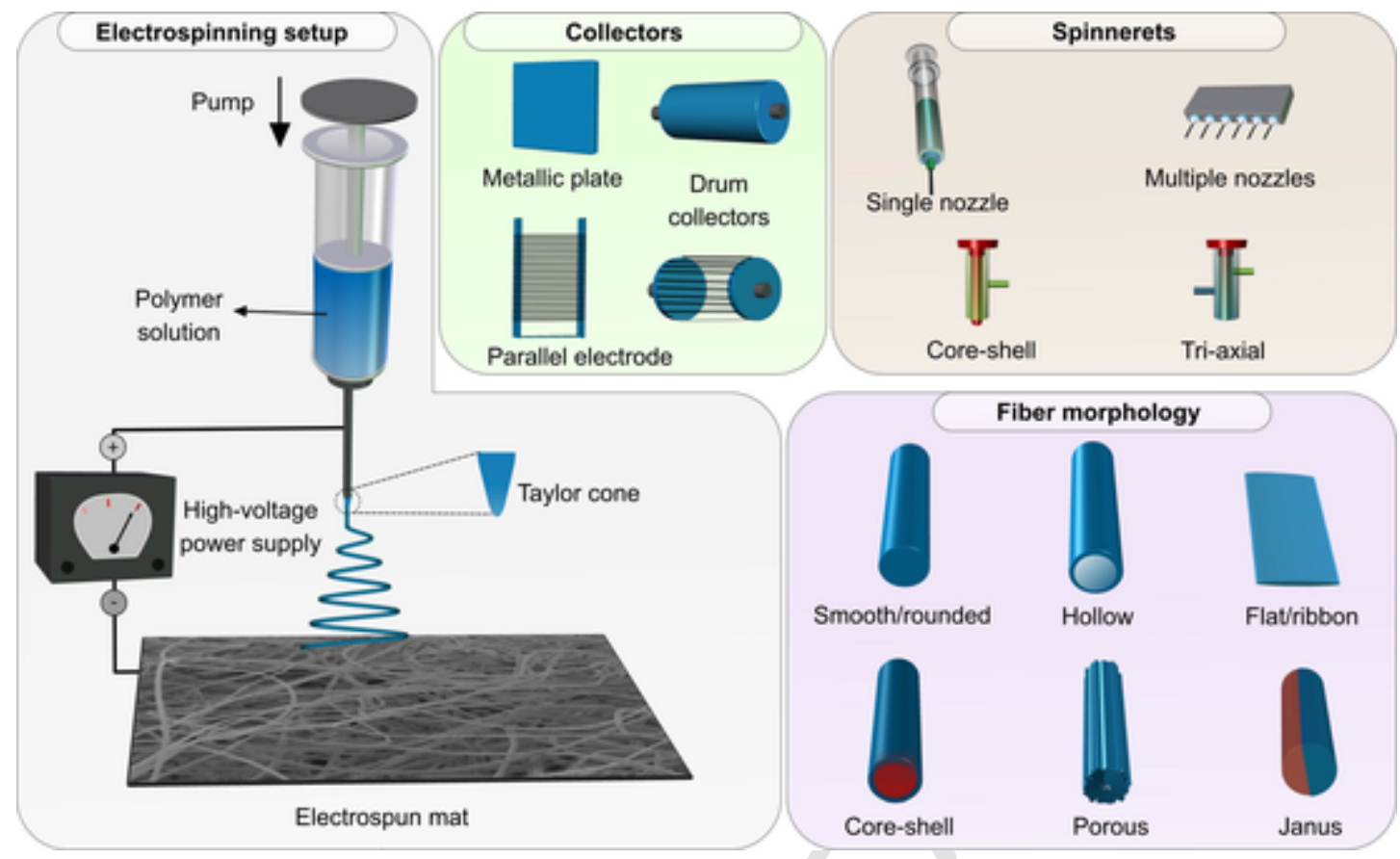

Fig. 1. A schematic illustration of the electrospinning process with its important components. Typical collectors, spinnerets and the structure of typical electrospun fibers are shown.

are also critical concerns for their use: for example, loose fibers may get into the food. However, this can be solved over fusing the fibers on a base substrate that will make a barrier between food and fibers. Their low barrier against oxygen and water vapor owing to their highly porous matrix stands as a critical problem.

The food application of electrospun fibers has grown drastically in the last decade, and several research papers and reviews have been reported on this topic. In one example, Bhushani et al. (2014) reported a review paper on electrospun and electrosprayed materials in food-based applications (Anu Bhushani \& Anandharamakrishnan, 2014), where the authors presented an overview on the applications of electrospun fibers and electrosprayed beads in food science, including food packaging. Likewise, Zhang and colleagues reported a literature review on the emulsion electrospinning for food applications, including a short section on food packaging applications (Zhang, Feng, \& Zhang, 2018). An overview on the use of the electrospinning system for the preparation of nanostructured multilayers for food packaging is also available as a book chapter, in which the authors categorized the electrospun films by their barrier properties (María José Fabra \& Lagaron, 2016). The same research group reported a review on the use of the electro-hydrodynamic process in food packaging and food encapsulation applications with a particular interest on nanoencapsulation, multilayer packaging and active food packaging (Echegoyen, Fabra, Castro-Mayorga, Cherpinski, \& Lagaron, 2017). Another review was reported on the use of electrospun fibers in different fields, including a short section on food packaging (Aruchamy, Mahto, \& Nataraj, 2018). An overview of electrospun nanofibers, containing antimicrobial plant extracts for their applications in different fields, encompassing active food packaging was reported (Zhang, Ronca, \& Mele, 2017). Torres-Giner and colleagues published a book chapter on the electrospinning system for the packaging industry, and the authors reported the packaging applications of electrospun fibers, particularly focusing on their technological impacts and potential scale-up, as well as a market introduction (Torres-Giner, Busolo, Cherpinski, \& Lagaron, 2018). Corradini et al. (2014) reviewed advances in the food-packaging applications of zein-based materials, including electrospun fibers. Koro de la Caba and the co-workers briefly mentioned the use of electrospinning for the development of protein products for food packaging applications (Corradini et al., 2014). Masumeh et al. (2016) reported a review on electrospun nanofibers in agriculture and the food industry (Noruzi, 2016). A review article on nanostructured bilayers in food packaging, covering the studies related to the electrospinning was reported (Fabra, Busolo, Lopez-Rubio, \& Lagaron, 2013). A book chapter on the production of electrospun nanostructures for food applications is also available (Neo, Ray, \& Perera, 2018). Recently, a review paper on the use of electrospun nanofibers for the food industry and packaging perspective was reported (Senthil Muthu Kumar et al., 2019b). Even though the presence of reports on the use of electrospinning for the development of food packaging materials, these reports mostly provide a short overview on the use of electrospun fibers for food and food packaging applications. In this paper, a comprehensive overview of the use of electrospinning for the fabrication of active food packaging materials is elaborated with incorporating all reports on the electrospun fibers for food packaging applications. Furthermore, the existing limitations and future scope are highlighted. The food packaging materials are categorized based on the components of electrospun nanofibers (i.e., polysaccharides, proteins, other bio-based polymers, synthetic polymers, and nanocomposite systems) (Fig. 2). All functional materials using electrospinning and/or intended for food applications are incorporated in the manuscript, focusing on their active properties (i.e., antioxidant, antimicrobial and antifungal). In the following section, the food packaging applications of electrospun fibers are elaborated and their active properties are discussed.

\subsection{Electrospun materials from natural polymers for food packaging}

\subsubsection{Polysaccharide-based electrospun materials}

Owing to their environmental abundance and low cost, various polysaccharides (e.g., cellulose, cellulose acetate, and chitosan) were exploited for the fabrication of electrospun food packaging materials. In one example, a blend of chitosan, poly(ethylene oxide) (PEO) and phenolic compounds were electrospun into a fibrous mat to be employed as food packaging materials (Kuntzler, Costa, \& Morais, 2018). The nanofibers with a mean diameter of $214 \pm 37 \mathrm{~nm}$ were generated from a blend of $3 \%$ chitosan $/ 2 \%$ PEO solution containing $1 \%$ phenolic compounds and showed antibacterial activity against the growth of Es- 

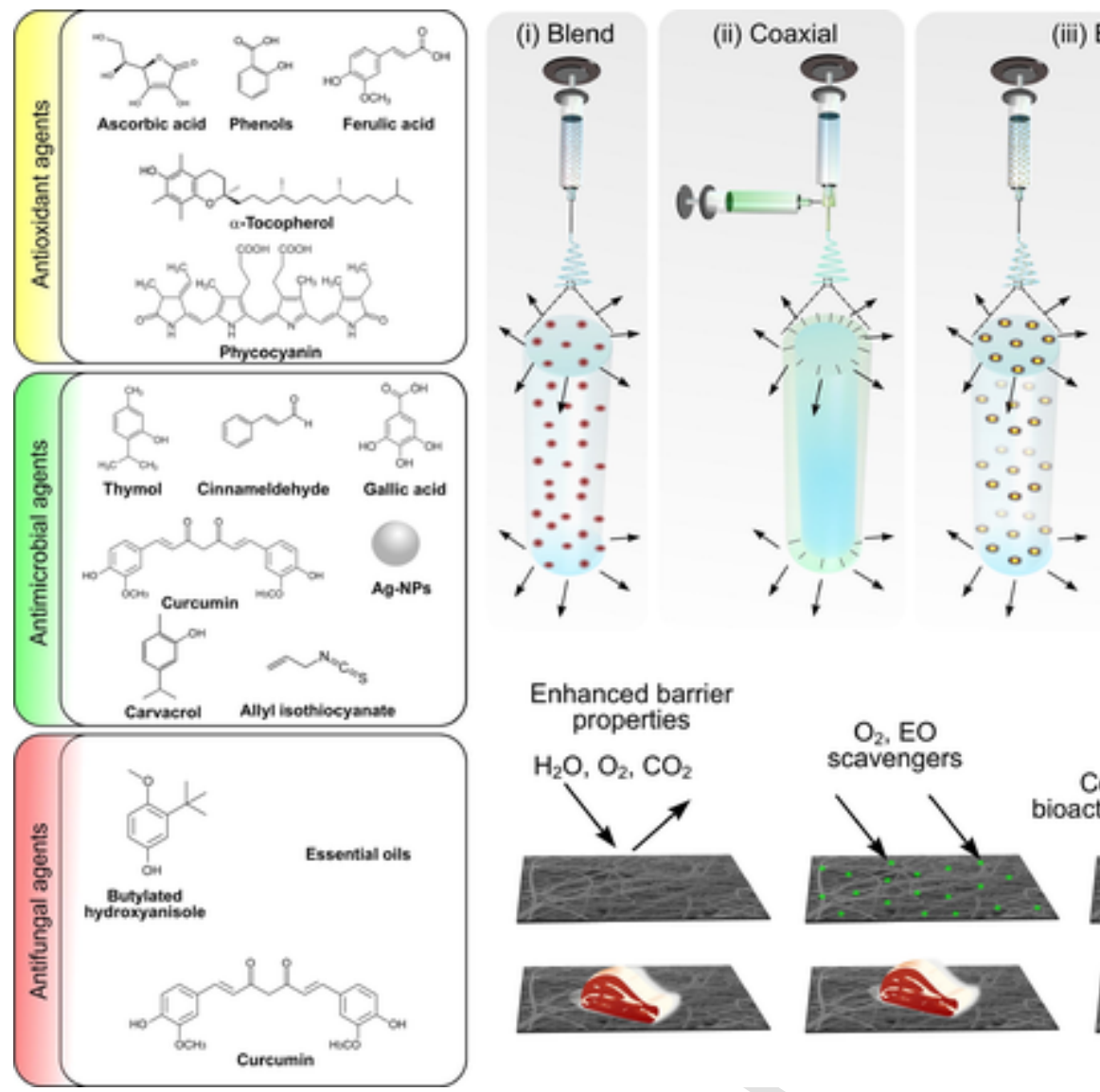

(iii) Emulsion

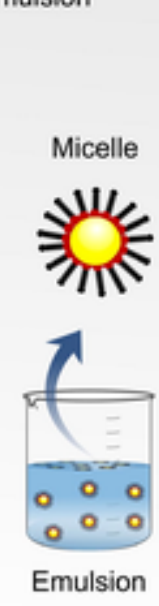

\section{Enhanced barrier properties}
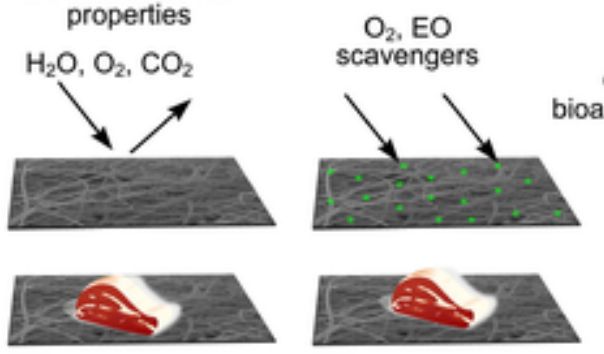

Controlled release of bioactives and nutraceuticals
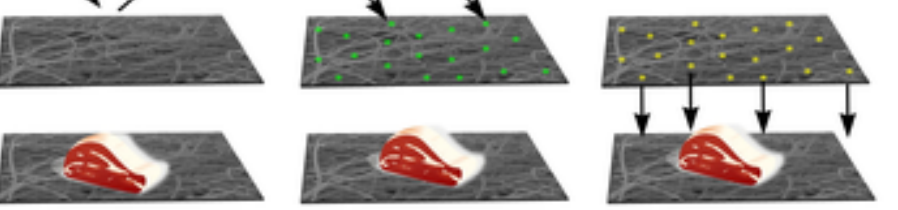

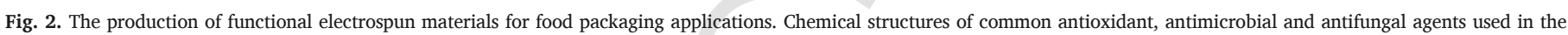
electrospun fibers are shown. The preparation of electrospun fibers with different structural properties and common routes for the incorporation of active reagents are illustrated.

cherichia coli (E. coli) ATCC 25972 and Staphylococcus aureus (S. aureus) ATCC 25923. Owing to the intrinsic biodegradability, biocompatibility, as well as antibacterial activity of the encapsulated phenolic compounds, the resultant electrospun materials have great potential to be used as active food packaging materials. Arkoun et al. (2017) reported the preparation of antibacterial chitosan-based nanofibers, which were produced by the electrospinning of chitosan and PEO (i.e., used as a carrier matrix) from their solutions in acetic acid (Arkoun, Daigle, Heuzey, \& Ajji, 2017a). By tuning the PEO content, bead-free fibers were produced sizing $\sim 80 \mathrm{~nm}$ in diameter. The antibacterial properties of the fibers were explored against Gram-negative Salmonella Typhimurium (S. Typhimurium) and E. coli, and Gram-positive Listeria innocua (L. innocua) and $S$. aureus bacteria, and the results showed that the nanofibers react with the bacterial cell wall, inducing the leakage of intracellular components, e.g., DNA and proteins. The same research group studied the mechanism of action of electrospun chitosan-based food packaging fibers against pathogenic bacteria and meat spoilage (Arkoun, Daigle, Heuzey, \& Ajji, 2017b). The nanofibers were prepared using the blend of chitosan and PEO, and the antimicrobial activity of the nanofibers was explored against $L$. innocua, S. Typhimurium, E. coli and S. aureus - common bacteria involved in food contamination and spoilage. The experimental findings revealed that the antibacterial action of the nanofibers, regardless of bacterial type, was dependent on the protonation of their amino groups. Furthermore, the bacterial susceptibility was strain-dependent, displaying higher susceptibility at a reduced rate of $99.9 \%$. Moreover, using the electrospun mat could prolong the shelf-life of fresh meat for one week, demonstrating their great potential in food packaging applications (Fig. 3A, B). Another paper from the same research group reported on the implementation of chitosan-based nanofibers as bioactive food packaging materials (Ark- oun, Daigle, Holley, Heuzey, \& Ajji, 2018). They produced chitosan-based nanofibers and investigated the in situ and in vitro efficiency of the electrospun nanofibers as the inner part of a multilayer packaging material in keeping the quality of the red meat over time. Similar to the previous study, the fibrous film of chitosan and PEO was produced by electrospinning on the top of conventional multilayer food packaging materials, and the oxygen (OTN) and water vapor properties (WVTR) of the fibers deposited film and neat membranes were explored. The OTN results showed neat $\mathrm{PEO}$ and composite $\mathrm{PEO} /$ chitosan packaging exhibited no drastic difference: i.e., $1.29 \pm 0.3 \mathrm{~mL} /\left(\mathrm{m}^{2} \mathrm{~d}\right)$ for the neat PEO packaging, while it was $1.46 \pm 0.3 \mathrm{~mL} /\left(\mathrm{m}^{2} \mathrm{~d}\right)$ for the chitosan/PEO based multilayer packaging. On the other hand, the WVTR measurements revealed a more drastic change, and the WVTR decreased from $19.10 \pm 2.3$ to $14.89 \pm 1.2 \mathrm{mg} /\left(\mathrm{m}^{2} \mathrm{~d}\right)$ with the use of chitosan/PEO multilayer food packaging material instead of the neat PEO film. The antimicrobial activity of the films was explored against the growth of $L$. innocua, S. aureus, S. enterica serovar Typhimurium and E. coli, which are common bacteria involved in the change of food products. The efficacy of the chitosan/PEO film against the meat spoilage by E. coli was also explored. After treating at $37{ }^{\circ} \mathrm{C}$ in PBS for $4 \mathrm{~h}$, the chitosan-based electrospun films showed substantial inhibition of bacterial growth (>99.9\%). The in situ testing of the chitosan-based film against the growth of $E$. coli on meat samples showed a substantial reduction of bacterial growth by $95 \%$, and their bactericidal effect extended the shelf-life of the meat up to one week (Fig. 3C and D).

Sumnu and colleagues reported the electrospinning of hydroxypropyl methylcellulose/PEO blend nanofibers and explored their physical properties, including water-vapor permeability (WVP) (Aydogdu, Sumnu, \& Sahin, 2018). The WVP of the hydroxypropyl cellulose nanofibers decreased with increasing polymer concentration. 

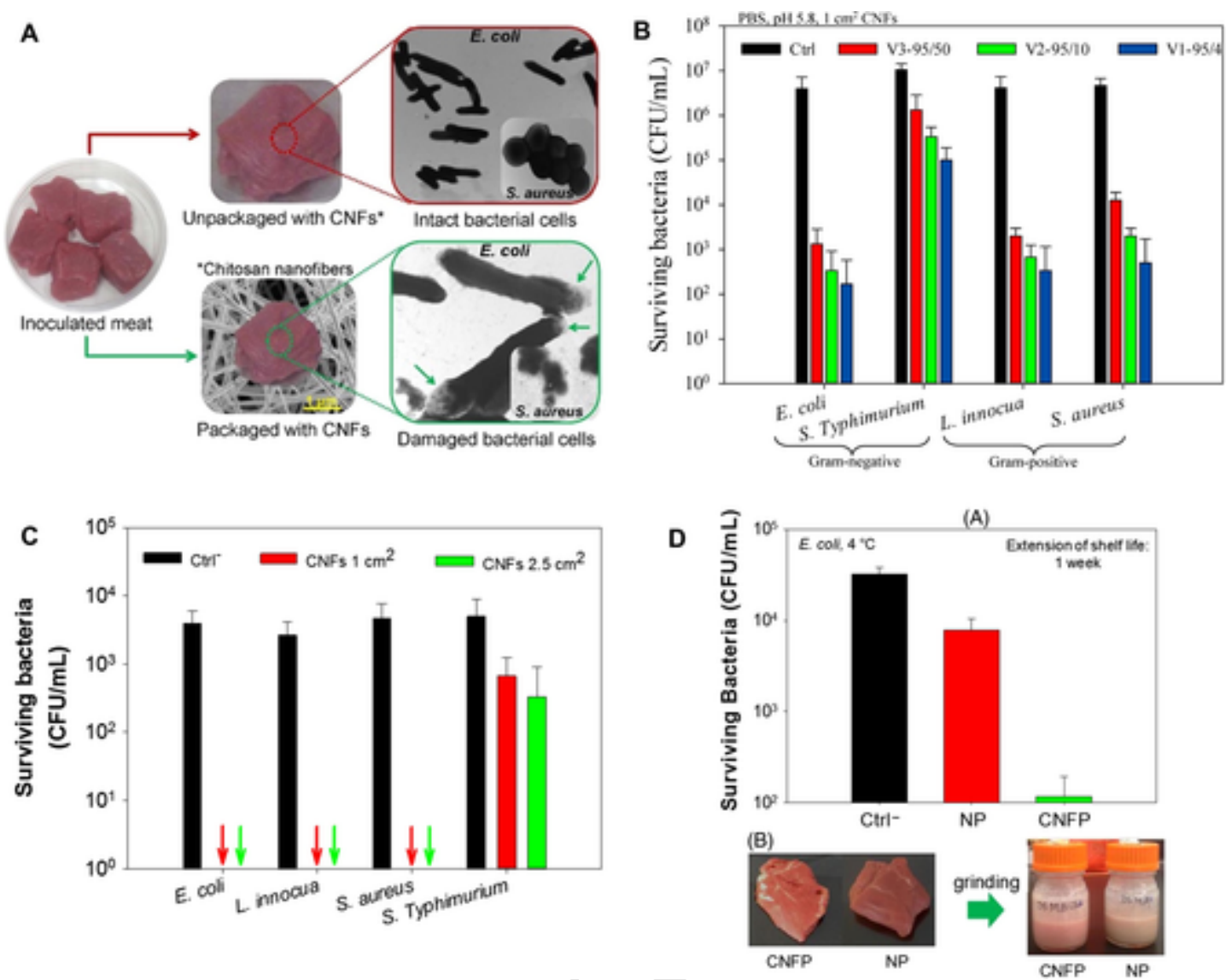

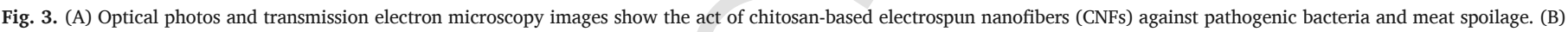

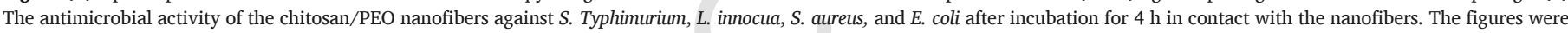

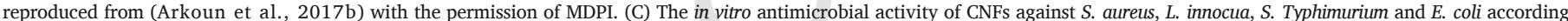

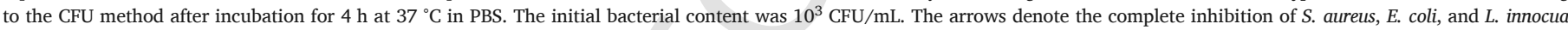

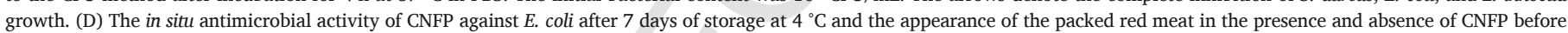

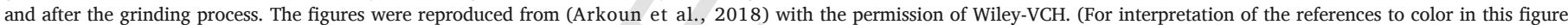
legend, the reader is referred to the web version of this article.)

The nanofibers exhibited a semicrystalline structure and high thermal stability. The low WVP and high thermal stability suggest the use of these biopolymer nanofibers as potential food packaging materials. Antimicrobial food packaging materials can also be prepared by phage therapy. In this regard, Korehei et al. (2013) reported T4 bacteriophage encapsulated cellulose diacetate/PEO fibers as potential food packaging materials (Korehei \& Kadla, 2014). T4 bacteriophage (T4 phage) was encapsulated in core/shell electrospun fibers of cellulose diacetate (CDA) and PEO, as well as in their blends. A burst release was observed upon submersion in the buffer when PEO was used as a shell layer, while the use of the blending of PEO and CDA drastically lowered the rate of phage release. On the other hand, no release of T4 phage was observed from the CDA fibers. After the release of the T4 phage, the fiber morphology changed from discontinuous to minimally swollen fibers. Composite biodegradable electrospun fibers of bacterial cellulose and polyindole were produced by in situ polymerization of indole in the presence of cellulose nanofibers activated in an acidic medium (Zhijiang, Cong, Ping, \& Yunming, 2018). The composite nanofibers demonstrated high antimicrobial affinity towards Gram-positive $S$. aureus and Gram-negative $E$. coli bacteria and could be degraded in 100 days in a simulated body fluid. A polysaccharide ternary fibrous system was produced by the electrospinning of the mixed solution of chitosan, PEO and lauric arginate (LAE) (Deng et al., 2018). The incorporation of LAE into the chitosan/PEO acetic solutions did not affect their physical properties, however, it led to an increase in the fluorescent intensity of chitosan as a result of electrostatic interactions.
The uniform bead-free nanofibers with a mean diameter of $150 \mathrm{~nm}$ were produced. The homogeneous distribution of LAE molecules throughout the fiber matrix was confirmed by both FTIR and thermal analysis. The existence of hydrogen bonding and electrostatic interactions mediated by the LAE incorporation affected intra- and intermolecular interactions between chitosan and PEO. Furthermore, with that, the mobility of the polymer molecules resulted in the enhanced crystallinity and reduced melting point. The incorporation of LAE significantly increased the hydrophilicity of the resultant fibers, as evidenced by a contact angle decrease from 39 to $10^{\circ}$. Meanwhile, the antimicrobial activity of the fibers against $S$. aureus and $E$. coli was directly related to the amount of LAE used. Moreover, the antimicrobial mechanism of the fibers was attributed to the cell membrane damage.

Diez-Pascual et al. (2015) reported antimicrobial and sustainable food packaging materials based on the chitosan nanofiber deposited poly(butylene adipate-co-terephthalate) (PBAT) films (Díez-Pascual \& Díez-Vicente, 2015). The antimicrobial food packaging materials were produced through the electrospinning of chitosan nanofibers on the surface of the PBAT films. Infrared (IR) spectroscopy analysis confirmed the presence of strong hydrogen bonding interactions between PBAT and chitosan nanofibers. The electrospun nanofibers served as nucleating agents and raised the crystallization temperature and the crystallinity degree of the polyesters. At the same time, they enhanced the thermal stability and flammability. Furthermore, the decoration of the PBAT surface with the chitosan nanofibers led to enhanced mechanical strength, stiffness, glass transition temperature while decreas- 
ing the water vapor and oxygen permeability, as well as ductility. The migration levels in both polar and non-polar simulants were substantially lower than the total limits established by the current regulation on food-contact materials. These bionanocomposites showed antimicrobial activity against foodborne pathogens: Gram-negative $E$. coli and $S$. enteritidis and Gram-positive B. Subtilis and S. aureus bacteria. However, a stronger biocidal activity was observed for Gram-negative cells. Owing to the sustainable and biodegradable structure, these materials can be exploited as green packaging stuff in the beverage and food industry. Active agents were incorporated into electrospun nanofibers using pharmaceutical excipients, such as cyclodextrin (CD). CD is a toroidal-shaped oligosaccharide with a wide range of applications, including their use as a host molecule for complexation with active agents to keep them at the stable and active form in electrospun nanofibers. In this regard, various research papers have been reported on the use of $\mathrm{CD}$ molecules for the encapsulation of quercetin (Aytac, Ipek, Durgun, \& Uyar, 2018; Aytac, Kusku, Durgun, \& Uyar, 2016b), $\alpha$-tocopherol (Aytac \& Uyar, 2016), (Aytac, Kusku, Durgun, \& Uyar, 2016a), allyl isothiocyanate (Aytac, Dogan, Tekinay, \& Uyar, 2014), eugenol (Kayaci, Ertas, \& Uyar, 2013), vanillin (Kayaci \& Uyar, 2012) in electrospun nanofibers. Likewise, Fuenmayor et al. (2013) reported the fabrication of pullulan based electrospun fibers for R- $(+)$-limonene encapsulation (Fuenmayor et al., 2013). An emulsion of pullulan and $\beta$-cyclodextrin ( $\beta$-CD) was mixed with the limonene and electrospun into nanofibers. The inner cavity of $\beta$-CD could complex with limonene, and with that, a high encapsulation yield was obtained. The limonene release was modulated from the materials with changes in the relative humidity, which could control the release as an active device for food packaging applications. An electrospun fiber material based on regenerated cellulose was used for the immobilization of lysozyme (Liu, Vincent Edwards, Prevost, Huang, \& Chen, 2018). A mixture of regenerated cellulose, graphene oxide and carboxylated carbon nanotubes (CNTs) was electrospun to produce nanofibrous mats to be used for the immobilization of lysozyme. The obtained lysozyme functional nanofibrous mats showed robust bioactivity and no cytotoxicity, and the lysozyme was used to break down the cell wall of bacteria by catalyzing the hydrolysis of the 1, 4- $\beta$-glycosidic bond. Hence, the lysozyme-functional nanofibrous mats showed high antibacterial activity against $M$. lysodeikticus cells. Recently, Loong-Tak Lim and co-workers reported the electrospinning of native and anionic corn starch fibers with various amylose contents (Fonseca et al., 2019). An aqueous 75\% formic acid (v/v) was used to dissolve starch. Depending on the used starch type, the morphology of the resultant fibers showed variations. Such fibers can be used for food packaging applications. Sumnu and co-workers recently reported gallic acid loaded hydroxypropyl methylcellulose nanofibers by electrospinning for active food packaging material (Aydogdu, Yildiz, Aydogdu et al., 2019). Gallic acid as an active agent was encapsulated in hydroxypropyl methylcellulose (HPMC) /PEO blend nanofibers prior to the electrospinning process. Owing to the antioxidant properties of the embedded gallic acid, the nanofibers exhibited strong antioxidant activity over the DPPH (2,2-diphenyl-1-picrylhydrazyl) method. The food storage potential of the nanofibers were explored using walnuts the nanofibers containing $10 \%$ gallic acid, along with a control sample (i.e., gallic acid free nanofibers). Peroxide values were measured to determine peroxides and hydroperoxides formed during the initial stages of lipid oxidation. The peroxide value of the control walnut sample was drastically higher than the walnuts packed in nanofibers. Likewise, anisidine and totox values were measured to measure secondary oxidation products and as an indication of overall oxidative stability, respectively. The $p$-anisidine and totox values of the control sample are significantly higher than those packed with nanofibers. Overall, the oxidation analyses demonstrated gallic acid loaded nanofibers reduced the oxidation reaction occurred during the storage owing to the antioxidant properties of the embedded gallic acid. Zhu, Cui, Li, and Lin (2019) reported the composite fibers of carboxymethyl cellulose (CMCS)/ poly(vinyl acetate) (PVA) by electrospinning (Zhu, Zaarour, \& Jin, 2019). The obtained nanofibers were used for the storage of the bananas pieces. The PVA nanofibers did not reveal any antibacterial activity, while the CMCS/PVA nanofibers showed antibacterial activity because of the intrinsic antioxidant activity of the CMCS. Furthermore, the food packaging potential of the composite nanofibers was also explored using banana pieces in beakers closed with the electrospun mats. Unlike control samples (i.e., the samples are not covered, covered with either PVA or polyurethane), the sample covered with the composite CMCS/ PVA fibers could preserve the freshness of banana samples, suggesting the use of these fibers for food packaging applications.

\subsubsection{Protein-based electrospun materials}

Like polysaccharides, various proteins were exploited for the fabrication of food packaging materials. Particularly, gelatin and zein are the most commonly used proteins as the main components of electrospun food packaging materials. In one example, Liu et al. (2018) reported the food packaging from gelatin, ethylcellulose and zinc oxide (ZnO) nanoparticles (Liu et al., 2018). The mixed solution of precursors was electrospun into nanofibrous mats, and the resultant materials were tested against the growth of $S$. aureus and $E$. coli. The antimicrobial efficiency of the fibers containing $1.5 \mathrm{wt} \% \mathrm{ZnO}$ against $S$. aureus found at $43.7 \%$, but it boosted to $62.5 \%$ after UV exposure at $364 \mathrm{~nm}$. This rise in antimicrobial activity was attributed to the higher content of intracellular reactive oxygen species. However, no practical application of them in food packaging was shown. Li et al. (2018) reported the fabrication of antioxidant, antibacterial, antifungal butylated hydroxyanisole (BHA)/gelatin fiber mats for strawberry preservation (Li et al., 2018). BHA could be encapsulated efficiently in gelatin fibers without any loss in their antioxidant activity. The addition of BHA enhanced the stability of gelatin by inducing the structural transformation from the $\beta$-turn and a random coil to $\beta$-sheet and $\alpha$-helix. The electrospun mats exhibited antibacterial activity against $S$. aureus. The release of BHA followed a Fickian diffusion mechanism. The fibers exhibited antifungal activity against four mold genera (Mucor sp., Rhizopus sp., Penicillium sp, and Aspergillus sp.). Furthermore, the shelf-life of strawberry could be extended with the BHA embedded gelatin nanofibers, demonstrating their great potential in food packaging (Fig. 4A). The Uyar research group reported the antibacterial electrospun zein nanoweb embedding thymol/ cyclodextrin (CD) inclusion complex (IC) (Aytac, Ipek, Durgun, Tekinay, \& Uyar, 2017). The IC of thymol and $\gamma$-CD was mixed with zein solution and then electrospun to produce nanowebs with bead-free fibers. Their practical application on meat samples demonstrated that zein-thymol/ $\gamma$-CD IC nanofibers could inhibit the bacterial growth (both $E$. coli and $S$. aureus) on meat samples up to 5 days at $4{ }^{\circ} \mathrm{C}$, suggesting their potential application as food packaging materials. Yilmaz et al. (2016) reported curcumin (Cur) loaded zein nanofibers as antifungal food packaging materials (Yilmaz et al., 2016). The nanofibers were tested with regard to the limitation of postharvest decay on the electrospun coated apples infected with Penicillium expansum and Botrytis cinerea. The electrospinning of a mixture of zein and Cur (2.5 and $5 \mathrm{wt} \%$ with respect to zein content) resulted in nanofibers with mean diameters smaller than $350 \mathrm{~nm}$. The in vivo tests were performed at $23{ }^{\circ} \mathrm{C}$ with $75 \%$ humidity of 6 days and the results were evaluated by bacterial tests for both coated (control) and uncoated apples. The lesion diameter was decreased by $50 \%$ on coated apples infected with $P$. expansum, demonstrating the potential of such fibers as antifungal food packaging materials (Fig. 4B). Another zein nanofibers were reported by Shao et al. (Shao, Yan, Chen, \& Xiao, 2018). Cinnamaldehyde was used as an active agent and encapsulated in surfactants at a critical micelle concentration. In this regard, several surfactants were exploited for the encapsulation of cinnamaldehyde. But, the addition of surfactants greatly influenced the fiber morphology and release profiles. The nanofibers in- 


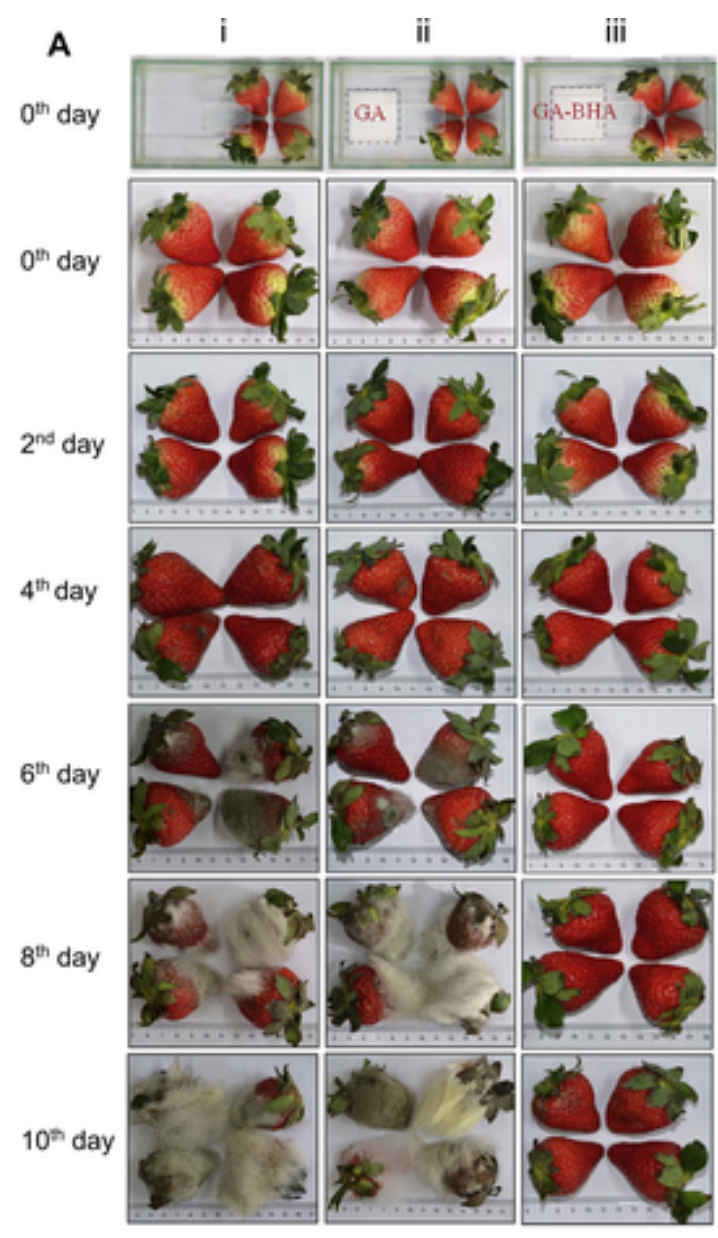

$\rightarrow 7$
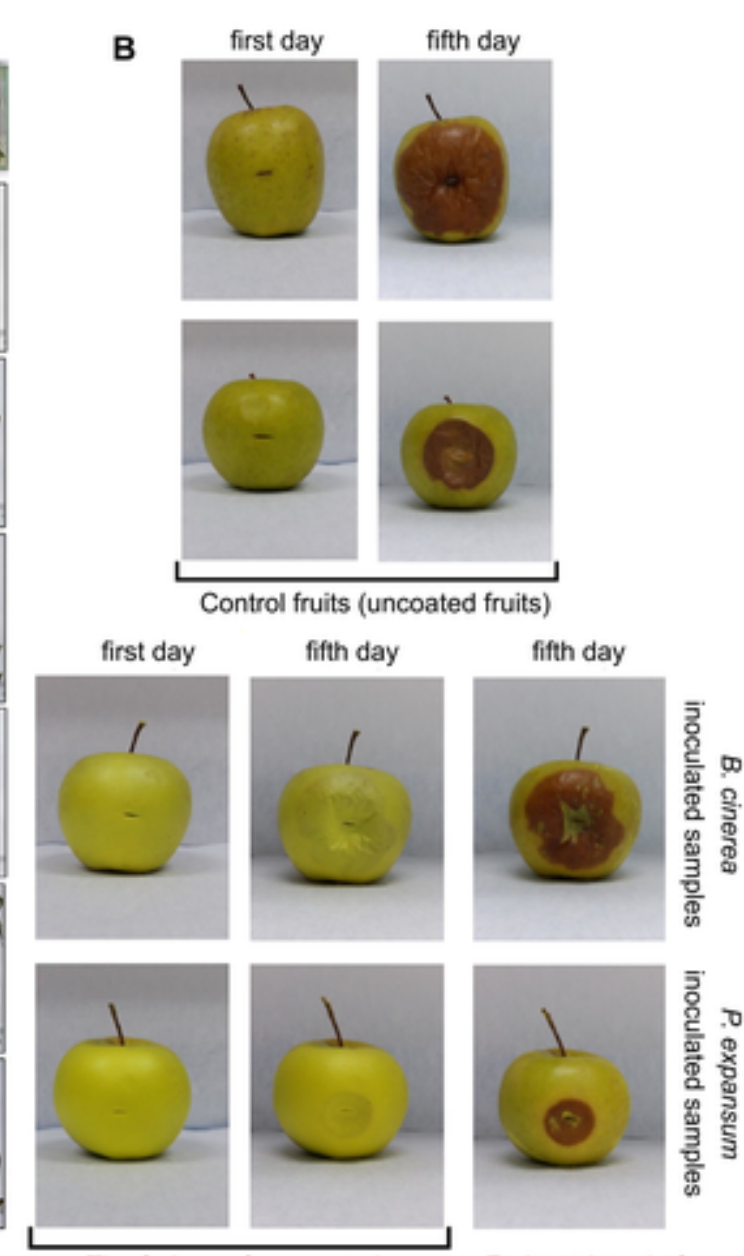

The fruits surface-coated

with nanofiber

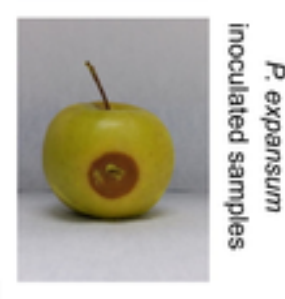

Fruits stripped of nanofiber coating

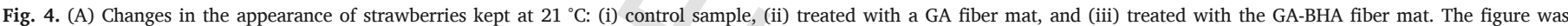

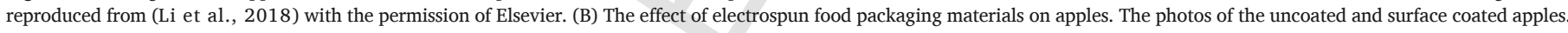

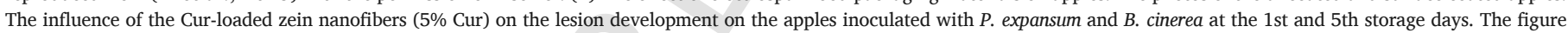
was reproduced from (Yilmaz et al., 2016) with the permission of Elsevier.

hibited the growth of the microorganisms and extended the shelf-life of mushrooms, demonstrating their use as active food packaging materials. Shao et al. reported the zein nanofibers loaded with cinnamaldehyde for active food packaging (Shao, Liu, Ritzoulis, \& Niu, 2019). A bioderived surfactant, lecithin, and other synthetic surfactants (i.e., cetyltrimethylammonium bromide (CTAB), TWEEN 80 and sodium dodecyl sulfate (SDS)) were used for the dissolution of cinnamaldehyde for its high loading into nanofibers. The addition of surfactants decreased fiber diameter. The fibers with CTAB reduced the release rate of CEO, while other surfactants promoted the CEO release in aqueous ethanol solutions. The nanofibers could inhibit the growth of microorganisms and extended the shelf-life of the tested mushrooms, suggesting their high potential as active food packaging materials.

Essential oils (EOs) were also incorporated into electrospun fibers to be benefited from their intrinsic properties. In this regard, Yao et al. (2017) presented an effective route to encapsulate EOs into the electrospun fibers of zein prolamine (ZP) (Yao et al., 2017). Orange essential oils (OEO) were encapsulated in the ZP fibers with an optimum loading capacity, and the encapsulation efficiency of oils was found to be $22.28 \%$ and $53.68 \%$ at the ZP concentration of $35 \mathrm{w} / \mathrm{v} \%$. The encapsulation yield could be enhanced with increasing ZP concentration. Cell morphology and CCK-8 assay assessment using HEK293T cells showed no critical variation in the presence of electrospun ZP and $\mathrm{ZP} / \mathrm{OEO}$ mats over the $8 \mathrm{~h}$ period. Furthermore, the antibacterial activ- ity of the membranes was confirmed over the inhibition of E. coli. Overall, the OEO-encapsulated ZP fibers can be implemented in active food packaging applications. Another food packaging material on zein nanofibers was reported using gallic acid (GA) as an active agent (Neo et al., 2013). The GA encapsulated electrospun zein fibers were produced, and the release of the GA was tested in water, which revealed a rapid release profile: GA diffused in a Fickian diffusion manner, and the diffusion data showed a better fit to Higuchi model. No cytotoxicity of the fibers was observed on L929 fibroblast cells. The GA encapsulation drastically improved the antibacterial activity of the nanofibers against $S$. aureus and $E$. coli. Whereas, the GA/zein fibers showed a moderate inhibition effect against $C$. albicans with a $\log$ reduction of $1-2$. The antibacterial activity of the fibers makes them promising materials candidates for food packaging applications. Another antibacterial zein-based electrospun fiber mat was produced by the electrospinning of eucalyptus essential oil (EEO)/CD IC embedded zein nanofibers (Dias Antunes et al., 2017). First, IC was prepared using EEO and $\beta$-CD by a co-precipitation technique, and thereafter, it was mixed with the aqueous ethanol solution of zein. The incorporation of IC enhanced the antibacterial activity of the fibers by $24 \%$. The composite electrospun membranes of zein/ $\beta$-CD/EEO are promising materials for food packaging applications.

Tomasula et al. (2016) reported the electrospun casein/pullulan fibers for food-grade applications (Tomasula et al., 2016). The aque- 
ous solutions of sodium or calcium caseinate (i.e., a pure milk protein) could not be electrospun into nanofibers, while the addition of pullulan assisted the formation of electrospun nanofibers with fiber diameters as low as $172 \pm 43 \mathrm{~nm}$. Such fibers with a food-grade carrier have the potential to be employed in food packaging applications. Cui, Bai, Rashed, and Lin (2018) reported antibacterial gelatin-based electrospun nanofibers for food packaging applications (Cui et al., 2018). Clove oil-loaded chitosan nanoparticles (CO@CNPs) were incorporated into the nanofibers of gelatin and used against the biofilms of $E$. coli O157: H7 on cucumbers. The initial content of clove oil (CO) was adjusted to $2.5 \mathrm{mg} / \mathrm{mL}$ for optimal CO@CNPs by the ionic cross-linking method. The CO@CNPs revealed high antibacterial activity against $E$. coli 0157: H7 biofilms. After the treatment of $8 \mathrm{~h}$ with the CO@CNPs at $30 \%(\mathrm{w} / \mathrm{v})$, E. coli O157: $\mathrm{H7}$ population was drastically reduced (99.98\%). The nanoparticles were incorporated into gelatin nanofibers. The population of an E. coli O157: H7 biofilm diminished by $\sim 99.99 \%$ with an exposure to $9 \mathrm{mg} / \mathrm{mL}$ gelatin/CO@CNPs for $24 \mathrm{~h}$. The antibacterial activity of the nanofibers was also evaluated on cucumbers. After the treatment of the nanofibers at 6 and $9 \mathrm{mg} \mathrm{mL}^{-1}$ at $12{ }^{\circ} \mathrm{C}$ for days, 4.28 and $4.97 \log _{10}$ reductions of the biofilm in the population were respectively detected. Furthermore, the sensory evaluation tests revealed that the nanofibers could preserve the flavor and color of cucumber well for $>4$ days. Fabra et al. (2016) reported multilayer packaging materials using an active zein/cinnamaldehyde (CNMA) based electrospun interlayer and investigated the antiviral activity of the resultant materials (Fabra et al., 2016). CNMA is one of the main components of cinnamon and thereby it gives flavor and odor (Gruenwald, Freder, \& Armbruester, 2010). It was explored for its virucidal activity on feline calicivirus (FCV), hepatitis A virus (HAV), murine norovirus (MNV), and norovirus surrogates. An electrospun interlayer of zein and CNMA was incorporated into PHB to form a multilayered structure. The biodegradable multilayer materials containing $2.60 \mathrm{mg} / \mathrm{cm}^{2}$ ( 9.7\%) CNMA could fully inactivate feline calicivirus (FCV) according to ISO 22196:2011, while murine norovirus (MNV) titers were reduced by $2.75 \log _{10}$. The antiviral activity of multilayers films was decreased with respect to the fresh multilayer films at $37^{\circ} \mathrm{C}$, demonstrating their potential for food contact applications and active packaging technologies.

Yao, Chang, Ahmad, and Li (2016) reported the production of rosehip seed oil (REO) loaded zein prolamine (ZP) fibers for food preservation (Yao et al., 2016). The microencapsulation of rosehip seed oil in ZP fibers was achieved through coaxial electrospinning. The morphology of the electrospun fibers showed variations with changes in the electrospinning process parameters (e.g., flow rate, and applied voltage) and polymer concentration. The loading capacity of REO was found to be related to the concentration of ZP. The encapsulation efficiency and optimal loading capacity were respectively found as $90.16 \%$ and $12.24 \%$ at the ZP concentration of $35 \mathrm{w} / \mathrm{v} \%$. The food packaging potential of the fibers was assessed using segmented and peeled fruits (i.e., cumquats and bananas), and the results revealed their efficiency in sustaining food health. Another zein based electrospun fiber system for food packaging was developed by Fabra et al. (2013) (Fabra, Lopez-Rubio, \& Lagaron, 2013). Multilayered materials based on polyhydroxybutyrate-co-valerate with a valerate content of $12 \%$ (PHBV12) and an interlayer electrospun zein nanofibers were produced. The properties of the materials changed depending on the method exploited for the preparation of the outer PHBV12 layers. Multilayer structure increased the mechanical resistance while it reduced the transparency and vapor permeability of the materials. The incorporation of the zein interlayer led to minimum changes in optical and mechanical film features while the addition of nanostructured zein interlayers drastically enhanced oxygen barrier properties. The influence of the interlayer on the water vapor permeability and limonene permeability varied depending on the zein content used. This biopolymer-based innovative approach with high barrier properties has great potential in food pack- aging. Lin et al. (2018) reported the preparation of gelatin/glycerin/E-poly-lysine nanofibers for monitoring $L$. monocytogenes on beef (Lin, Gu, \& Cui, 2018). The optimal composition of gelatin:glycerin: $\varepsilon$-polylysine was found to be $25: 6: 10(\mathrm{w} / \mathrm{v} / \mathrm{v})$ for electrospinning with a mean fiber diameter of $204 \mathrm{~nm}$. The addition of glycerin enhanced the tensile strength up to $1.63 \pm 0.04 \mathrm{MPa}$. The nanofibers showed higher thermal stability than their components. The in vitro test on a beef sample showed very high antibacterial activity against L. monocytogenes during 10 days of storage at $4{ }^{\circ} \mathrm{C}$ and 7 days of storage at $12{ }^{\circ} \mathrm{C}$ without showing any change on the sensory properties and sample color, demonstrating their usability as food packaging materials. Gelatin nanofibers with embedded thyme essential oil were used for active packaging against Campylobacter jejuni in chicken (Lin, Zhu, \& Cui, 2018). Campylobacter jejuni is a food pathogen, which is one of the most common reasons for food poisoning (Altekruse, Swerdlow, \& Stern, 1998). It is thus a serious threat to the meat industry and human health. For controlling the propagation of $C$. jejuni, gelatin nanofibers embedded with thyme essential oil/ $\beta$-CD $\varepsilon$-poly-lysine nanoparticles (TCPNs), which were synthesized by ionic gelation, were produced. TCPNs exhibited outstanding antibacterial activity against $C$. jejuni, causing membranolysis. The TCPNs incorporated gelatin nanofibers showed great antimicrobial activity against $C$. jejuni on chicken, and the TCPNs embedded nanofiber packaged chicken samples had a lower aerobic bacterial count, thiobarbituric acid (TBA), $\mathrm{pH}$, and total volatile basic nitrogen (TVB-N) values without showing any undesired effect on texture, sensory, and color evolution, demonstrating the potential of these nanofibers as food packaging materials for meat preservation. Recently, hybrid nanofibers of zein and ethyl cellulose with improved water resistance were produced through electrospinning for food preservation (Niu et al., 2019). With varying the ethyl acetate content, the mean diameter of the nanofibers could be varied. As a result of hydrogen bonds between the hydroxyl groups of ethyl acetate and the amino group of zein, the water-resistance of the nanofibers could be enhanced. For food preservation, the cinnamon essential oil (CEO) was encapsulated into the nanofibers, and the food packaging potential of the CEO-loaded nanofibers was explored using Agaricus bisporus. The nanofibers could decrease the weight loss of the Agaricus bisporus, while maintaining the firmless and quality of Agaricus bisporus during the storage.

\subsubsection{Electrospun materials from other biopolymers}

In addition to the use of polysaccharides and proteins in the fabrication of bio-based electrospun food packaging materials, some bacterially derived biopolymers were also exploited for the preparation of electrospun food packaging materials. In this context, Cerqueira et al. (2016) reported that antibacterial biodegradable multilayer structures from polyhydroxybutyrate-co-valerate (i.e., a biopolymer produced naturally by bacteria) (Cerqueira et al., 2016). A polyhydroxybutyrate-co-valerate film with a valerate content of $8 \%$ (PHBV8) was used as a support. The electrospun zein fibers were prepared in the presence or absence of cinnamaldehyde and exploited as an interlayer, and different outer layers were implemented: (i) without any outer layer, (ii) a PHBV8 film, or (iii) alginate-based film. The multilayer structures were characterized by their thermal properties, intermolecular arrangement, as well as oxygen and water vapor permeability. The highest antibacterial activity was observed for the PHBV + zein/CNMA + PHBV multilayer system. The release profiles of the encapsulated cinnamaldehyde were highly dependent on the multilayer structure used. The deposition of the electrospun cinnamaldehyde loaded zein fibers on a PHBV8 layer is a promising approach for an active bio-based multilayer system for food packaging applications. Fan et al. (2015) reported the preparation of antimicrobial biodegradable polyhydroxybutyrate (PHB) fibrous membranes by electrospinning (Fan et al., 2015). After exposed to chlorine bleach, the fibers became biocidal, and the chlorinated membranes exhibited outstanding antimicrobial functions and could inacti- 
vate $85.04 \%$ E. coli O157: $\mathrm{H7}$ and $92.10 \%$ S. aureus within $30 \mathrm{~min}$ of contact with the nanofibers. Such antimicrobial fibers have great potential to be implemented as food packaging materials. Lagaron and co-workers have reported various studies on the fabrication of multilayer structures from PHB and PHBV, and their use with different polymeric systems. In one example, Cherpinski et al. (2018) studied the effect of the electrospun PHB and PHBV double-side coatings on the physical properties and barrier performance of cellulose nanofibrils (CNFs) and lignocellulose nanofibrils (LCNFs) films (Cherpinski, Torres-Giner, Vartiainen, et al., 2018). The resultant multilayer structures enhanced the water contact resistance and barrier performance of the neat films against the water vapor. Even though the PHA-coated films offered faintly lower aroma barrier owing to the intrinsic affinity of the PHA for limonene uptake. The multilayer films enhanced the oxygen barrier performance of the films. Overall, the multilayer bio-based materials with the electrospun PHB and PHBV layers showed outstanding oxygen and water vapor barrier properties with promising applications in food packaging. The production of other multilayer films based on the annealed electrospun ultrathin fibers of PHB, PVA, and PLA on paper was reported by the same research group (Cherpinski, Torres-Giner, Cabedo, et al., 2018). The mono and multilayer electrospun structures self-adhered on the paper were produced. After the thermal treatment of an electrospun biopolymer, transparent films were obtained. However, the supporting substrate paper was opaque and hence, after the electrospinning process, it could maintain its opaque structure, but with a glossier surface obtained by the bioplastic coating. The biopolymer coating significantly enhanced the paper barrier properties against the limonene and water vapor, and the best performing multilayer packaging structure was observed for the film of paper/PVA/PHB. The same research group also produced PHB films by means of electrospinning and thereafter their post-processing by different physical treatments (Cherpinski, Torres-Giner, Cabedo, \& Lagaron, 2017). With annealing at $160{ }^{\circ} \mathrm{C}$, which is below the melting point of the homopolyester, homogeneous transparent films could be produced. The gradual cooling of the films induced the lowest permeability for water vapor, oxygen, and limonene. The rigidity of the post-processed PHB fibers was similar to those produced by the compression-molded PHA films, however, a boosted elongation at toughness and break was observed (Cherpinski et al., 2017). Such electrospun materials have great potential in the fabrication of adhesive interlayers, coatings and barrier layers for plastic and fiber-based food packaging films.

Fabra et al. (2016) reported the corn-starch films possessing bacterial cellulose nanowhiskers (BCNW)/ PHB electrospun fibers as potential food packaging materials (Fabra, López-Rubio, Ambrosio-Martín, \& Lagaron, 2016). BCNW containing thermoplastic corn starch (TPCS) nanocomposites were prepared by melt mixing. The composites showed an enhanced barrier against oxygen and water vapor at high relative humidity (80\%). The best performance was observed for the sample containing $15 \mathrm{wt} \%$ BCNW loading with the corresponding drop of $95 \%$ and $46 \%$ for oxygen and water permeability, respectively. In parallel, bionanocomposites with $15 \mathrm{wt} \%$ BCNW were hydrophobized with the electrospun fibers of PHB or PHB-BCNW fibers. Furthermore, hybrid electrospun PHB fibers were reinforced with the incorporation of highly dispersed crystalline BCNW with concentrations up to $15 \mathrm{wt} \%$ and both sides of TPCS bionanocomposites, containing $15 \mathrm{wt} \%$ BCNW were decorated with the electrospun fibers. The presence of good adhesion between the layers gave rise to higher barrier performance. The use of BCNW in one of the layers reduced the oxygen permeability regardless of the position of the BCNW introduced. The highest reduction in the water vapor permeability was observed for multilayer films having BCNW in both sides, PHB coating, and TPCS inner layer. Overall, the resultant materials having both nanocomposite and multilayered structures have great potential to be implemented in food packaging. Lin, Dai, and Cui (2017) reported the preparation of antibacterial polyhydroxybutyrate/poly(butylene adipate-co-terephtha- late) (PHB/PBAT) nanofibrous mats by electrospinning (X. Lin, X. Fan, et al., 2018). The electrospinning of the blends of PHB and PBAT produced nanofibrous membranes, followed by the grafting of perfluorooctyl acrylate and 1-allylhydantoin on the mat led to antimicrobial fibers. The obtained nanofibrous mats were chlorinated using chlorine bleach and characterized. The resultant mats showed high antimicrobial activity against $S$. aureus (ATCC 6538) and E. coli O157: H7 (ATCC 43895) with a 5.78 and $6.08 \mathrm{log}$ reduction, respectively. The treated fibers exhibited good durability and stability against UV exposure and storage, suggesting their potential as food packaging materials.

\subsection{Electrospun materials from synthetic polymers for food packaging}

Synthetic polymers were also exploited for the preparation of electrospun food packaging materials. In one example, Lagaron and colleagues reported the oxygen scavenging electrospun films of polyhydroxybutyrate (PHB) containing palladium nanoparticles (Pd-NPs) for active packaging applications (Cherpinski, Gozutok, et al., 2018). The Pd-NPs are modified with either tetraethyl orthosilicate (TEOS) or hexadecyltrimethylammonium bromide (CTAB) to enhance the dispensability of particles in PHB. Using CTAB led to the better dispersion of Pd-NPs, and the presence of Pd-NPs reduced both the degree of crystallinity and the melting point of PHB. However, they induced lower barrier properties than the neat PHB film as a result of a lower crystallinity degree and the existence of unbound interfacial regions and/ or voids between the polymer and nanoparticles. In another study, Alvarado et al. (2018) reported active food packaging materials based on thymol-loaded PLA films filled with electrospun PVA-cellulose nanocrystals nanofibers (Alvarado et al., 2018). Cellulose nanocrystals doped PVA nanofibers were successfully generated by electrospinning and incorporated in PLLA films by the casting approach. Afterward, the materials were loaded with thymol, which was subsequently dissolved in supercritical $\mathrm{CO}_{2}\left(\mathrm{scCO}_{2}\right)$. Such food packaging materials showed a drastic improvement in its thermal and mechanical properties. Zehetmeyer et al. (2017) reported poly(butylene adipate-co-terephthalate) (PBAT) based biodegradable and antimicrobial electrospun films (Zehetmeyer et al., 2017). The electrospun films were produced with different contents of antimicrobial peptide nisin by electrospinning. The electrospun films exhibited good thermal stability, and the incorporation of nisin did not affect the chemical structure and thermal stability of the PBAT: i.e., both films (with/without nisin peptide) showed no significant difference in the melting temperature $\left(124-125.4{ }^{\circ} \mathrm{C}\right)$ and the glass transition temperature, and even crystalline peaks and the tensile strength of PBAT were preserved. On the other hand, a decrease in Young modulus was observed with the nisin incorporation. The antimicrobial activity of the films was explored against the growth of the Gram-positive bacterium $L$. monocytogenes, and the results showed the enhanced antibacterial activity of the films with an increasing concentration of nisin, suggesting the use of such films in food packaging applications. Another food packaging material was produced by the electrospinning of the blend of PLA and PHB (Arrieta, López, López, Kenny, \& Peponi, 2015). The electrospun material was produced at various compositions of both polymers. The incorporation of PHB into the PLA solution induced the bead formation. The electrospun mats of PLA and PLA75-PHB25 were plasticized with the incorporation of acetyl tri-n-butyl citrate (ATBC), which drastically boosted the mechanical properties of the electrospun mats. Furthermore, PLA75/PHB25/ ATBC materials revealed higher thermal stability as a result of interactions among the components. Disintegration tests under composting conditions demonstrated the biodegradable character of the electrospun mats. The presence of PHB decreased the degradation rate while the presence of ATBC fastened the process.

Recently, Arrieta, López de Dicastillo, Garrido, Roa, and Galotto (2018) reported the use of electrospun bionanocomposite PVA fibers loaded with antioxidant fillers and studied their properties (Arri- 
eta et al., 2018). The antioxidant ingredients of Durvillaea Antarctica algae were obtained by aqueous extraction and encapsulated in the PVA fibers. The nanoparticle in the extract involved as a reinforcing component and the plasticized PLA was added with fibers and effectively transformed into films by the solvent casting method. The incorporation of $D$. Antarctica as well as PVA electrospun fiber induced PLA crystallization, resulting in an obvious enhancement of mechanical performance and oxygen barrier, particularly in terms of stretchability with an elongation at break around $70 \%$. Furthermore, the films displayed a UV blocking effect while preserving their high transparency. The antioxidant activity of the films was explored over the inhibition of the radical cation $\mathrm{ABTS}^{+}$, following its exposure in a fatty food simulant. On the other hand, the films showed low antimicrobial activity against the growth of $E$. coli. Overall, the PLA nanocomposites with the incorporated electrospun PVA fibers, which were loaded with $D$. Antarctica extract) can be employed as sustainable antioxidant packaging materials. A layered nanocomposite low-density polyethylene film (LDPE) was prepared by the electrospinning of poly( $\varepsilon$-caprolactone) and the electrospraying of nanostructured silica $\left(\mathrm{SiO}_{2}\right)$ microparticles on the LDPE films (Lasprilla-Botero, Torres-Giner, Pardo-Figuerez, Álvarez-Láinez, \& M. Lagaron, 2018). The films were later thermally treated for physical adhesion between the LDPE film and bilayer coating. Tailoring the deposition time of the PCL and $\mathrm{SiO}_{2}$ particles allowed the production of superhydrophobic coating with a sliding angle of $8^{\circ}$ and an apparent contact angle of $157^{\circ}$ on the LDPE film. The incorporation of $\mathrm{SiO}_{2} \mathrm{mi}-$ croparticles decreased the aroma (i.e., limonene) barrier of the films to some extent. Overall, the process allowed the production of permanent and thermally stable superhydrophobic films for food packaging applications, particularly easy-to-empty packaging of high water activity products. Camerlo, Vebert-Nardin, Rossi, and Popa (2013) produced the electrospun fibers of PLA with the encapsulated (R)-(+)-limonene (Camerlo et al., 2013). For high encapsulation capacity, the emulsion approach was used and higher than $50 \%$ encapsulation was observed. The encapsulation efficiency was found to be related to the emulsion formulation, particularly on the concentration of the continuous phase and the ratio between the aqueous and organic phases. The fiber morphology showed changes depending on the viscosity of the emulsion mixture. The encapsulated limonene was slowly released from the fiber matrix over 15 days, suggesting the use of such fibers for food packaging applications.

Chalco-Sandoval, Fabra, López-Rubio, and Lagaron (2015) produced multilayer polystyrene-based films with temperature buffering capacity for intelligent food packaging applications (Chalco-Sandoval et al., 2015). Phase change materials (PCMs) were incorporated into the matrix of electrospun PCL. PCMs are interesting materials that can absorb or release a great quantity of energy during their melting/crystallization process so that the resultant films can offer thermal protection to the packaged food. In this regard, an RT5 (i.e., a commercial blend of paraffin's with a transition temperature at $5{ }^{\circ} \mathrm{C}$ ) was exploited as a PCM and mixed with PCL and thereafter electrospun onto PS films. Differential scanning calorimetry (DSC) analysis showed that the RT5 could successfully be encapsulated in the PCL fibers, and the heat shock capacity of the materials was not only affected by the multilayer structure, but also by the temperature and storage time. The multilayer structures with a thermal energy storage/release capacity of 88-119 J/g are promising for food packaging applications for their intrinsic efficient temperature buffering effect. The same research group extended the work by incorporating the RT5 into PCL and PS slabs and studied the effect of storage temperature $\left(4{ }^{\circ} \mathrm{C}\right.$ and $\left.25^{\circ} \mathrm{C}\right)$ and time on the morphology and thermal characteristics of the PS/RT5 and PCL/RT5 slabs (Chalco-Sandoval, Fabra, López-Rubio, \& Lagaron, 2014). Both slaps were produced by the electrospinning of the respective mixtures. The results confirmed the encapsulation of RT5 into both polymers while better encapsulation was observed for PCL. Furthermore, the encapsulation efficiency is not only affected by the poly- mer matrix, but also through storage time at RT. The highest encapsulation efficiency (98.6\%) and optimum heat management performance were accomplished for PCL/PCM slabs, which were kept at $4{ }^{\circ} \mathrm{C}$, and the materials composed of $44 \mathrm{wt} \%$ of PCM (core materials) and $56 \mathrm{wt} \%$ of the PCL shell materials. The temperature buffering property of such materials is of interest to maintain the quality of packaged food and reduce energy consumption in the refrigeration equipment. Kara et al. (2015) reported antibacterial PLA films grafted with electrospun fibers of allyl isothiocyanate (AITC)/PLA fibers for food packaging (Kara et al., 2016). AITC encapsulated PLA nanofibers were deposited onto PLA films. The fusion of two phases to form a bilayered fiber-grafted film structure was evidenced by scanning electron microscopy. The bilayer film could preserve the mechanical properties of PLA. The temperature-dependent release of the embedded AITC was observed, and the temperature below $4{ }^{\circ} \mathrm{C}$, the encapsulated AITC remained in the fibers without losing activity, while at room temperature, AITC was released from the fiber matrix in a sustained manner over weeks. The AITC encapsulated fibers significantly inhibited the growth of $L$. innocua and $E$. coli k12 in grape and ready-to-eat (RTE) deli turkey meat after storage at $22{ }^{\circ} \mathrm{C}$ for $40 \mathrm{~h}$. Another antimicrobial food packaging was reported by the Uyar research group using the electrospun fibers of carvacrol-loaded zein and PLA (Altan, Aytac, \& Uyar, 2018). Carvacrol was loaded at three different concentrations (i.e., 5, 10 and 20\%) into either PLA or zein fibers, and such concentration variations led to drastic differences in the morphology and diameter of the resultant fibers. Depending on the carvacrol loading, the antioxidant activity of the fibers increased from 62 to $75 \%$ for carvacrol-loaded zein fibers, while the antioxidant activity of the PLA fibers varied from 53 to $65 \%$ for the fibers loaded with 5 and $20 \%$ carvacrol. The active food packaging property of the fibers was tested using bread samples, and the experimental findings showed that increasing carvacrol content directly boosted the shelf-life and freshness of the bread (Fig. 5A and B). In another study, Wen et al. (2016) reported CEO loaded PVA nanofibrous film for active food packaging (P. Wen, Zhu, Wu, et al., 2016). The nanofibers with a mean diameter of $240 \pm 40 \mathrm{~nm}$ were prepared by the electrospinning of a mixture of PVA, $\beta$-CD and CEO. TGA analysis revealed that the CEO formed IC with $\beta$-CD due to its enhanced thermal stability. The nanofibrous mat showed outstanding antimicrobial activity against $S$. aureus and $E$. coli at very low contents. The PVA/CEO/ $\beta$-CD nanofibrous mat could effectively extend the shelf life of strawberry, demonstrating its potential in active food packaging (Fig. 5C).

The Uyar research group reported the electrospinning of geraniol/ cyclodextrin inclusion complexes embedded PVA fibers for possible food packaging materials (Kayaci, Sen, Durgun, \& Uyar, 2014). Different native CDs were implemented for the preparation of inclusion complexes (ICs). The highest inclusion complexation was observed between $\gamma$-CD and geraniol both experimentally and theoretically, and the ICs were incorporated into PVA nanofibers prior to the electrospinning process. Uniform bead-free nanofibers were produced and thermal analysis suggested the higher thermal stability of geraniol because of their inclusion complexation, which enhanced the thermal stability of geraniol. Geraniol is a volatile compound, which could not be preserved in the matrix of PVA in the absence of $\gamma-\mathrm{CD}$ during the electrospinning and storage and even after 1 day, the encapsulated geraniol evaporated from the fiber matrix. On the other hand, the use of $\mathrm{CD}$ for inclusion complexation with geraniol mitigated its loss from the PVA/ geraniol/ $\gamma$-CD IC nanofibers even after two years of storage. These materials have great potential to be employed in food packaging. T4 bacteriophage was incorporated into the electrospun fibers of synthetic polymers to develop antibacterial packaging materials. In this regard, Korehei et al. (2013) reported the encapsulation of the T4 bacteriophage in the electrospun fibers of PEO (R. Korehei \& Kadla, 2013). The incorporation of T4 bacteriophage via suspension electrospinning caused five orders of magnitude decrease in bacteriophage activity. 
A

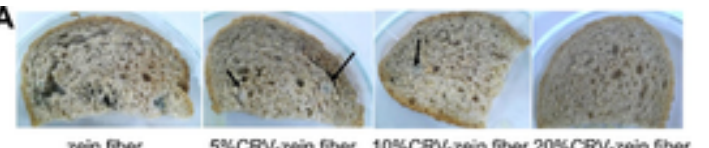

zein fiber 5\%CFV-rein fiber 10\%CFV-zein fiber 20\%CRV-zein fiber

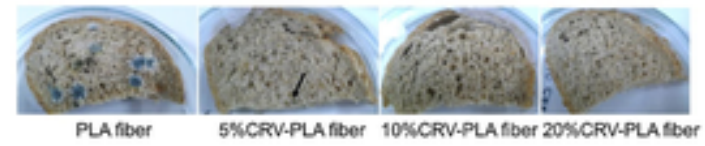

B

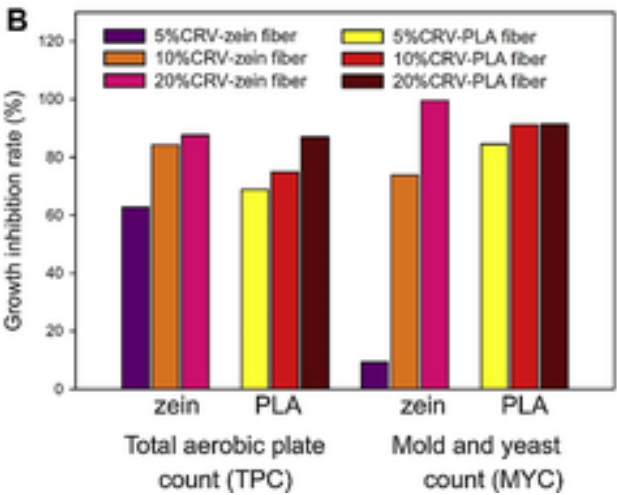

C

0 day

$2^{\text {st }}$ day

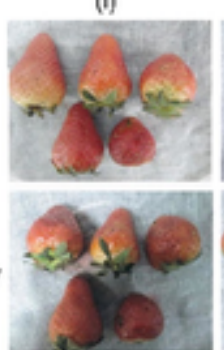

(i)

$4^{\text {sh }}$ day

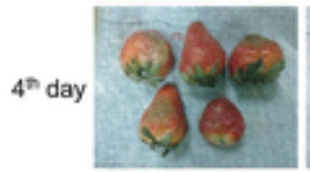

$6^{\text {s }}$ day

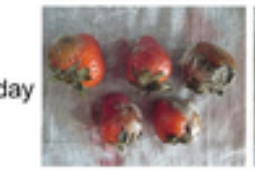

(i)

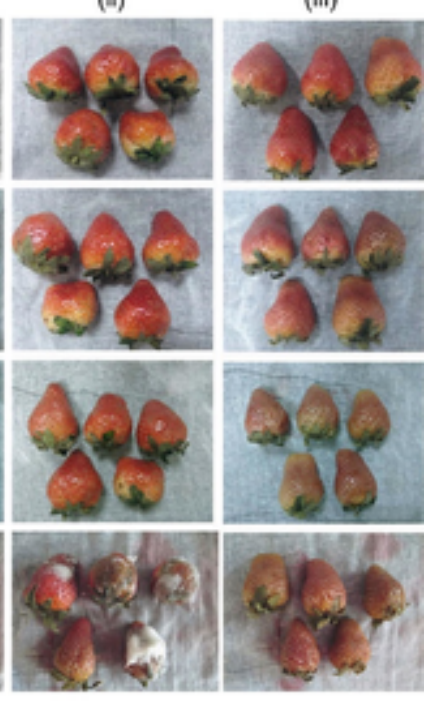

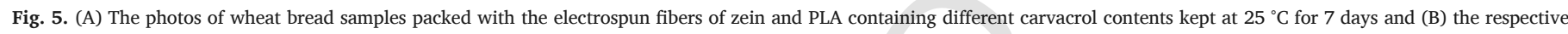

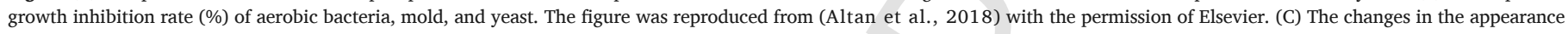

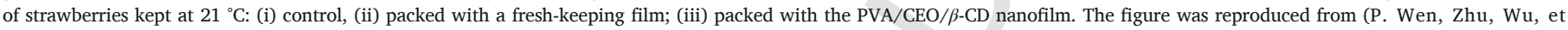
al., 2016) with the permission of Elsevier.

To preserve the activity, the emulsion approach was used. Firstly, T4 bacteriophage was pre-encapsulated in an alginate reservoir via the emulsion process and then electrospun into fibers. This process increased the activity of T4 bacteriophage, but still suffered two orders of the magnitude drop in the T4 activity. On the other hand, the full activity could be maintained via the co-axial electrospinning process with the $\mathrm{T} 4$ bacteriophage in the core. The encapsulated bacteriophage exhibited viability after storing for several weeks at $+4{ }^{\circ} \mathrm{C}$. In another study, Fabra et al. (2016) developed thermoplastic corn starch-based films using different biopolyester electrospun coatings made of PCL, PLA, and PHB (Fabra, López-Rubio, Cabedo, \& Lagaron, 2016). The authors investigated the effect of electrospun coatings on oxygen and water vapor barrier properties of a thermoplastic corn starch film. The formation of a multilayer structure was confirmed by SEM analysis. The incorporation of electrospun biopolyester coatings resulted in an exponential decrease in oxygen and water vapor permeability as the amount of the electrospun coating increased. Chalco-Sandoval et al. (2015) reported the use of phase change materials (PCMs) to develop electrospun coatings for their use in food packaging applications (Chalco-Sandoval, Fabra, López-Rubio, \& Lagaron, 2017). The authors reported a heat management polystyrene (PS) foam tray containing an ultrathin fiber-structured PS/PCM coatings by electrospinning. The RT5 (i.e., a blend of paraffins with a transition temperature at $5{ }^{\circ} \mathrm{C}$ ) was used as a PCM and was encapsulated into the PS matrix before its electrospinning. The PS tray was decorated with the electrospun fibers of the PCM encapsulated PS with a good encapsulation efficiency (78\%), and the resultant PS fibers showed a heat storage capacity equivalent to $34 \mathrm{wt} \%$ of the neat PCM. The heat storage capacity of the materials was influenced not only by the storage time, but also by the temperature. These fibers can be implemented as heat management materials for food packaging applications.

Peng et al. (2017) reported the fabrication of a novel antimicrobial electrospun nanofilm from PVA, $\beta$-cyclodextrin, cinnamon essential oil (CEO) and lysozyme (LYS) (K. Feng et al., 2017). Both CEO and LYS were exploited as antimicrobial agents and their optimum concentrations were determined to be $2 \mathrm{wt} \%$ and $0.25 \mathrm{wt} \%$, respectively. Thermal analysis of the films showed an improvement in the ther- mal stability of the CEO and LYS owing to their interaction with other components. In contrast to the films of PVA/LYS, the PVA/ $\beta-\mathrm{CD} /$ CEO/LYS films showed higher antibacterial activity against L. monocytogenes and Salmonella enteritidis. Moreover, the films showed outstanding antifungal activity against $L$. monocytogenes and $S$. enteritidis, and its minimum inhibition concentration (MIC) against $L$. monocytogenes and $S$. enteritidis was determined as $0.8-1 \mathrm{mg} \mathrm{mL}^{-1}$ with the corresponding CEO concentration of $7.6-9.5 \mathrm{mg} \mathrm{mL}^{-1}$ and LYS concentration of $36-45 \mathrm{U} \mathrm{mL}^{-1}$. The minimum bactericidal concentration (MBC) was approximately $6-7 \mathrm{mg} \mathrm{mL}^{-1}$ with the corresponding CEO concentration of $57-66.5 \mathrm{mg} \mathrm{mL}^{-1}$ and LYS concentration of $270-315 \mathrm{U} \mathrm{mL}^{-1}$. These high values suggest the use of the PVA/ $\beta$-CD/LYS-CEO film as potential active food packaging materials. Shao et al. (2017) reported active food packaging materials based on electrospun PVA/permutite fibrous film loaded with cinnamaldehyde (Shao, Yan, et al., 2018). A highly porous film (i.e., with a pore size ranging from 1.7 to $56.7 \mathrm{~nm}$ ) was obtained by electrospinning. The food packaging potential of the films was explored by the storage of strawberries over 1st, 3rd and 7th days over the firmness and appearance changes. The PVA/permutite/ CEO film could delay the rapid corruption of strawberries during storage. In contrast to the polyethylene (PE) plastic wrap, the fibrous film could reduce the weight loss of strawberries more effectively owing to the moisture adsorption capacity of PVA. The PVA/permutite/CEO fibrous film is promising material for the development of active bacterial packaging to extend the shelf-life of freshly cut fruits. Listeria monocytogenes (L. monocytogenes) make a serious threat in cheese production and therefore, many different concepts have been developed to get rid of this problem. In one example, nisin/poly- $\gamma$-glutamic acid ( $\gamma$-PGA)/ chitosan nanoparticles were embedded in chitosan nanofibers and used as food packaging materials (Cui, Wu, Li, \& Lin, 2017). The nanoparticles were mixed with PEO and electrospun into fibers. The nanoparticles produced with $5 \mathrm{mg} \mathrm{mL}^{-1}$ nisin showed desirable encapsulation efficiency and loading capacity. The nisin/ $\gamma$-PGA/chitosan nanoparticles embedded PEO nanofibers showed satisfactory antibacterial activity against $L$. monocytogenes on cheese. These nanofibers have great potential to be exploited as potential food packaging materials. Another PEO-based nanofibers embedded with antibacterial tea tree oil (TTO) 
was produced using $\beta-\mathrm{CD}$ as an inclusion agent for the complexation with TTO (Cui, Bai, \& Lin, 2018). At the temperature of $60{ }^{\circ} \mathrm{C}$, the encapsulation efficiency of TTO in the IC could reach to $73.23 \%$. Following the plasma treatment process, the nanofibers showed the highest antimicrobial activity against $E$. coli O157: H7, which was tested on a beef sample for 7 days, with an inhibition efficiency of $99.99 \%$ at 4 or $12{ }^{\circ} \mathrm{C}$. The plasma-treated PEO fibers functionalized with the IC of $\mathrm{TTO} / \beta$-CD-IC has great potential in food preservation.

Dai et al. (2015) embedded defatted mustard seed meal powder (MSMP) as a source of allyl isothiocyanate (AITC) into the nanofibers of PLA-PEO blends (Dai \& Lim, 2015). AITC is a proven antimicrobial volatile molecule released from Brassicaceae plants. Normally, MSMP particles were larger than the electrospun fibers of the PLA-PEO. SEM analysis showed the physical entrapment of the mustard seed particles and homogeneous distribution of them throughout the fiber matrix. Tailoring the ratio of PLA and PEO blend, the release rate of AITC and quantity released from the fiber matrix could be varied. No specific interactions were detected between MSMP, PLA, and PEO by FTIR. On the other hand, DSC analysis revealed the interfering of MSMP with the chain packing of the crystalline phases of both polymers. Although the study did not show any results on the antimicrobial activity of the fibers, the materials can be useful for food packaging applications because of the intrinsic antibacterial activity of AITC. Dumitriu, Mitchell, Davis, and Vasile (2017) reported the vitamin E loaded PCL fibers as antioxidant food packaging materials (Dumitriu et al., 2017). Vitamin E ( $\alpha$-tocopherol) was used as a plant-based antioxidant and incorporated into the solution of PCL, whose electrospinning led to fibers, and the antioxidant activity was confirmed testing with 2,2-diphenyl-1-picrylhydrazyl (DPPH) radical assay. These antioxidant electrospun materials can be used for food packaging applications. Estevez-Areco, Guz, Candal, and Goyanes (2018) reported the release kinetics of rosemary polyphenols from PVA nanofibers in various food simulants (Estevez-Areco et al., 2018). The mixed solution of PVA and rosemary (Rosmarinus officinalis) polyphenols (Ros) were electrospun in nanofibers with the retention of $88 \pm 2 \%$. Because of the presence of physical interactions between PVA and Ros, their thermal stability was significantly increased. The RVA/Ros mats exhibited a polyphenol content of $15.4 \pm 0.5 \mathrm{mg}$ gallic acid equivalent/g of the mat (mg GAE/g) and achieved an oxidant activity of $120 \pm 8 \mu \mathrm{mols}$ Trolox equivalent $/ \mathrm{g}$ of the mat as determined by DPPH assay and Folin-Ciocalteu method. The release rate of the polyphenols to food simulants was monitored, and the obtained kinetic data were fitted by Weibull model, Fick's diffusion law and Power-law. The obtained parameters demonstrated that polymer chain relaxation is the main mechanism in a hydrophilic simulant. On the other hand, an anomalous release took place in an acidic medium. A burst release of the polyphenols was detected in a lipophilic simulant, restricting its effectiveness over time. Overall, these electrospun materials have great potential to be exploited in the food packaging industry, particularly for hydrophilic and acid food products. Fabra et al. (2016) showed a route to develop a multilayer corn starch-based food packaging materials with the embedded $\beta$-carotene by electrospinning (Fabra, López-Rubio, Sentandreu, \& Lagaron, 2016). An antioxidant multilayer structure using thermoplastic corn starch (TPCS) was produced by the electrospinning of PCL on TPCS films. Afterward, $\beta$-carotene loaded PCL fibers were deposited on both sides of the film so that antioxidant multilayered packaging structure could be produced. The barrier properties of the film were improved by the electrospun fibers. Although the incorporation of $\beta$-carotene did not affect the properties of the film, their presence boosted the antioxidant activity of the materials. The stability of the $\beta$-carotene was drastically influenced by the annealing step, which was used to improve the adhesion between layers) even when it was embedded in the PCL fiber mat. Lin et al. (2017) reported the preparation of antibacterial cinnamon essential oil (CEO)/ $\beta$-CD proteoliposomes loaded PEO nanofibers (Lin et al., 2017). PEO was used as a stabilizing polymer and a carrier matrix for producing $\mathrm{CEO} / \beta-\mathrm{CD}$ proteoliposomes nanofibers. The IC of CEO/ $\beta$-CD was produced by the aqueous solution method. After the treatment of the proteoliposomes nanofibers, a pleasing antibacterial efficiency against B. cereus on beef was shown without any influence on the sensory quality of beef, suggesting that the proteoliposomes nanofibers can drastically prolong the shelf life of beef samples as food packaging materials. The Uyar research group reported antibacterial triclosan/CD IC embedded PLA nanofibrous webs for potential food packaging materials (Kayaci, Umu, Tekinay, \& Uyar, 2013). The experiments were performed using three different CD molecules ( $\alpha, \beta$, and $\gamma$ CDs), however, no IC formation was observed for $\alpha$-CD due to its small cavity interior. On the other hand, both $\beta$ and $\gamma$-CDs could form ICs with triclosan, and the optimal molar ratio of triclosan and $\mathrm{CD}$ was found to be 1:1. The encapsulation of $\beta-\mathrm{CD} /$ triclosan and $\gamma$-CD/triclosan ICs into PLA nanofibers was succeeded, and their presence was confirmed by both SEM and XRD analyses. The antibacterial activity of the nanowebs was explored against the growth of $S$. aureus and $E$. coli bacteria and a higher antibacterial activity was observed for those produced without using CD molecules. Such nanowebs have the potential to be implemented in food packaging.

Jiang et al. (2014) reported the development of nanofibrous membranes from nisin-loaded phosphorylated soybean protein isolate (PSPI)/PLLA/zirconium dioxide (nisin-PSPI/PLLA/ZrO ${ }_{2}$ ) (Jiang et al., 2015). The nanofiber diameter increased with increasing concentration of PSPI while spindle-shaped bead appeared when PSPI content reaches to $25 \mathrm{wt} \%$. Variations in the nisin dosage did not cause any notable change in the fiber size and morphology when nisin content was $<9 \mathrm{wt} \%$. The incorporation of PSPI and $\mathrm{ZrO}_{2}$ led to a decrease in the PLLA crystallinity as a $\beta$ result of the presence of hydrogen and $\mathrm{Zr}-\mathrm{O}-\mathrm{C}$ bonds among PSPI, PLLA and $\mathrm{ZrO}_{2}$ units. Furthermore, the water adsorption capability and degradation rate of the PSPI/PLLA/ZrO $\mathrm{Zr}_{2}$ nanofibrous mat boosted with a PSPI content rise. A better antimicrobial activity of the membranes was observed for $S$. aureus, and the release of nisin fitted to the Fickian diffusion model. The nisin-PSPI/PLLA/ $/ \mathrm{ZO}_{2}$ nanofibrous membranes have great potential to be exploited in food packaging. Neoh, Ariyanto, Menéndez Galvan, and Yoshii (2017) reported the controlled release of 1-methylcyclopropene (1-MCP) from polystyrene (PS) fibers and studied its release profiles from the fiber matrix under constant and linearly ramped humidity (Neoh et al., 2017). 1-MCP is a phytohormone antagonist that efficiently inhibits ethylene ripening in various fresh productions, and delays ethylene-induced color change, ripening, and senescence (Perera, Balchin, Baldwin, Stanley, \& Tian, 2003; Sisler, Dupille, \& Serek, 1996). $\alpha$-CD was used to form IC with 1-MCP, and the IC was mixed with PS solution and electrospun into fibers. Microfibers with 1.5-4.4 $\mu \mathrm{m}$ diameter were produced using $12.5-20.0 \mathrm{wt} \%$ PS solution. The IC-functionalized fibers could be produced from $20 \%$ PS and $50 \mathrm{wt} \%$ IC. The release of 1-MCP from the fibers was explored under linearly ramping humidity conditions at a constant temperature with a home-built humidity regulating system, which is coupled with gas chromatography. The irregular release profiles were modeled and the activation energies of the release from the fibers found as 128 and $69 \mathrm{~kJ} \mathrm{~mol}^{-1}$, respectively. Ge, Zhao, Mo, Li, and Li (2012) showed an approach for the immobilization of glucose oxidase (GO) in the nanofibrous mats for food preservation (Ge et al., 2012). The mixture of PVA, chitosan, tea extract, and GO was electrospun into a nanofibrous material. The immobilization of GO in the nanofibers was confirmed by FTIR, and the optimal activity of the immobilized GO was found over $68 \%$ of the free enzyme. The use of the GO functional nanofibers revealed $73 \%$ deoxidation to the tested samples, and the growth and reproduction of microorganisms were drastically inhibited when the oxygen level was lower than $1 \%$, extending the shelf-life of the packaged food. Liu, Wang, Zhang, Lan, and Qin (2017) reported the development of PLA-based fibers loaded with the CEO for antimicrobial applications (Liu et al., 2017). First, 
CEO with different concentrations $(1,1.5,2$, and $2.5 \% \mathrm{v} / \mathrm{v})$ was encapsulated in chitosan nanoparticles through oil-in-water $(\mathrm{o} / \mathrm{w})$ emulsion and ionic gelation methods. The nanoparticles were mixed with the PCL solution and electrospun into fibers. The resultant fibers displayed good stability and sustained release profile of the CEO, leading to antimicrobial activity. The electrospun fibers revealed high long-term inactivation rates against $S$. aureus and $E$. coli due to the sustained release of the CEO, suggesting their potential to be used in the food packaging industry. Liu et al. (2018) reported antimicrobial PLA/tea polyphenol nanofibers for food packaging applications (Liu, Liang, Wang, Qin, \& Zhang, 2018). The electrospinning of the solution of PLA and tea polyphenol produced nanofibers. The color of the resultant fibers was related to the content of tea polyphenol used. The incorporation of tea polyphenol decreased both tensile strength and elongation at break, however, it affected the hydrophilic/hydrophobic balance and release behavior of the composite fibers. The nanofibers showed antioxidant activity with DPPH radical scavenging capabilities of up to $95.07 \pm 10.55 \%$. The fibers exhibited antibacterial activity against $E$. coli and $S$. aureus up to $92.26 \%$ $\pm 5.93 \%$ and $94.58 \pm 6.53 \%$, respectively for the combination of PLA: TP (3:1), suggesting the use of the resultant fibers for food packaging applications. The Uyar research group reported CD-based IC embedded nanofibers for food packaging. In this regard, $\alpha$-tocopherol $(\alpha-\mathrm{TC})$ and $\alpha$-TC/CD IC incorporated into electrospun PLA nanofibers by electrospinning (Aytac, Keskin, et al., 2017). The nanofibers were formulated in the presence of $\gamma$-CD and tested for the release of $\alpha$-TC into a 95\% ethanol solution (i.e., a fatty food simulant). The release of $\alpha$-TC was much higher for the PLA/ $\alpha$-TC/ $\gamma$-CD-IC nanofibers than from the PLA/ $\alpha$-TC nanofibers, and furthermore, 2,2-diphenyl-1-picrylhydrazyl (DPPH) radical scavenging assay showed 97\% antioxidant activity for both fibers, demonstrating their possible role in preventing lipid oxidation. Both nanofibers were treated directly on beef following the thiobarbituric acid reactive substance (TBARS) method, and the electrospun nanofibers showed lower TBARS content than the unpackaged meat sample, demonstrating that the nanofibers are ideal materials to be used as food packaging materials.

Sumnu and colleagues reported nanofibrous active food packaging for oxidative protection to walnuts (Aydogdu, Yildiz, Aydogdu et al., 2019). The packaging material was produced by the electrospinning of the solution of PEO, lentil flour and gallic acid. The presence of gallic acid in the fibers was confirmed by DSC over the disappearance of enthalpy peaks resulting from the melting of the crystalline structure of gallic acid. The gallic acid-containing nanofibrous food packaging material was exploited to pack walnuts, and a reduction in the walnuts oxidation with lower peroxide, Totox values and $p$-anisidine were detected. These packaging materials have great potential for the packaging of oxidation sensitive foods. The same research group reported the deposition of soy protein/hydroxypropyl methylcellulose (HPMC) electrospun fibers onto a PLA sheet for possible food packaging materials (Aydogdu, Yildiz, Ayhan, et al., 2019). The use of electrospun fibers deposited PLA sheets reduced the transparency of the PLA sheet while no improvement in the permeability values was detected. Such materials can be exploited for the packaging of light-sensitive foods. Recently, Pan, Ai, Shao, Chen, and Gao (2019) reported the preparation of PVA $/ \beta$-CD antimicrobial nanofibers for fresh mushroom packaging (Pan et al., 2019). The electrospun food packaging material was prepared by cross-linked PVA fibers embedded with $\beta$-CD/ $\mathrm{CEO}$. The release tests showed a sustained release profile for CEO from the fibrous mats. Glutaraldehyde atomization fumigation was exploited for the chemical cross-linking and physical welding. The electrospun mats showed in vitro antibacterial activity against $S$. aureus and E. coli, and could delay the decay of mushroom during storage, demonstrating their high potential as food packaging material. Another antibacterial nanofiber system was developed by the electrospinning of PEO containing Dendrobium officinale polysaccharide (DOP), and the fiber mat was used for pork packaging (Y. Zhu et al., 2019). The fiber morphology was tuned by the content of DOP added: a higher DOP content worsened the fiber morphology, however, the addition of adipic acid improved the electrospinnability of the solutions even at high DOP contents. The adipic acid added PEO nanofibers with a high DOP loading showed better antibacterial activity against $E$. coli on pork samples, demonstrating the feasibility of the nanofibers as packaging material. A food packaging material was developed by the electrospinning of PVA containing pomegranate peel extract (PPE) and sodium dehydroacetate (SD) (He, Lan, Ahmed, Qin, \& Liu, 2019). The addition of PPE and SD to the PVA film could improve the mechanical properties while no significant effect was observed on both light transmission and water vapor permeability. The presence of PPE resulted in antioxidant activity, and bacteriostatic experiments revealed an increase in antibacterial activity of the films with increasing PPE and SD contents.

\subsection{Electrospun nanocomposite materials for food packaging}

Nanocomposites possess ideal barrier properties desired in food packaging applications. Nanocomposite food packaging is an alternative approach to conventional food packaging because of its enhanced physical properties, particularly barrier, and mechanical properties, by the simple incorporation of reinforcing compounds (fillers). Even incorporation of small quantities from nanoparticles, such as nanoclays improved the gaseous barrier property (e.g., oxygen transmission rates) of packaging material (Garc1 et al., 2003). Furthermore, the incorporation of nanoclay enhanced transparency and shelf life and reduces haze. Agarwal et al. (2014) reported a food packaging materials based on the electrospun nanoweb of montmorillonite and nylon-6 over polypropylene (PP) films on bread and potato chips (Agarwal et al., 2014). The deposition of composite nanofibers on the polypropylene (PP) films drastically enhanced the OTR of PP of $963 \mathrm{~cm}^{3} / \mathrm{m}^{2} / 24 \mathrm{~h}$ increased to 35 on N6 coating. But, it was increased to 12.5 by the coating with montmorillonite added N6. On the other hand, the Moisture Vapour Transfer Rate (MVTR) of PP did not reveal any significant improvement with the N6 coating, while a clear improvement was observed with the incorporation of clays. The level of malondialdehyde in potato chips was boosted by 0.15 in test to $0.95 \mu \mathrm{M} \mathrm{g}^{-1}$ in control samples, demonstrating the lower rancidity of chips in test packets owing to less oxygen permeability. A slight reduction (2\%) was observed in moisture absorption in the test packets. The shelf life of the packaged bread increased by 2 days as a result of inhibition of microbial growth and the effect of clays in oxygen and moisture absorption. Hybrid antimicrobial food packaging materials based on biodegradable PU supplemented with zinc oxide and virgin olive oil were prepared by electrospinning (Amna, Yang, Ryu, \& Hwang, 2015). The incorporation of olive oil worsened the fiber structure. The presence of $\mathrm{ZnO}_{2}$ nanoparticles was confirmed by EDS, TEM and XRD analyses. The antimicrobial affinity of the packaging materials was tested against two common pathogens, S. Typhimurium and $S$. aureus. The incorporation of olive oil influenced the morphology of PU nanofibers, and the nanocomposite packaging was enabled to inhibit the growth of both pathogens. Recently, Lin, Mao, Sun, Rajivgandhi, and Cui (2019) reported the fabrication of moringa oil-loaded chitosan nanoparticles (MO@CNPs) and their embedment into gelatin nanofibers for the biocontrol of $S$. aureus and L. monocytogenes on cheese (Lin, Gu, \& Cui, 2019). The optimal MO@CNPs were synthesized by the ionic cross-linking method with the concentrations of moringa oil and chitosan at 20 and $3.0 \mathrm{mg} \mathrm{mL}^{-1}$, respectively. The slower release of moringa oil from the nanoparticles was reduced from the nanofibers. The MO@CNPs nanofibers showed high antibacterial activity against $S$. aureus and $L$. monocytogenes at $4{ }^{\circ} \mathrm{C}$ and $25{ }^{\circ} \mathrm{C}$ for 10 days. Munteanu, Aytac, Pricope, Uyar, and Vasile (2014) reported PLA/Ag-NPs/ vitamin $\mathrm{E}$ bionanocomposite electrospun nanofibers with antioxidant and antibacterial properties (Munteanu et al., 2014). The nanofibers 
were formulated using antibacterial Ag-NPs and antioxidant vitamin $\mathrm{E}$ in the PLA nanofibers. The nanofibers with a mean diameter of $140 \pm 60 \mathrm{~nm}$ and nanoparticles of $2.7 \pm 1.5 \mathrm{~nm}$ in diameter were produced. The bionanocomposite nanofibers inhibited the growth of $E$. coli, L. monocytogenes, and S. Typhimurium up to $100 \%$. Ag was slowly released from the fiber matrix, and the antioxidant activity of the fibers was found to be $94 \%$ according to DPPH assay. The tests on fresh apples and apple juice revealed the nanoweb could actively reduce the polyphenol oxidase activity. These nanofibrous materials have great potential as food packaging materials.

A flexible food packaging material was developed by the electrospinning of mesoporous silica nanoparticles (MSNs), ascorbic acid, and PLA (Cacciotti \& Nanni, 2016). A plasticizer (acetyl tri-n-butyl citrate, ATBC) was exploited to enhance the mechanical properties in terms of the flexibility of the mat, and such incorporation increased the thermal properties of the mat as a result of interactions among the precursors. The fiber stability was explored at a laboratory scale level according to the ISO 20200 standard, in which electrospun materials $(15 \mathrm{~mm} \times 15 \mathrm{~mm})$ were buried at the depth of $4-6 \mathrm{~cm}$ in perforated plastic boxes containing a solid synthetic wet waste prepared with $10 \%$ of compost (Mantillo, Spain), 10\% starch, 30\% rabbit food, $5 \%$ sugar, $40 \%$ sawdust, $4 \%$ corn oil and $1 \%$ urea, and approximately $50 \mathrm{wt} \%$ of water content at aerobic conditions at $58{ }^{\circ} \mathrm{C}$. The results revealed that the incorporation of ATBC fastened the mat disintegration. Whereas, PHB increased the disintegration time of the mat. Overall, such flexible biodegradable electrospun mats can be implemented as sustainable flexible materials for food packaging applications. An antimicrobial nanocomposite bilayer was prepared by the electrospinning of PHBV and copper oxide nanoparticles ( $\mathrm{CuO}$ NPs) onto the compressed molded PHBV3 (3\% mol valerate) for active packaging and coating applications (Castro Mayorga, Fabra Rovira, Cabedo Mas, Sánchez Moragas, \& Lagarón Cabello, 2018). The water vapor permeability increased with the $\mathrm{CuO}$ NPs addition. On the other hand, a slight enhancement was observed in the oxygen barrier properties with the incorporation of $0.05 \%$. The incorporation of CuO NPs into the films slightly affected the properties of the bilayer structures. With a lower concentration of $\mathrm{CuO}$ nanoparticles in a well-dispersed manner by electrospinning, a significant bactericidal and virucidal performance against the foodborne pathogens, S. enterica, L. monocytogenes, and murine norovirus was observed. The bio-disintegration test of the samples under composting conditions showed that the biodegradation takes place in 35 days. Likewise, a matrix of PHBV and AgNP-based coating obtained by means of electrospinning (Castro-Mayorga, Randazzo, et al., 2017). The authors first investigated the efficiency of silver nitrate $\left(\mathrm{AgNO}_{3}\right)$ and $\mathrm{AgNP}$ for inactivating norovirus surrogates, the feline calicivirus (FCV) and the murine norovirus (MNV), which were exposed to $\mathrm{AgNO}_{3}$ and Ag-NPs solutions for $24 \mathrm{~h}$ at $25^{\circ} \mathrm{C}$, and a significant decrease in FVC and MNV infectivity was observed in a dose-dependent manner. Moreover, PHBV films were produced by the deposition of thermally post-processed electrospun mats of PHBV18/Ag-NPs over the compression-molded PHBV3 films. After 1 day exposure at $37{ }^{\circ} \mathrm{C}$ and $100 \% \mathrm{RH}$, no infectious FCV was recovered when in contact with the Ag-NPs films while MNV titers decreased by $0.86 \log$. Overall, the materials can be employed as antiviral surfaces for possible food packaging applications. The same research group incorporated $\mathrm{ZnO}$ particles into PHBV films by the electrospinning with PHBV18 (18 mol\% valerate content) (Castro-Mayorga, Fabra, Pourrahimi, Olsson, \& Lagaron, 2017). First, ZnO micro and nanoparticles with different morphologies were synthesized and implemented as antibacterial materials against foodborne pathogens. Different effective bactericide systems were produced: (i) direct melt-mixing, (ii) melt-mixing of the pre-incorporated $\mathrm{ZnO}$ into the fiber mats of PHBV18 made by electrospinning, and (iii) as a coating of the annealed electrospun PHBV18/ZnO fiber mats over compression-molded PHBV. The incorporation of $\mathrm{ZnO}$ enhanced the thermal stability of $\mathrm{PH}-$ BV18. The pre-incorporation method was found to be the most ef- ficient in decreasing the negative impact that the PHBV18 possessed on the barrier, thermal stability, and optical properties of the PHBV films. Antibacterial test results showed that the high amounts of the $\mathrm{PH}$ BV18/ZnO are required to obtain a bactericide effect against L. monocytogenes. Overall, the materials are promising for food packaging applications. Deng et al. (2012) reported the composites production using quaternized chitosan (HTCC)-organic rectorite (OREC) intercalated into electrospun nanofibrous materials, which are produced from the HTCC-OREC/PVA solutions (Deng et al., 2012). TEM analysis confirmed HTCC chains were between the exfoliated OREC interlayers. The addition of OREC led to a better fibrous structure. FTIR and EDS analyses evidenced the presence of OREC in the PVA/HTCC-OREC nanofibrous materials. XRD confirmed the intercalated structure in fibrous mats owing to the intercalation of PVA chains and HTCC into the interlayer of the OREC. The addition of OREC enhanced the antibacterial activity of the electrospun mats, suggesting the potential of this ternary system in food packaging applications.

Recently, Liu and colleagues reported antibacterial nanocomposite materials of PLA and $\mathrm{TiO}_{2}$ using both electrospinning and solution casting processes (Feng, Zhang, Ahmed, \& Liu, 2019). The incorporation of $\mathrm{TiO}_{2}$ significantly reduced the water vapor transmittance rate of the nanofibers and films while drastically improved the water solubility. Under UV-A irradiation, the nanofibers and films displayed inhibition zones of $4.86 \pm 0.50$ and $3.69 \pm 0.40 \mathrm{~mm}$ for the diffusion test of $E$. coli, and $5.98 \pm 0.77$ and $4.63 \pm 0.45 \mathrm{~mm}$ for $S$. aureus, respectively, which is much higher than the counterpart films. These materials with a very low water-vapor transmittance property have great promising to be used in food packaging applications. Another antimicrobial nanofiber system was developed based on Ag-NPs and PVA. Ag-NPs were synthesized using Vitis vinifera (black grapes) fruit peel, and thereafter, mixed with PVA prior to the electrospinning (Senthil Muthu Kumar et al., 2019a). The antibacterial activity of the Ag-NPs embedded PVA nanofibers was evidenced by food pathogenic bacterial strains. The nanofibers were used to package fruits, Citrus limon (lemon) and Fragaria ananassa (strawberry), and the results revealed an enhanced shelf life, preventing the decaying caused because of food pathogens, suggesting the use of such fibers for food packaging applications. Another hybrid electrospun material was developed using PLA, chitosan and carbon nanotubes additives (Liu, Wang, Lan, \& Qin, 2019). The mechanical, swelling and solubility of the fiber films were improved with an increasing chitosan content. Likewise, the antibacterial activity of the fibers was enhanced with the incorporation of chitosan content, and the best performance was observed when the chitosan content was $7 \mathrm{wt} \%$. The composite nanofibers demonstrated good preservation effects for strawberries, suggesting the use of such materials for food packaging applications.

\section{Concluding remarks and future outlook}

The last decade has witnessed significant breakthroughs in engineering innovative food packaging materials with the desired barrier and active properties to be effectively used in food packaging applications. In this regard, one of the most important breakthroughs is the use of electrospun food packaging materials to enable the control of structural properties of the packaging materials at the nanoscale with the appropriate selection of components, and preparation route while allowing high loading of active agents. The electrospinning process allows the preparation of eco-friendly, active food packaging electrospun materials using biopolymers, biocompatible synthetic polymers, and their nanocomposites. The use of such polymers with further incorporating active components permits the fabrication of active packaging materials with antimicrobial, antifungal, or antioxidant properties. In this regard, the incorporated active agents define the overall functionality of the packaging materials: e.g., the incorporation of antioxidant ingredients into electrospun fibers leads to antioxidant food packaging materials (Tables 1-4). The high surface to volume ratio, ease of en- 
Table 1

Polysaccharide-based electrospun materials for food packaging applications.

\begin{tabular}{|c|c|c|c|c|c|}
\hline Polysaccharide & Other ingredients & Active agent & $\begin{array}{l}\text { Active } \\
\text { properties }\end{array}$ & Remarks & Refs \\
\hline Chitosan & $\begin{array}{l}\text { Chrysanthemum essential } \\
\text { oil (CHEO) }\end{array}$ & CHEO & Antibacterial & $\begin{array}{l}\text { The CHEO nanofibers could prevent the growth of } L \text {. } \\
\text { monocytogenes on beef with an inhibition rate of }>99.9 \% \text { at } \\
\text { different temperatures }\left(4,12 \text { and } 25{ }^{\circ} \mathrm{C}\right) \text { after } 7 \text { days of } \\
\text { exposure. }\end{array}$ & (Lin et al., 2019) \\
\hline Chitosan & $\begin{array}{l}\text { Polybutylene adipate-co- } \\
\text { terephthalate (PBAT) } \\
\text { films }\end{array}$ & Chitosan & Antibacterial & $\begin{array}{l}\text { The fibers showed antibacterial activity against } S \text {. aureus, } B \text {. } \\
\text { subtilis, } E \text {. coli, and } S \text {. enteritidis bacteria, with a stronger biocide } \\
\text { effect for Gram-negative cells. }\end{array}$ & $\begin{array}{l}\text { (Díez-Pascual \& Díez- } \\
\text { Vicente, 2015) }\end{array}$ \\
\hline Cellulose & $\begin{array}{l}\text { Chitosan, epigallocatechin } \\
\text { gallate (EGCG) }\end{array}$ & EGCG & Antimicrobial & $\begin{array}{l}\text { The composites enhanced the antimicrobial effects of chitosan } \\
\text { and EGCG. }\end{array}$ & (Tian et al., 2016) \\
\hline $\begin{array}{l}\text { Cellulose } \\
\text { acetate (CA) }\end{array}$ & $\begin{array}{l}\text { Chitosan, pectin/organic } \\
\text { rectorite (OREC) }\end{array}$ & $\begin{array}{l}\text { Chitosan, } \\
\text { pectin/OREC }\end{array}$ & Antibacterial & $\begin{array}{l}\text { The resultant materials showed antibacterial activity against } E \text {. } \\
\text { coli and } S \text {. Aureus. }\end{array}$ & (Xin et al., 2013) \\
\hline Chitosan & $\begin{array}{l}\text { Poly(ethylene oxide) } \\
\text { (PEO), microalgae } \\
\text { phenolic compounds }\end{array}$ & $\begin{array}{l}\text { Microalgae } \\
\text { phenolic } \\
\text { compounds }\end{array}$ & Antibacterial & $\begin{array}{l}\text { The materials showed antibacterial activity against } S \text {. Aureus } \\
\text { and } E \text {. coli. }\end{array}$ & (Kuntzler et al., 2018) \\
\hline Chitosan & - & - & - & $\begin{array}{l}\text { The fibers have great potential as a wrapping material for } \\
\text { improved quality during the dry-aging of beef. }\end{array}$ & $\begin{array}{l}\text { (Gudjónsdóttir et al., } \\
\text { 2015) }\end{array}$ \\
\hline $\begin{array}{l}\text { Cellulose } \\
\text { acetate (CA) }\end{array}$ & $\begin{array}{l}\text { Poly(ethylene oxide) } \\
\text { (PEO), zinc oxide } \\
\text { nanoparticles (ZnO NPs) }\end{array}$ & - & - & $\begin{array}{l}\text { The incorporation of the } \mathrm{ZnO} \text { NPs improved the mechanical } \\
\text { properties of the fibrous film. }\end{array}$ & $\begin{array}{l}\text { (Pittarate, Yoovidhya, } \\
\text { Srichumpuang, } \\
\text { Intasanta, \& } \\
\text { Wongsasulak, 2011) }\end{array}$ \\
\hline $\begin{array}{l}\text { Cellulose } \\
\text { acetate (CA) }\end{array}$ & $\begin{array}{l}\text { Poly(ethylene oxide) } \\
\text { (PEO), T4 bacteriophage }\end{array}$ & - & - & $\begin{array}{l}\text { The blending of CA and PEO drastically reduced the rate of the } \\
\text { phage release while no releasing of no T4 phage could be } \\
\text { observed from the solely CA fibers. }\end{array}$ & (Korehei \& Kadla, 2014) \\
\hline Pullulan & $\begin{array}{l}\beta \text {-cyclodextrin }(\beta-\mathrm{CD}) \\
\text { perillaldehyde }\end{array}$ & - & - & The incorporated $\beta$-CD decreased the release of aroma. & $\begin{array}{l}\text { (Mascheroni et al., } \\
\text { 2013) }\end{array}$ \\
\hline $\begin{array}{l}\text { Pullulan/ } \\
\text { carboxymethyl } \\
\text { cellulose } \\
\text { (CMC) }\end{array}$ & Tea polyphenols (TP) & $\mathrm{TP}$ & - & $\begin{array}{l}\text { The nanofibers considerably reduced the weight loss and could } \\
\text { maintain the firmness of the strawberries, and enhanced the } \\
\text { fruit quality during the storage. }\end{array}$ & $\begin{array}{l}\text { (Shao, Niu, Chen, \& } \\
\text { Sun, 2018) }\end{array}$ \\
\hline Kefiran & $\begin{array}{l}\text { Poly(ethylene oxide) } \\
\text { (PEO) }\end{array}$ & Kefiran & Antimicrobial & $\begin{array}{l}\text { The kefiran/PEO nanofibers showed antimicrobial activity } \\
\text { against } S \text {. aureus. }\end{array}$ & $\begin{array}{l}\text { (Jenab, Roghanian, } \\
\text { Emtiazi, \& Ghaedi, } \\
\text { 2017) }\end{array}$ \\
\hline Chitosan & $\begin{array}{l}\text { Poly(ethylene oxide) } \\
\text { (PEO) }\end{array}$ & - & - & $\begin{array}{l}\text { The susceptibility order was as follows: } \\
\text { E. coli }>\text { L. innocua }>\text { S. aureus }>\text { S. typhimurium. }\end{array}$ & (Arkoun et al., 2017b) \\
\hline Chitosan & $\begin{array}{l}\text { The nanofibers were post } \\
\text { modified with alkyl } \\
\text { groups. }\end{array}$ & - & - & $\begin{array}{l}\text { Water contact angle measurements showed that the length of } \\
\text { acyl side chains directly affected the wetting properties of the o- } \\
\text { acylated CSNFs. }\end{array}$ & (Zhang et al., 2017) \\
\hline $\begin{array}{l}\text { Regenerated } \\
\text { cellulose (RC) }\end{array}$ & $\begin{array}{l}\text { Carboxylated carbon } \\
\text { nanotubes (CNT) and } \\
\text { graphene oxide, lysozyme }\end{array}$ & Lysozyme & Antibacterial & $\begin{array}{l}\text { The cellulose/lysozyme conjugates were found to have robust } \\
\text { bioactivity with no indication of cell cytotoxicity. }\end{array}$ & (Liu et al., 2018) \\
\hline $\begin{array}{l}\text { Bacterial } \\
\text { cellulose (BC) }\end{array}$ & $\begin{array}{l}\text { Polyindole ((Pin) by post- } \\
\text { treatment) }\end{array}$ & & Antibacterial & $\begin{array}{l}\text { The PIn/BC fibers showed good antibacterial performance and } \\
\text { biodegradability. }\end{array}$ & (Zhijiang et al., 2018) \\
\hline
\end{tabular}

capsulating active agents in fibers, smaller pore size between intertwined fibers (i.e., for the prevention of bacterial entry) and the small size of fibers that allows a rapid response with the timely release of active molecules are main advantages of electrospun materials in food packaging applications.

Currently, the food packaging applications of electrospun fibers are suffering from the insufficiency of nontoxic solvents for the solubilization of many biopolymers and biocompatible synthetic polymers. Since the resultant materials are intended to be used in food science, the ingredients of packaging materials, including solvents should have GRAS (Generally recognized as safe) status. In parallel, initiative attempts are required on their use at a pilot scale, which will attract the interest of the researchers working in the food packaging field. These issues currently stand as major obstacles in the food packaging applications of electrospun materials before being placed on the market. The first problem can be solved by an appropriate selection of polymers and solvent systems, such as commercial green solvents. In this regard, melt-electrospinning can be used to produce fibrous packaging materials without requiring any toxic solvent. The latter issue can be dealt with the use of industrial electrospinning systems to produce electrospun materials in large quantities. In this regard, in addition to a nozzle- based solution electrospinning system, which has been exploited for the production of most electrospun food packaging materials, other electrospinning methods (both nozzle-based and nozzle-less) can also be applied to produce nanofibers in large quantities. Moreover, the electrospinning yield can be boosted using an alternative current electrospinning system, which will allow the higher production of the nanofibers than the conventional direct current electrospinning system. Besides those major drawbacks of electrospinning systems, there are other significant issues related to their highly porous structure, which drastically decreases its barrier performance than their film counterparts. Water vapor and oxygen can be penetrated from such porous matrices of polymer fibers easily. In this regard, the use of specific polymers or ingredients that can adsorb both water vapor and $\mathrm{O}_{2}$ is very crucial. Moreover, the high loading efficiency of active molecules into electrospun materials can be provided using particular solubilization enhancers, such as cyclodextrins (CDs). Such molecules can complex with active ingredients and drastically improve their solubility for high loading as mentioned in the previous sections. The nanoencapsulation of such active ingredients is also possible using bio-derived surfactants. The most important disadvantage of electrospun fibers in food packaging is the attachment of loose fibers on foods. However, this can 
Table 2

Protein and other bio-based electrospun materials for food packaging applications.

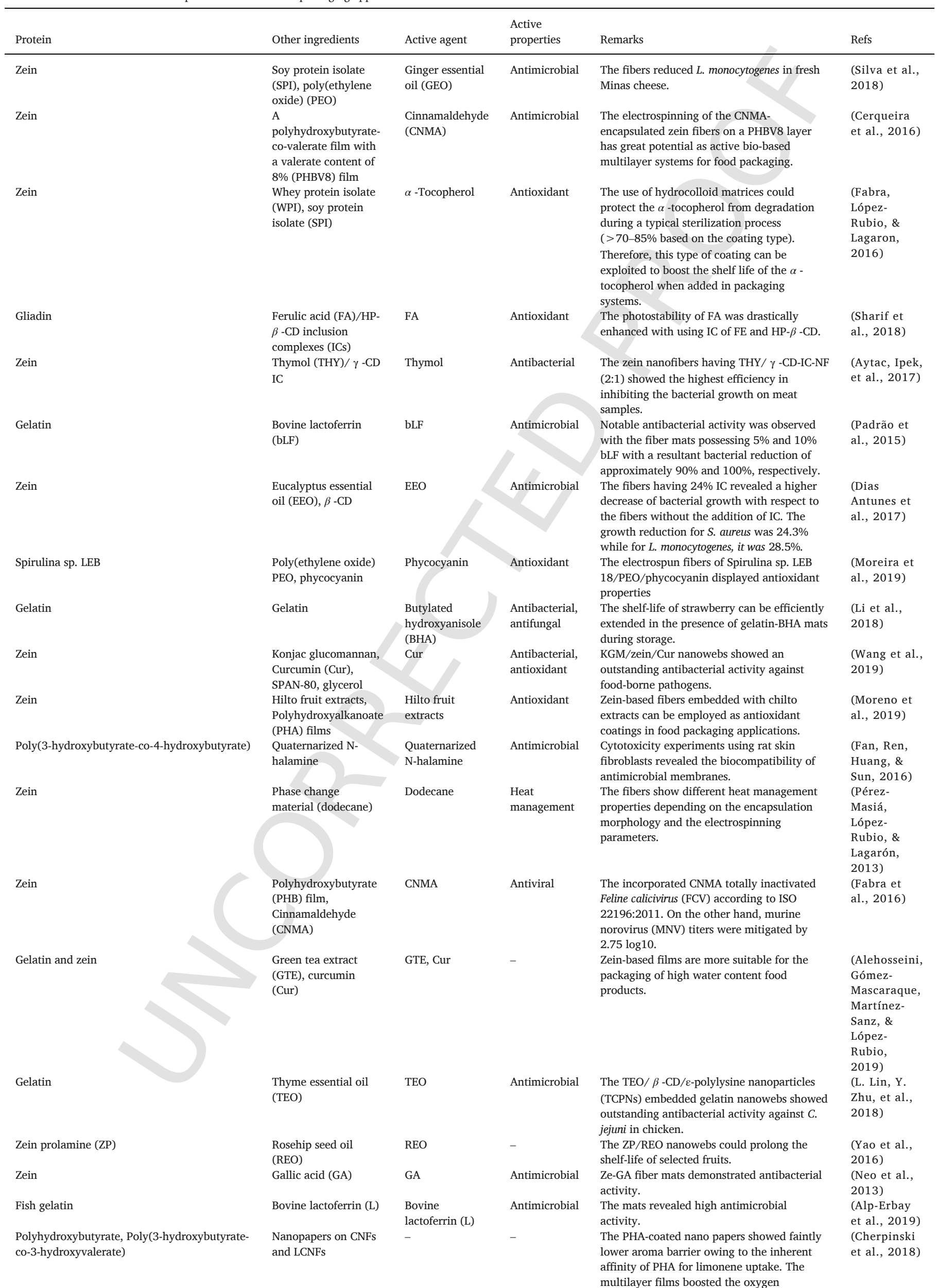


Table 2 (Continued)

\begin{tabular}{|c|c|c|c|c|c|}
\hline Protein & Other ingredients & Active agent & $\begin{array}{l}\text { Active } \\
\text { properties }\end{array}$ & Remarks & Refs \\
\hline Zein & $\begin{array}{l}\text { Polyhydroxybutyrate (PHB), } \\
\text { PHBV5 (5\% valate content), } \\
\text { Poly(L-lactic acid) (PLA) or } \\
\text { poly(ethylene terephthalate) } \\
\text { PET films }\end{array}$ & - & - & $\begin{array}{l}\text { The water vapor permeability of the multilayer systems } \\
\text { showed variations depending on the material used. The use of } \\
\text { zein nanofibers as an interlayer was only an effective concept } \\
\text { as a barrier component in the PHA materials as compared to } \\
\text { the PLA based one. }\end{array}$ & $\begin{array}{l}\text { (Fabra, } \\
\text { Lopez-Rubio, } \\
\text { \& Lagaron, } \\
\text { 2014) }\end{array}$ \\
\hline Gelatin, $\varepsilon$-Poly-lysine & Glycerin & $\varepsilon$-Poly-lysine & Antibacterial & $\begin{array}{l}\text { The resultant nanofibers were used for the protection of beef, } \\
\text { and the results showed excellent antibacterial activity against } \\
\text { L. monocytogenes without any change in sensory properties } \\
\text { and meat color. }\end{array}$ & $\begin{array}{l}\text { (L. Lin, Y. } \\
\text { Gu, et al., } \\
2018 \text { ) }\end{array}$ \\
\hline $\begin{array}{l}\text { Whey protein isolate } \\
\text { (WPI), pullulan, zein }\end{array}$ & $\begin{array}{l}\text { Polyhydroxybutyrate-co- } \\
\text { valerate film }\end{array}$ & - & - & $\begin{array}{l}\text { The electrospun WPI nanostructures with beaded fiber } \\
\text { morphology did not drastically reduce the oxygen and water } \\
\text { vapor permeability of the PHBV3-multilayer systems like zein } \\
\text { and pullulan fibers. }\end{array}$ & $\begin{array}{l}\text { (Fabra, } \\
\text { López-Rubio, } \\
\text { \& Lagaron, } \\
\text { 2014) }\end{array}$ \\
\hline Polyhydroxybutyrate & - & - & Antibacterial & The obtained nanofibers could inhibit the growth of $S$. aureus. & $\begin{array}{l}\text { (Kuntzler, } \\
\text { Almeida, } \\
\text { Costa, \& } \\
\text { Morais, } \\
\text { 2018) }\end{array}$ \\
\hline Zein & Curcumin (Cur) & Cur & Antibacterial & $\begin{array}{l}\text { The antibacterial activity of the materials was higher for } S \text {. } \\
\text { aureus than } E \text {. coli. }\end{array}$ & $\begin{array}{l}\text { (Wang et al., } \\
\text { 2017) }\end{array}$ \\
\hline Zein & $\begin{array}{l}\text { Saffron extract (picrocrocin, } \\
\text { safranal, and crocin) }\end{array}$ & Saffron extract & & $\begin{array}{l}\text { The release profiles of picrocrocin, safranal, and crocin from } \\
\text { the encapsulation structures showed better fitting for the } \\
\text { Peppas-Sahlin model }\left(R^{2}=0.98\right) \text {, demonstrating the release } \\
\text { mechanism takes place as diffusion. }\end{array}$ & $\begin{array}{l}\text { (Alehosseini, } \\
\text { Gómez- } \\
\text { Mascaraque, } \\
\text { Ghorani, \& } \\
\text { López-Rubio, } \\
\text { 2019) }\end{array}$ \\
\hline Zein & $\begin{array}{l}\text { Poly(3-hydroxybutyrate-co- } \\
\text { hydroxyvalerate) (PHBV) } \\
\text { with valate content of } 12 \% \\
\text { (PHBV12) film }\end{array}$ & - & - & $\begin{array}{l}\text { The addition of the fibrous zein interlayers drastically } \\
\text { enhanced the oxygen barrier properties of the resultant films. }\end{array}$ & $\begin{array}{l}\text { (Fabra, } \\
\text { Lopez-Rubio, } \\
\text { et al., 2013) }\end{array}$ \\
\hline Zein & $\begin{array}{l}\text { Chamomile essential oil (CO) } \\
\text { and peppermint essential oil } \\
\text { (PO) }\end{array}$ & $\begin{array}{l}\text { Chamomile } \\
\text { essential oil } \\
\text { (CO) and } \\
\text { peppermint } \\
\text { essential oil } \\
\text { (PO) }\end{array}$ & Antibacterial & $\begin{array}{l}\text { The nanofibers containing PO showed better antibacterial } \\
\text { activity against } E \text {. coli and } S \text {. aureus. Furthermore, no } \\
\text { cytotoxicity of the nanofibers was observed. }\end{array}$ & $\begin{array}{l}\text { (Tang et al., } \\
\text { 2019) }\end{array}$ \\
\hline
\end{tabular}

be overcome with the integration of electrospun fibers with films in an efficient and reproducible manner. With that, food packaging films in a multilayer structure either using layers of different polymeric fibers or with films can drastically reduce the permeability of both $\mathrm{O}_{2}$ and water molecules, thereby increasing the shelf-life of the foods while active agents embedded in the fibers can involve in a specific function with getting in touch with the food.

In the future, more research should be focused on the intelligent packaging materials of electrospun materials since the higher surface area of nanofibrous packaging materials will drastically enhance the response rate and amplitude compared to their conventional film counterparts. In this regard, a wide variety of sensing molecules can be incorporated or used for the surface decoration of the fibers. So far, phase change materials (PCMs) were incorporated into the fibers to pro- duce intelligent packaging materials that can control the heat-storage capacity of the fibers. On the other hand, even though many studies have focused on the production of active electrospun materials, more studies are required to observe their performance with foods for the long term and their applicability in a feasible manner. Furthermore, comparative studies are essential to test their performance with conventional films made by the same components.

\section{Uncited references}

Uyar and Kny (2017).

\section{Declaration of Competing Interest}

The authors have no conflicts of interest to declare. 
Table 3

Electrospun materials from synthetic polymers for food packaging applications.

\begin{tabular}{|c|c|c|c|c|c|}
\hline Polymer & Other ingredients & Active agent & $\begin{array}{l}\text { Active } \\
\text { properties }\end{array}$ & Remarks & Refs \\
\hline Polystyrene & $\begin{array}{l}\text { Phase change materials } \\
\text { (PCM) }\end{array}$ & PCM & $\begin{array}{l}\text { Heat } \\
\text { management }\end{array}$ & $\begin{array}{l}\text { The heat management property was mainly dependent on } \\
\text { the storage temperature. }\end{array}$ & $\begin{array}{l}\text { (Chalco-Sandoval et } \\
\text { al., 2017) }\end{array}$ \\
\hline $\begin{array}{l}\text { Polycaprolactone } \\
\text { (PCL) }\end{array}$ & Gelatin film & $\begin{array}{l}\text { Black pepper } \\
\text { oleoresin (OR) }\end{array}$ & Antimicrobial & $\begin{array}{l}\text { The PCL ultrathin nanofibers and OR improved the } \\
\text { properties of the gelatin films. }\end{array}$ & $\begin{array}{l}\text { (Figueroa-Lopez, } \\
\text { Castro-Mayorga, } \\
\text { Andrade-Mahecha, } \\
\text { Cabedo, \& Lagaron, } \\
2018 \text { ) }\end{array}$ \\
\hline Poly(ethylene oxide) & $\begin{array}{l}\text { Cinnamon essential oil } \\
(\mathrm{CEO}) / \beta-\mathrm{CD}\end{array}$ & CEO & Antimicrobial & $\begin{array}{l}\text { High antibacterial efficiency against } B \text {. cereus on beef was } \\
\text { observed without any influence on the sensory quality of } \\
\text { beef. }\end{array}$ & (Lin et al., 2017) \\
\hline $\begin{array}{l}\text { Poly(L-lactic acid), } \\
\text { Polyhydroxybutyrate }\end{array}$ & $\begin{array}{l}\text { Poly(3-hydroxybutyrate- } \\
\text { co-3-hydroxyvalerate) } \\
\text { (PHBV) film, catechin }\end{array}$ & Catechin & Antioxidant & $\begin{array}{l}\text { The bilayer films displayed high disintegration in compost } \\
\text { conditions in } \sim 3 \text { months. }\end{array}$ & $\begin{array}{l}\text { (Arrieta, Díez García, } \\
\text { López, Fiori, \& } \\
\text { Peponi, 2019) }\end{array}$ \\
\hline $\begin{array}{l}\text { Poly(L-lactic acid) } \\
\text { (PLA) }\end{array}$ & Carvacrol & Carvacrol & $\begin{array}{l}\text { Antioxidant, } \\
\text { antimicrobial }\end{array}$ & $\begin{array}{l}\text { The carvacrol loaded electrospun zein and PLA nanofibers } \\
\text { could preserve the freshness of bread samples. }\end{array}$ & (Altan et al., 2018) \\
\hline $\begin{array}{l}\text { Polylactic-co- } \\
\text { glycolic acid, } \\
\text { Polycaprolactone } \\
\text { (PCL) }\end{array}$ & - & - & Antimicrobial & $\begin{array}{l}\text { A marked reduction in the formation of biofilm was } \\
\text { detected for the PCL fibers. }\end{array}$ & $\begin{array}{l}\text { (Clavijo-Grimaldo, } \\
\text { Ponce-Zapata, \& } \\
\text { Casadiego-Torrado, } \\
\text { 2019) }\end{array}$ \\
\hline $\begin{array}{l}\text { Poly(L-lactic acid), } \\
\text { Polyhydroxybutyrate }\end{array}$ & $\begin{array}{l}\text { ATBC (acetyl tri-n-butyl } \\
\text { citrate) }\end{array}$ & - & - & $\begin{array}{l}\text { The disintegration tests under composting conditions } \\
\text { demonstrated the biodegradable characters for all } \\
\text { electrospun mat formulations. }\end{array}$ & (Arrieta et al., 2015) \\
\hline Poly(L-lactic acid) & PEO, phycocyanin & Phycocyanin & $\begin{array}{l}\text { Color change } \\
\text { on } \mathrm{pH} \\
\text { variations }\end{array}$ & $\begin{array}{l}\text { The } \mathrm{pH} \text { indicators from phycocyanin-containing ultrafine } \\
\text { fibers have great potential for smart food packaging. }\end{array}$ & $\begin{array}{l}\text { (Moreira, Terra, } \\
\text { Costa, \& Morais, } \\
\text { 2018) }\end{array}$ \\
\hline Polystyrene & $\begin{array}{l}\text { Phase change material } \\
\text { (PCM) }\end{array}$ & PCMs & Heat storage & $\begin{array}{l}\text { The resultant materials with an efficient temperature } \\
\text { buffering effect have the potential to be used in food } \\
\text { packaging applications to able to preserve the quality of } \\
\text { refrigerated packaged food products. }\end{array}$ & $\begin{array}{l}\text { (Chalco-Sandoval et } \\
\text { al., 2015) }\end{array}$ \\
\hline Poly(L-lactic acid) & Tea polyphenols (TP) & $\mathrm{TP}$ & $\begin{array}{l}\text { Antioxidant, } \\
\text { antimicrobial }\end{array}$ & $\begin{array}{l}\text { The antimicrobial activities against } E \text {. coli and } S \text {. aureus } \\
\text { were found to be } 92.26 \pm 5.93 \% \text { and } 94.58 \pm 6.53 \% \text {. }\end{array}$ & (Liu et al., 2018) \\
\hline Poly(vinyl alcohol) & $\begin{array}{l}\text { Durvillaea Antarctica } \\
\text { algae extract }\end{array}$ & $\begin{array}{l}\text { D. Antarctica } \\
\text { algae extract }\end{array}$ & $\begin{array}{l}\text { Antimicrobial, } \\
\text { antioxidant }\end{array}$ & $\begin{array}{l}\text { Bionanocomposites containing } D \text {. Antarctica showed higher } \\
\text { mechanical resistance and oxygen barrier properties, } \\
\text { together with high antioxidant activity. }\end{array}$ & (Arrieta et al., 2018) \\
\hline Poly(vinyl alcohol) & $\begin{array}{l}\text { Cinnamon essential oil } \\
(\mathrm{CEO}) / \beta-\mathrm{CD}\end{array}$ & CEO & Antimicrobial & $\begin{array}{l}\text { The inclusion complexation between CEO and } \beta \text {-CD } \\
\text { enhanced the preservation of EEO during the } \\
\text { electrospinning process, and therefore the materials showed } \\
\text { higher antibacterial activity than its casting film. }\end{array}$ & $\begin{array}{l}\text { (P. Wen, Zhu, Wu, et } \\
\text { al., 2016) }\end{array}$ \\
\hline Poly(vinyl alcohol) & $\mathrm{CEO} / \beta$-CD/lysozyme & CEO/lysozyme & Antimicrobial & $\begin{array}{l}\text { Outstanding antifungal activity against Penicillium and } \\
\text { Aspergillus niger. Its minimum inhibition concentration } \\
\text { against } S . \text { enteritidis and L. monocytogenes } \\
\text { was } \sim 0.8 \mathrm{mg} \mathrm{mL}^{-1} \text {. }\end{array}$ & (Feng et al., 2017) \\
\hline $\begin{array}{l}\text { Poly(L-lactic acid) } \\
\text { (PLA) }\end{array}$ & $\mathrm{CEO} / \beta-\mathrm{CD}$ & CEO & Antimicrobial & $\begin{array}{l}\text { The PLA/CEO/ } \beta \text {-CD nanoweb could extend the shelf life of } \\
\text { pork. }\end{array}$ & $\begin{array}{l}\text { (P. Wen, Zhu, Feng, } \\
\text { et al., 2016) }\end{array}$ \\
\hline Polycaprolactone & $\alpha$-tocopherol & $\alpha$-tocopherol & Antioxidant & The fibers showed antioxidant activity. & $\begin{array}{l}\text { (Dumitriu et al., } \\
\text { 2017) }\end{array}$ \\
\hline Poly(vinyl alcohol) & $\begin{array}{l}\text { Chitosan, tea extract, } \\
\text { GO }\end{array}$ & $\begin{array}{l}\text { Tea extract, } \\
\text { GO }\end{array}$ & Antimicrobial & $\begin{array}{l}\text { The reproduction of microorganisms was significantly } \\
\text { inhibited when the oxygen concentration was } 1 \% \text {. }\end{array}$ & (Ge et al., 2012) \\
\hline $\begin{array}{l}\text { Poly(L-lactic acid), } \\
\text { poly[(lactic acid)-co- } \\
\text { lysine] }\end{array}$ & Mustard powder (MP) & $\begin{array}{l}\text { Allyl } \\
\text { isothiocyanate } \\
\text { (AITC) }\end{array}$ & - & $\begin{array}{l}\text { The release time of AITC from the electrospun fibers could } \\
\text { be extended by using coaxial electrospinning. }\end{array}$ & $\begin{array}{l}\text { (Yao, Zhang, Lim, \& } \\
\text { Chen, 2017) }\end{array}$ \\
\hline Polycaprolactone & Cellulose acetate, nisin & Nisin & Antimicrobial & $\begin{array}{l}\text { The triaxial fiber nanowebs offered more robust and } \\
\text { sustained antimicrobial activity. }\end{array}$ & $\begin{array}{l}\text { (Han, Sherman, } \\
\text { Filocamo, \& Steckl, } \\
\text { 2017) }\end{array}$ \\
\hline Poly(ethylene oxide) & $\begin{array}{l}\text { Tea tree oil (TTO) } / \beta- \\
\text { CD IC }\end{array}$ & TTO & Antibacterial & $\begin{array}{l}\text { The highest antibacterial activity with inhibition efficiently } \\
\text { of } 99.99 \% \text { against } E \text {. coli O157: H7, which was tested on } \\
\text { beef samples for } 7 \mathrm{~d} \text {. }\end{array}$ & (Cui et al., 2018) \\
\hline $\begin{array}{l}\text { Polyhydroxybutyrate } \\
\text { (PHB) }\end{array}$ & - & PHB & Antibacterial & $\begin{array}{l}\text { Chlorinated membranes have outstanding antimicrobial } \\
\text { functions, which could inactivate } 85.04 \% \text { E. coli O157 and } \\
92.10 \% \text { S. aureus. }\end{array}$ & (Fan et al., 2015) \\
\hline Poly(vinyl alcohol) & $\begin{array}{l}\text { Wheat gluten } \\
\text { (WG)/Zirconia }\end{array}$ & WG/Zirconia & Antimicrobial & $\begin{array}{l}\text { The electrospun mat showed well-controlled release profiles } \\
\text { and higher antimicrobial activity against } S \text {. Aureus. }\end{array}$ & (Wang et al., 2015) \\
\hline Poly(L-lactic acid) & $\begin{array}{l}\text { Allium ursinum L. (AU) } \\
\text { extract }\end{array}$ & AU extract & Antimicrobial & $\begin{array}{l}\text { The addition of the AU extract led to a mechanical } \\
\text { reinforcement on the electrospun PLA films and faintly } \\
\text { boosted the water barrier performance. }\end{array}$ & (Radusin et al., 2019) \\
\hline Poly(vinyl alcohol) & $\begin{array}{l}\text { Rosmarinus officinalis } \\
\text { polyphenols }\end{array}$ & $\begin{array}{l}\text { Rosmarinus } \\
\text { officinalis } \\
\text { polyphenols }\end{array}$ & Antioxidant & $\begin{array}{l}\text { A burst release was detected in a lipophilic food simulant, } \\
\text { restricting its effectiveness over time. }\end{array}$ & $\begin{array}{l}\text { (Estevez-Areco et al., } \\
\text { 2018) }\end{array}$ \\
\hline
\end{tabular}


Table 3 (Continued)

\begin{tabular}{|c|c|c|c|c|c|}
\hline Polymer & Other ingredients & Active agent & $\begin{array}{l}\text { Active } \\
\text { properties }\end{array}$ & Remarks & Refs \\
\hline Poly(L-lactic acid) & $\begin{array}{l}\text { PEO, Defatted } \\
\text { mustard seed meal } \\
\text { powder (MSMP) }\end{array}$ & $\begin{array}{l}\text { Allyl } \\
\text { isothiocyanate } \\
\text { (AITC) }\end{array}$ & - & $\begin{array}{l}\text { Relative humidity-sensitive MSMP-containing nonwovens can } \\
\text { be used in active food packaging applications }\end{array}$ & (Dai \& Lim, 2015) \\
\hline Poly(L-lactic acid) & Thymol & Thymol & - & $\begin{array}{l}\text { The rate of thymol release was drastically slower with the } \\
\text { incorporation of PV/CNC nanofibers into the polymer } \\
\text { structure. }\end{array}$ & (Alvarado et al., 2018) \\
\hline Polycaprolactone & $\begin{array}{l}\text { Low-density } \\
\text { polyethylene (LDPE) } \\
\text { films, } \\
\text { electrosprayed } \mathrm{SiO}_{2}\end{array}$ & - & - & $\begin{array}{l}\text { The addition of silica mitigated the limonene (aroma) barrier } \\
\text { to some extent as a result of the higher surface-to-volume ratio } \\
\text { of the materials, for easy-to-empty packaging applications }\end{array}$ & $\begin{array}{l}\text { (Lasprilla-Botero et } \\
\text { al., 2018) }\end{array}$ \\
\hline $\begin{array}{l}\text { Poly(L-lactic acid), } \\
\text { Polycaprolactone, } \\
\text { Polyhydroxybutyrate }\end{array}$ & $\begin{array}{l}\text { Thermoplastic corn } \\
\text { starch (TPCS) film }\end{array}$ & - & - & $\begin{array}{l}\text { The incorporation of electrospun biopolyester coatings gave } \\
\text { rise to an exponential water vapor and oxygen permeability } \\
\text { drop as the content of the electrospun coating increased. }\end{array}$ & $\begin{array}{l}\text { (María José Fabra \& } \\
\text { Lagaron, 2016) }\end{array}$ \\
\hline Poly(L-lactic acid) & $\begin{array}{l}\text { Nisin- } \\
\text { phosphorylated } \\
\text { soybean protein } \\
\text { isolate, } \mathrm{ZrO}_{2}\end{array}$ & $\begin{array}{l}\text { Nisin- } \\
\text { phosphorylated } \\
\text { soybean } \\
\text { protein isolate, } \\
\mathrm{ZrO}_{2}\end{array}$ & Antibacterial & $\begin{array}{l}\text { The fibrous materials showed a well-controlled release and } \\
\text { higher antimicrobial activity against the growth of } S \text {. aureus. }\end{array}$ & (Jiang et al., 2015) \\
\hline $\begin{array}{l}\text { Poly(vinyl alcohol) } \\
\text { (PVA) }\end{array}$ & $\begin{array}{l}\text { Cinnamon essential } \\
\text { oil nanophytosome } \\
(\mathrm{N} / \mathrm{CEO})\end{array}$ & N/CEO & Antibacterial & $\begin{array}{l}\text { The N/CEO embedded PVA nanofibers showed antibacterial } \\
\text { activity on a raw shrimp for } 7 \text { days of storage. }\end{array}$ & (Nazari et al., 2019) \\
\hline
\end{tabular}


Table 4

Nanocomposite electrospun materials for food packaging applications.

\begin{tabular}{|c|c|c|c|c|c|}
\hline Polymer(s) & Nanoparticles & Acive agent & $\begin{array}{l}\text { Active } \\
\text { properties }\end{array}$ & Remarks & Ref \\
\hline $\begin{array}{l}\text { Polycaprolactone, } \\
\text { poly(L-lactic acid) }\end{array}$ & $\begin{array}{l}\text { Phycocyanin/PVA } \\
\text { nanoparticles }\end{array}$ & Phycocyanin & Antioxidant & $\begin{array}{l}\text { The nanoparticles had a nanoencapsulation efficiency } \\
\text { of } 75.1 \pm 0.2 \% \text { and exhibited antioxidant activity. }\end{array}$ & $\begin{array}{l}\text { (Schmatz, Costa, \& } \\
\text { Morais, 2019) }\end{array}$ \\
\hline Polyamide 11 & $\begin{array}{l}\text { Hallow nanotubes } \\
\text { (HNTs) loaded with } \\
\text { lysozyme ( } 50 \mathrm{wt} \% \text { of } \\
\text { lysozyme) }\end{array}$ & Lysozyme & Antimicrobial & $\begin{array}{l}\text { The films were exploited as antimicrobial pads for the } \\
\text { storage of chicken meat. }\end{array}$ & $\begin{array}{l}\text { (Bugatti, Vertuccio, } \\
\text { Viscusi, \& Gorrasi, 2018) }\end{array}$ \\
\hline $\begin{array}{l}\text { Polyhydroxybutyrate/ } \\
\text { Polycaprolactone }\end{array}$ & Silica having N-halamine & N-halamine & Antibacterial & $\begin{array}{l}\text { The fibers exhibited antibacterial activity against } S \text {. } \\
\text { aureus and E. coli O157: H7 with } 99.91 \% \text { and } 99.95 \% \\
\text { bacterial reduction within } 60 \text { min. }\end{array}$ & $\begin{array}{l}\text { (X. Lin, M. Yin, et al., } \\
\text { 2018) }\end{array}$ \\
\hline Poly(L-lactic acid) & $\mathrm{ZnO}$ and $\mathrm{SiO}_{2} / \mathrm{ZnO} \mathrm{NPs}$ & $\mathrm{ZnO}$ & Antibacterial & $\begin{array}{l}\text { The growth of } E \text {. coli was mitigated drastically from } \\
80 \% \text { to } 30 \% \text { when the highest } \mathrm{ZnO} \text { content was used. }\end{array}$ & $\begin{array}{l}\text { (Rokbani, Daigle, \& Ajji, } \\
\text { 2018) }\end{array}$ \\
\hline Poly(L-lactic acid) & Chitosan/CEO NPs & CEO & Antibacterial & $\begin{array}{l}\text { The resultant fibers exhibited long-term inactivation } \\
\text { rates against } S \text {. aureus and } E \text {. coli owing to the } \\
\text { sustained CEO release. }\end{array}$ & (Liu et al., 2017) \\
\hline Nylon-6 & Montmorillonite & - & Antifungal & $\begin{array}{l}\text { The nanofibers on PP films prolonged the shelf life of } \\
\text { foods and prevented lipid peroxidation, as well as } \\
\text { microbial growth by reducing moisture and oxygen } \\
\text { transfer. }\end{array}$ & (Agarwal et al., 2014) \\
\hline Cellulose acetate (CA) & $\begin{array}{l}\text { Poly(ethylene oxide } \\
\text { (PEO), ZnO } \\
\text { nanoparticles (NPs) }\end{array}$ & - & - & $\begin{array}{l}\text { The } \mathrm{ZnO} \text { NPs addition at } 20 \mathrm{wt} \% \text { of PEO gave rise to a } \\
\text { considerable improvement in the tensile strength and } \\
\text { elongation of the CA-PEO fibrous film. }\end{array}$ & (Pittarate et al., 2011) \\
\hline $\begin{array}{l}\text { Poly(3-hydroxybutyrate- } \\
\text { co-3-hydroxyvalerate } \\
\text { (PHBV) }\end{array}$ & $\begin{array}{l}\text { Mesoporous silica } \\
\text { nanoparticles (MSN) } \\
\text { with loaded eugenol }\end{array}$ & Eugenol & Antimicrobial & $\begin{array}{l}\text { The resultant PHBV films having } 10 \mathrm{wt} \% \text { of MSN } \\
\text { containing eugenol successfully inhibited bacterial } \\
\text { growth. }\end{array}$ & $\begin{array}{l}\text { (Melendez-Rodriguez et } \\
\text { al., 2019) }\end{array}$ \\
\hline Polycaprolactone (PCL) & Montmorillonite & - & - & $\begin{array}{l}\text { The incorporation of clay in the fibrous structure did } \\
\text { not alter the cell proliferation efficiency with respect } \\
\text { to the neat PCL matrix. }\end{array}$ & $\begin{array}{l}\text { (Samanta, Takkar, } \\
\text { Kulshreshtha, Nandan, \& } \\
\text { Srivastava, 2016) }\end{array}$ \\
\hline Polyhydroxybutyrate & $\begin{array}{l}\text { Palladium nanoparticles } \\
\text { (Pd-NPs), } \\
\text { cetyltrimethylammonium } \\
\text { bromide (CTAB) }\end{array}$ & Pd-NPs, & $\begin{array}{l}\text { Oxygen } \\
\text { scavenger }\end{array}$ & $\begin{array}{l}\text { The nanocomposites having CTAB showed the best } \\
\text { oxygen-scavenging performance in tested samples. }\end{array}$ & $\begin{array}{l}\text { (Cherpinski, Gozutok, et } \\
\text { al., 2018) }\end{array}$ \\
\hline $\begin{array}{l}\text { Poly(ethylene-co-vinyl } \\
\text { alcohol) }\end{array}$ & $\begin{array}{l}\text { Graphene nanoplatelets } \\
\text { (GNPs) }\end{array}$ & GNPs & Conductive & $\begin{array}{l}\text { The resultant nanocomposite electrospun mats were } \\
\text { conductive even with the maximum at } 0.5 \text { wt- } \% \text { GNPs } \\
\text { content. }\end{array}$ & $\begin{array}{l}\text { (Torres-Giner et al., } \\
\text { 2018) }\end{array}$ \\
\hline $\begin{array}{l}\text { Poly(vinyl alcohol), } \\
\text { Gum karaya }\end{array}$ & $\begin{array}{l}\text { Silver nanoparticles (Ag- } \\
\text { NPs) }\end{array}$ & Ag-NPs & Antibacterial & $\begin{array}{l}\text { The obtained fibers showed antibacterial activity } \\
\text { against } E \text {. coli, } S \text {. aureus, and } P \text {. aeruginosa. }\end{array}$ & $\begin{array}{l}\text { (Padil \& V., Nguyen, N. } \\
\text { H. A., Sevcu, A., Cernik, } \\
\text { M. , 2015) }\end{array}$ \\
\hline Polyhydroxybutyrate & $\begin{array}{l}\text { Bacterial cellulose } \\
\text { nanowhiskers (BCNW) }\end{array}$ & BCNW & & $\begin{array}{l}\text { The addition of BCNW between the layers resulted in } \\
\text { a reduction in the oxygen permeability values. }\end{array}$ & $\begin{array}{l}\text { (María José Fabra \& } \\
\text { Lagaron, 2016) }\end{array}$ \\
\hline Poly(ethylene oxide) & Montmorillonite & - & & $\begin{array}{l}\text { The film was produced with a very high oxygen } \\
\text { barrier }\left(0.2 \times 10^{-16} \mathrm{~cm}^{3} \mathrm{~cm} \mathrm{~cm}^{-2} \mathrm{~s}^{-1} \mathrm{~Pa}^{-1}\right) \text { and } \\
\text { moisture barrier }\left(4.6 \times 10^{-6} \mathrm{~g} \mathrm{~mm}^{-2} \mathrm{~s}^{-1} \mathrm{~atm}^{-1}\right. \\
\text { under the exposure of } 90 \% \text { humidity. }\end{array}$ & (Wang et al., 2018) \\
\hline Gelatin & Chitosan NPs & $\begin{array}{l}\text { Moringa } \\
\text { oil/chitosan } \\
\text { NPs }\end{array}$ & Antibacterial & $\begin{array}{l}\text { The resultant nanofibers exhibited high antibacterial } \\
\text { activity against } S \text {. aureus and L. monocytogenes at } 4{ }^{\circ} \mathrm{C} \\
\text { and } 25^{\circ} \mathrm{C} \text { after } 10 \text { days of treatment. }\end{array}$ & (Lin, Gu, et al., 2019) \\
\hline $\begin{array}{l}\text { Polycaprolactone, } \\
\text { Polyhydroxybutyrate }\end{array}$ & Pd-NPs & Pd-NPs & & $\begin{array}{l}\text { PCL/Pd-NPs biopaper showed much a higher oxygen } \\
\text { scavenging capacity than the sample having no Pd- } \\
\text { NPs. }\end{array}$ & $\begin{array}{l}\text { (Cherpinski, Szewczyk, } \\
\text { Gruszczyński, } \\
\text { Stachewicz, \& Lagaron, } \\
\text { 2019; Cherpinski et al., } \\
\text { 2018) }\end{array}$ \\
\hline Poly(L-lactic acid) & Ag-NPs, Vitamin E & $\begin{array}{l}\text { Ag-NPs, } \\
\text { Vitamin E }\end{array}$ & $\begin{array}{l}\text { Antibacterial, } \\
\text { antioxidant }\end{array}$ & $\begin{array}{l}\text { The fibers showed both antioxidant and antibacterial } \\
\text { activity. }\end{array}$ & (Munteanu et al., 2014) \\
\hline Quaternized chitosan & Organic rectorite (OREC) & $\begin{array}{l}\text { Quaternized } \\
\text { chitosan, } \\
\text { OREC }\end{array}$ & Antibacterial & $\begin{array}{l}\text { The antibacterial activity of the nanofibers increased } \\
\text { depending on the amount of the OREC increased. }\end{array}$ & (Deng et al., 2012) \\
\hline Gelatin & $\begin{array}{l}\text { Clove oil-loaded chitosan } \\
\text { nanoparticles } \\
\text { (CO@CNPs) }\end{array}$ & CO@CNPs & Antibacterial & $\begin{array}{l}\text { The antibacterial activity of the resultant nanofibers } \\
\text { was shown using cucumbers against } E \text {. coli O157: H7 } \\
\text { biofilm. }\end{array}$ & $\begin{array}{l}\text { (Cui, Bai, Rashed, et al., } \\
\text { 2018) }\end{array}$ \\
\hline
\end{tabular}

\section{References}

Agarwal, A., Raheja, A., Natarajan, T. S., \& Chandra, T. S. (2014). Effect of electrospun montmorillonite-nylon 6 nanofibrous membrane coated packaging on potato chips and bread. Innovative Food Science \& Emerging Technologies, 26, 424-430.

Alehosseini, A., Gómez-Mascaraque, L. G., Ghorani, B., \& López-Rubio, A. (2019). Stabilization of a saffron extract through its encapsulation within electrospun/electrosprayed zein structures. LWT, 113, 108280.
Alehosseini, A., Gómez-Mascaraque, L. G., Martínez-Sanz, M., \& López-Rubio, A. (2019). Electrospun curcumin-loaded protein nanofiber mats as active/bioactive coatings for food packaging applications. Food Hydrocolloids, 87, 758-771.

Alp-Erbay, E., Yeşilsu, A. F., \& Türe, M. (2019). Fish gelatin antimicrobial electrospun nanofibers for active food-packaging applications. Journal of Nano Research, 56, 80-97.

Altan, A., Aytac, Z., \& Uyar, T. (2018). Carvacrol loaded electrospun fibrous films from zein and poly(lactic acid) for active food packaging. Food Hydrocolloids, 81, 48-59.

Altekruse, S. F., Swerdlow, D. L., \& Stern, N. J. (1998). Campylobacter Jejuni. Veterinary Clinics of North America: Food Animal Practice, 14(1), 31-40. 
Alvarado, N., Romero, J., Torres, A., López de Dicastillo, C., Rojas, A., Galotto, M. J., \& Guarda, A. (2018). Supercritical impregnation of thymol in poly(lactic acid) filled with electrospun poly(vinyl alcohol)-cellulose nanocrystals nanofibers: Development an active food packaging material. Journal of Food Engineering, 217, 1-10.

Alves, V., Costa, N., Hilliou, L., Larotonda, F., Gonçalves, M., Sereno, A., \& Coelhoso, I. (2006). Design of biodegradable composite films for food packaging. Desalination, 199(1), 331-333.

Amna, T., Yang, J., Ryu, K.-S., \& Hwang, I. H. (2015). Electrospun antimicrobial hybrid mats: Innovative packaging material for meat and meat-products. Journal of Food Science and Technology, 52(7), 4600-4606.

Anka, F. H., \& Balkus, K. J. (2013). Novel nanofiltration hollow fiber membrane produced via electrospinning. Industrial \& Engineering Chemistry Research, 52(9), 3473-3480.

Anu Bhushani, J., \& Anandharamakrishnan, C. (2014). Electrospinning and electrospraying techniques: Potential food based applications. Trends in Food Science \& Technology, 38(1), 21-33.

Arkoun, M., Daigle, F., Heuzey, M.-C., \& Ajji, A. (2017). Antibacterial electrospun chitosan-based nanofibers: A bacterial membrane perforator. Food Science \& Nutrition, 5(4), 865-874.

Arkoun, M., Daigle, F., Heuzey, M.-C., \& Ajji, A. (2017). Mechanism of action of electrospun chitosan-based nanofibers against meat spoilage and pathogenic bacteria. Molecules (Basel, Switzerland), 22(4), 585

Arkoun, M., Daigle, F., Holley, R. A., Heuzey, M. C., \& Ajji, A. (2018). Chitosan-based nanofibers as bioactive meat packaging materials. Packaging Technology and Science, 31(4), 185-195.

Arrieta, M. P., Díez García, A., López, D., Fiori, S., \& Peponi, L. (2019). Antioxidant bilayers based on PHBV and plasticized electrospun PLA-PHB fibers encapsulating catechin. Nanomaterials (Basel, Switzerland), 9(3), 346.

Arrieta, M. P., López de Dicastillo, C., Garrido, L., Roa, K., \& Galotto, M. J. (2018). Electrospun PVA fibers loaded with antioxidant fillers extracted from Durvillaea antarctica algae and their effect on plasticized PLA bionanocomposites. European Polymer Journal, 103, 145-157.

Arrieta, M. P., López, J., López, D., Kenny, J. M., \& Peponi, L. (2015). Development of flexible materials based on plasticized electrospun PLA-PHB blends: Structural, thermal, mechanical and disintegration properties. European Polymer Journal, 73, 433-446.

Aruchamy, K., Mahto, A., \& Nataraj, S. K. (2018). Electrospun nanofibers, nanocomposites and characterization of art: Insight on establishing fibers as product. Nano-Structures \& Nano-Objects, $16,45-58$.

Ayala, A., Munoz, M., \& S, A. (2014). Lipid peroxidation: Production, metabolism, and signaling mechanisms of malondialdehyde and 4-hydroxy-2-nonenal. Oxidative Medicine and Cellular Longevity, 2014, 31

Aydogdu, A., Sumnu, G., \& Sahin, S. (2018). A novel electrospun hydroxypropyl methylcellulose/polyethylene oxide blend nanofibers: morphology and physicochemical properties. Carbohydrate Polymers, 181, 234-246.

Aydogdu, A., Yildiz, E., Aydogdu, Y., Sumnu, G., Sahin, S., \& Ayhan, Z. (2019). Enhancing oxidative stability of walnuts by using gallic acid loaded lentil flour based electrospun nanofibers as active packaging material. Food Hydrocolloids, 95, 245-255.

Aydogdu, A., Yildiz, E., Ayhan, Z., Aydogdu, Y., Sumnu, G., \& Sahin, S. (2019). Nanostructured poly(lactic acid)/soy protein/HPMC films by electrospinning for potential applications in food industry. European Polymer Journal, 112, 477-486.

Aytac, Z., Dogan, S. Y., Tekinay, T., \& Uyar, T. (2014). Release and antibacterial activity of allyl isothiocyanate/ $\beta$-cyclodextrin complex encapsulated in electrospun nanofibers. Colloids and Surfaces B: Biointerfaces, 120, 125-131.

Aytac, Z., Ipek, S., Durgun, E., Tekinay, T., \& Uyar, T. (2017). Antibacterial electrospun zein nanofibrous web encapsulating thymol/cyclodextrin-inclusion complex for food packaging. Food Chemistry, 233, 117-124.

Aytac, Z., Ipek, S., Durgun, E., \& Uyar, T. (2018). Antioxidant electrospun zein nanofibrous web encapsulating quercetin/cyclodextrin inclusion complex. Journal of Materials Science, 53(2), 1527-1539.

Aytac, Z., Keskin, N. O. S., Tekinay, T., \& Uyar, T. (2017). Antioxidant $\alpha$-tocopherol/ $\gamma$-cyclodextrin-inclusion complex encapsulated poly(lactic acid) electrospun nanofibrous web for food packaging. Journal of Applied Polymer Science, 134(21).

Aytac, Z., Kusku, S. I., Durgun, E., \& Uyar, T. (2016). Encapsulation of gallic acid/cyclodextrin inclusion complex in electrospun polylactic acid nanofibers: Release behavior and antioxidant activity of gallic acid. Materials Science and Engineering: C, 63, 231-239.

Aytac, Z., Kusku, S. I., Durgun, E., \& Uyar, T. (2016). Quercetin/ $\beta$-cyclodextrin inclusion complex embedded nanofibres: slow release and high solubility. Food Chemistry, 197, 864-871.

Aytac, Z., \& Uyar, T. (2016). Antioxidant activity and photostability of $\alpha$-tocopherol/ $\beta$-cyclodextrin inclusion complex encapsulated electrospun polycaprolactone nanofibers. European Polymer Journal, 79, 140-149.

Aytac, Z., \& Uyar, T. (2018). 13 - Applications of core-shell nanofibers: Drug and biomolecules release and gene therapy. In M. L. Focarete \& A. Tampieri (Eds.), Core-Shell Nanostructures for Drug Delivery and Theranostics (pp. 375-404): Woodhead Publishing.

Azeredo, H. M. C., Barud, H., Farinas, C. S., Vasconcellos, V. M., \& Claro, A. M. (2019). Bacterial cellulose as a raw material for food and food packaging applications. Frontiers in Sustainable Food Systems, 3(7).

Bailén, G., Guillén, F., Castillo, S., Serrano, M., Valero, D., \& Martínez-Romero, D. (2006). Use of activated carbon inside modified atmosphere packages to maintain tomato fruit quality during cold storage. Journal of Agricultural and Food Chemistry, 54(6), 2229-2235.
Balogh, A., Cselkó, R., Démuth, B., Verreck, G., Mensch, J., Marosi, G., \& Nagy, Z. K. (2015). Alternating current electrospinning for preparation of fibrous drug delivery systems. International Journal of Pharmaceutics, 495(1), 75-80.

Bhullar, S. K., Kaya, B., \& Jun, M. B.-G. (2015). Development of bioactive packaging structure using melt electrospinning. Journal of Polymers and the Environment, 23(3), 416-423.

Bugatti, V., Vertuccio, L., Viscusi, G., \& Gorrasi, G. (2018). Antimicrobial membranes of bio-based PA 11 and HNTs filled with lysozyme obtained by an electrospinning process. Nanomaterials (Basel, Switzerland), 8(3), 139.

Cacciotti, I., \& Nanni, F. (2016). Poly(lactic) acid fibers loaded with mesoporous silica for potential applications in the active food packaging. AIP Conference Proceedings, 1738(1), 270018.

Cai, X., Zhu, P., Lu, X., Liu, Y., Lei, T., \& Sun, D. (2017). Electrospinning of very long and highly aligned fibers. Journal of Materials Science, 52(24), 14004-14010.

Camerlo, A., Vebert-Nardin, C., Rossi, R. M., \& Popa, A. M. (2013). Fragrance encapsulation in polymeric matrices by emulsion electrospinning. European Polymer Journal, 49(12), 3806-3813.

Castro-Mayorga, J. L., Fabra, M. J., Pourrahimi, A. M., Olsson, R. T., \& Lagaron, J. M. (2017). The impact of zinc oxide particle morphology as an antimicrobial and when incorporated in poly(3-hydroxybutyrate-co-3-hydroxyvalerate) films for food packaging and food contact surfaces applications. Food and Bioproducts Processing, 101, $32-44$.

Castro-Mayorga, J. L., Randazzo, W., Fabra, M. J., Lagaron, J. M., Aznar, R., \& Sánchez, G. (2017). Antiviral properties of silver nanoparticles against norovirus surrogates and their efficacy in coated polyhydroxyalkanoates systems. LWT - Food Science and Technology, 79, 503-510.

Castro Mayorga, J. L., Fabra Rovira, M. J., Cabedo Mas, L., Sánchez Moragas, G., \& Lagarón Cabello, J. M. (2018). Antimicrobial nanocomposites and electrospun coatings based on poly(3-hydroxybutyrate-co-3-hydroxyvalerate) and copper oxide nanoparticles for active packaging and coating applications. Journal of Applied Polymer Science, 135(2), 45673.

Celebioglu, A., Topuz, F., \& Uyar, T. (2019). Water-insoluble hydrophilic electrospun fibrous mat of cyclodextrin-epichlorohydrin polymer as highly effective sorbent. ACS Applied Polymer Materials, 1(1), 54-62.

Celebioglu, A., Topuz, F., Yildiz, Z. I., \& Uyar, T. (2019). Efficient removal of polycyclic aromatic hydrocarbons and heavy metals from water by electrospun nanofibrous polycyclodextrin membranes. ACS Omega, 4(4), 7850-7860.

Celebioglu, A., \& Uyar, T. (2011). Electrospun porous cellulose acetate fibers from volatile solvent mixture. Materials Letters, 65(14), 2291-2294.

Cerqueira, M. A., Fabra, M. J., Castro-Mayorga, J. L., Bourbon, A. I., Pastrana, L. M., Vicente, A. A., \& Lagaron, J. M. (2016). Use of electrospinning to develop antimicrobial biodegradable multilayer systems: Encapsulation of cinnamaldehyde and their physicochemical characterization. Food and Bioprocess Technology, 9(11), 1874-1884.

Chalco-Sandoval, W., Fabra, M. J., López-Rubio, A., \& Lagaron, J. M. (2014). Electrospun heat management polymeric materials of interest in food refrigeration and packaging. Journal of Applied Polymer Science, 131(16).

Chalco-Sandoval, W., Fabra, M. J., López-Rubio, A., \& Lagaron, J. M. (2015). Development of polystyrene-based films with temperature buffering capacity for smart food packaging. Journal of Food Engineering, 164, 55-62

Chalco-Sandoval, W., Fabra, M. J., López-Rubio, A., \& Lagaron, J. M. (2017). Use of phase change materials to develop electrospun coatings of interest in food packaging applications. Journal of Food Engineering, 192, 122-128.

Cherpinski, A., Gozutok, M., Sasmazel, H. T., Torres-Giner, S., \& Lagaron, J. M. (2018). Electrospun oxygen scavenging films of poly(3-hydroxybutyrate) containing palladium nanoparticles for active packaging applications. Nanomaterials (Basel, Switzerland), 8(7), 469.

Cherpinski, A., Szewczyk, P. K., Gruszczyński, A., Stachewicz, U., \& Lagaron, J. M. (2019). Oxygen-scavenging multilayered biopapers containing palladium nanoparticles obtained by the electrospinning coating technique. Nanomaterials (Basel, Switzerland), 9(2), 262.

Cherpinski, A., Torres-Giner, S., Cabedo, L., \& Lagaron, J. M. (2017). Post-processing optimization of electrospun submicron poly(3-hydroxybutyrate) fibers to obtain continuous films of interest in food packaging applications. Food Additives \& Contaminants: Part A, 34(10), 1817-1830.

Cherpinski, A., Torres-Giner, S., Cabedo, L., Méndez, J. A., \& Lagaron, J. M. (2018). Multilayer structures based on annealed electrospun biopolymer coatings of interest in water and aroma barrier fiber-based food packaging applications. Journal of Applied Polymer Science, 135(24), 45501.

Cherpinski, A., Torres-Giner, S., Vartiainen, J., Peresin, M. S., Lahtinen, P., \& Lagaron, J. M. (2018). Improving the water resistance of nanocellulose-based films with polyhydroxyalkanoates processed by the electrospinning coating technique. Cellulose, 25(2), 1291-1307.

Clavijo-Grimaldo, D., Ponce-Zapata, N., \& Casadiego-Torrado, C. A. (2019). Control of bacterial proliferation and formation of biofilm in membranes for food packaging manufactured by electrospinning. Chemical Engineering Transactions, 75, 241-246.

Corradini, E., Curti, P. S., Meniqueti, A. B., Martins, A. F., Rubira, A. F., \& Muniz, E. C. (2014). Recent advances in food-packing, pharmaceutical and biomedical applications of zein and zein-based materials. International Journal of Molecular Sciences, 15(12), 22438-22470.

Cui, H., Bai, M., \& Lin, L. (2018). Plasma-treated poly(ethylene oxide) nanofibers containing tea tree oil/beta-cyclodextrin inclusion complex for antibacterial packaging. Carbohydrate Polymers, 179, 360-369.

Cui, H., Bai, M., Rashed, M. M. A., \& Lin, L. (2018). The antibacterial activity of clove oil/chitosan nanoparticles embedded gelatin nanofibers against Escherichia 
coli O157:H7 biofilms on cucumber. International Journal of Food Microbiology, 266, 69-78.

Cui, H., Wu, J., Li, C., \& Lin, L. (2017). Improving anti-listeria activity of cheese packaging via nanofiber containing nisin-loaded nanoparticles. LWT - Food Science and Technology, 81, 233-242.

Dai, R., \& Lim, L.-T. (2015). Release of allyl isothiocyanate from mustard seed meal powder entrapped in electrospun PLA-PEO nonwovens. Food Research International, 77, 467-475.

Dalton, P. D., Grafahrend, D., Klinkhammer, K., Klee, D., \& Möller, M. (2007). Electrospinning of polymer melts: Phenomenological observations. Polymer, 48(23), 6823-6833.

Daniels, J. A., Krishnamurthi, R., \& Rizvi, S. S. H. (1985). A review of effects of carbon dioxide on microbial growth and food quality. Journal of Food Protection, 48(6), 532-537.

Deng, H., Lin, P., Xin, S., Huang, R., Li, W., Du, Y., ... Yang, J. (2012). Quaternized chitosan-layered silicate intercalated composites based nanofibrous mats and their antibacterial activity. Carbohydrate Polymers, 89(2), 307-313.

Deng, L., Taxipalati, M., Zhang, A., Que, F., Wei, H., Feng, F., \& Zhang, H. (2018). Electrospun chitosan/poly(ethylene oxide)/lauric arginate nanofibrous film with enhanced antimicrobial activity. Journal of Agricultural and Food Chemistry, 66(24), $6219-6226$.

Dey, A., \& Neogi, S. (2019). Oxygen scavengers for food packaging applications: A review. Trends in Food Science \& Technology, 90, 26-34.

Dias Antunes, M., da Silva Dannenberg, G., Fiorentini, Â., Pinto, V. Z., Lim, L.-T., da Rosa Zavareze, E., \& Dias, A. R. G. (2017). Antimicrobial electrospun ultrafine fibers from zein containing eucalyptus essential oil/cyclodextrin inclusion complex. International Journal of Biological Macromolecules, 104, 874-882.

Díez-Pascual, A. M., \& Díez-Vicente, A. L. (2015). Antimicrobial and sustainable food packaging based on poly(butylene adipate-co-terephthalate) and electrospun chitosan nanofibers. RSC Advances, 5(113), 93095-93107.

Dumitriu, R. P., Mitchell, G. R., Davis, F. J., \& Vasile, C. (2017). Functionalized coatings by electrospinning for anti-oxidant food packaging. Procedia Manufacturing, 12, 59-65

Echegoyen, Y., Fabra, M. J., Castro-Mayorga, J. L., Cherpinski, A., \& Lagaron, J. M. (2017). High throughput electro-hydrodynamic processing in food encapsulation and food packaging applications: Viewpoint. Trends in Food Science \& Technology, 60, 71-79.

Echegoyen, Y., \& Nerín, C. (2013). Nanoparticle release from nano-silver antimicrobial food containers. Food and Chemical Toxicology, 62, 16-22.

Estevez-Areco, S., Guz, L., Candal, R., \& Goyanes, S. (2018). Release kinetics of rosemary (Rosmarinus officinalis) polyphenols from polyvinyl alcohol (PVA) electrospun nanofibers in several food simulants. Food Packaging and Shelf Life, 18, 42-50.

Fabra, M. J., Busolo, M. A., Lopez-Rubio, A., \& Lagaron, J. M. (2013). Nanostructured biolayers in food packaging. Trends in Food Science \& Technology, 31(1), 79-87.

Fabra, M. J., Castro-Mayorga, J. L., Randazzo, W., Lagarón, J. M., López-Rubio, A., Aznar, R., \& Sánchez, G. (2016). Efficacy of cinnamaldehyde against enteric viruses and its activity after incorporation into biodegradable multilayer systems of interest in food packaging. Food and Environmental Virology, 8(2), 125-132.

Fabra, M. J., López-Rubio, A., Ambrosio-Martín, J., \& Lagaron, J. M. (2016). Improving the barrier properties of thermoplastic corn starch-based films containing bacterial cellulose nanowhiskers by means of PHA electrospun coatings of interest in food packaging. Food Hydrocolloids, 61, 261-268.

Fabra, M. J., López-Rubio, A., Cabedo, L., \& Lagaron, J. M. (2016). Tailoring barrier properties of thermoplastic corn starch-based films (TPCS) by means of a multilayer design. Journal of Colloid and Interface Science, 483, 84-92.

Fabra, M. J., Lopez-Rubio, A., \& Lagaron, J. M. (2013). High barrier polyhydroxyalcanoate food packaging film by means of nanostructured electrospun interlayers of zein. Food Hydrocolloids, 32(1), 106-114.

Fabra, M. J., Lopez-Rubio, A., \& Lagaron, J. M. (2014). Nanostructured interlayers of zein to improve the barrier properties of high barrier polyhydroxyalkanoates and other polyesters. Journal of Food Engineering, 127, 1-9.

Fabra, M. J., López-Rubio, A., \& Lagaron, J. M. (2014). On the use of different hydrocolloids as electrospun adhesive interlayers to enhance the barrier properties of polyhydroxyalkanoates of interest in fully renewable food packaging concepts. Food Hydrocolloids, 39, 77-84.

Fabra, M. J., López-Rubio, A., \& Lagaron, J. M. (2016). Use of the electrohydrodynamic process to develop active/bioactive bilayer films for food packaging applications. Food Hydrocolloids, 55, 11-18.

Fabra, M. J., López-Rubio, A., Sentandreu, E., \& Lagaron, J. M. (2016). Development of multilayer corn starch-based food packaging structures containing $\beta$-carotene by means of the electro-hydrodynamic processing. Starch - Stärke, 68(7-8), 603-610.

Fan, X., Jiang, Q., Sun, Z., Li, G., Ren, X., Liang, J., \& Huang, T. S. (2015). Preparation and characterization of electrospun antimicrobial fibrous membranes based on polyhydroxybutyrate (PHB). Fibers and Polymers, 16(8), 1751-1758.

Fan, X., Ren, X., Huang, T.-S., \& Sun, Y. (2016). Cytocompatible antibacterial fibrous membranes based on poly(3-hydroxybutyrate-co-4-hydroxybutyrate) and quaternarized N-halamine polymer. RSC Advances, 6(48), 42600-42610.

Feng, K., Wen, P., Yang, H., Li, N., Lou, W. Y., Zong, M. H., \& Wu, H. (2017). Enhancement of the antimicrobial activity of cinnamon essential oil-loaded electrospun nanofilm by the incorporation of lysozyme. RSC Advances, 7(3), 1572-1580.

Feng, S., Zhang, F., Ahmed, S., \& Liu, Y. (2019). Physico-mechanical and antibacterial properties of $\mathrm{PLA} / \mathrm{TiO}_{2}$ composite materials synthesized via electrospinning and solution casting processes. Coatings, 9(8), 525.
Fernandez-Saiz, P. (2011). 20 - Chitosan polysaccharide in food packaging applications. In J.-M. Lagarón (Ed.), Multifunctional and Nanoreinforced Polymers for Food Packaging (pp. 571-593): Woodhead Publishing.

Figueroa-Lopez, K. J., Castro-Mayorga, J. L., Andrade-Mahecha, M. M., Cabedo, L., \& Lagaron, J. M. (2018). Antibacterial and barrier properties of gelatin coated by electrospun polycaprolactone ultrathin fibers containing black pepper oleoresin of interest in active food biopackaging applications. Nanomaterials (Basel, Switzerland), 8(4), 199.

Foltynowicz, Z. (2019). Nanoiron-based composite oxygen scavengers for food packaging. In Cirillo, G., Kozlowski, M.A., Spizzirri, U. G. (Ed.), Composites Materials for Food Packaging (pp. 209-234). Beverly, MA Scrivener Publishing.

Fonseca, L. M., de Oliveira, J. P., de Oliveira, P. D., da Rosa Zavareze, E., Dias, A. R. G., \& Lim, L.-T. (2019). Electrospinning of native and anionic corn starch fibers with different amylose contents. Food Research International, 116, 1318-1326.

Fuenmayor, C. A., Mascheroni, E., Cosio, M. S., Piergiovanni, L., Benedetti, S., Ortenzi, M., ... Mannino, S. (2013). Encapsulation of R- $(+)$-limonene in edible electrospun nanofibers. Chemical Engineering Transactions, 32, 1771-1776.

Fuertes, G., Soto, I., Carrasco, R., Vargas, M., Sabattin, J., \& Lagos, C. (2016). Intelligent packaging systems: Sensors and nanosensors to monitor food quality and safety. Journal of Sensors, 2016, 8.

Gaikwad, K. K., Singh, S., \& Ajji, A. (2019). Moisture absorbers for food packaging applications. Environmental Chemistry Letters, 17(2), 609-628.

Garc1, x, a-López, D., Picazo, O., Merino, J. C., \& Pastor, J. M. (2003). Polypropylene-clay nanocomposites: effect of compatibilizing agents on clay dispersion. European Polymer Journal, 39 (5), 945-950

Ge, L., Zhao, Y.-S., Mo, T., Li, J.-R., \& Li, P. (2012). Immobilization of glucose oxidase in electrospun nanofibrous membranes for food preservation. Food Control, 26(1), 188-193.

Ghaani, M., Cozzolino, C. A., Castelli, G., \& Farris, S. (2016). An overview of the intelligent packaging technologies in the food sector. Trends in Food Science \& Technology, 51, 1-11.

Gómez-Estaca, J., López-de-Dicastillo, C., Hernández-Muñoz, P., Catalá, R., \& Gavara, R. (2014). Advances in antioxidant active food packaging. Trends in Food Science \& Technology, 35(1), 42-51.

Gruenwald, J., Freder, J., \& Armbruester, N. (2010). Cinnamon and health. Critical Reviews in Food Science and Nutrition, 50(9), 822-834.

Gudjónsdóttir, M., Gacutan, M. D., Mendes, A. C., Chronakis, I. S., Jespersen, L., \& Karlsson, A. H. (2015). Effects of electrospun chitosan wrapping for dry-ageing of beef, as studied by microbiological, physicochemical and low-field nuclear magnetic resonance analysis. Food Chemistry, 184, 167-175.

Haider, A., Haider, S., \& Kang, I.-K. (2018). A comprehensive review summarizing the ef fect of electrospinning parameters and potential applications of nanofibers in biomedical and biotechnology. Arabian Journal of Chemistry, 11(8), 1165-1188.

Hamsici, S., Cinar, G., Celebioglu, A., Uyar, T., Tekinay, A. B., \& Guler, M. O. (2017) Bioactive peptide functionalized aligned cyclodextrin nanofibers for neurite outgrowth. Journal of Materials Chemistry B, 5(3), 517-524.

Han, D., Sherman, S., Filocamo, S., \& Steckl, A. J. (2017). Long-term antimicrobial effect of nisin released from electrospun triaxial fiber membranes. Acta Biomaterialia, 53, 242-249.

Han, D., \& Steckl, A. J. (2013). Triaxial electrospun nanofiber membranes for controlled dual release of functional molecules. ACS Applied Materials \& Interfaces, 5(16), 8241-8245.

Han, J.-W., Ruiz-Garcia, L., Qian, J.-P., \& Yang, X.-T. (2018). Food packaging: A comprehensive review and future trends. Comprehensive Reviews in Food Science and Food Safety, 17(4), 860-877.

Han, J. H. (2005). Antimicrobial packaging systems. In Han, J. H. (Ed.), Innovations in Food Packaging (pp. 80-107). London: Academic Press.

He, L., Lan, W., Ahmed, S., Qin, W., \& Liu, Y. (2019). Electrospun polyvinyl alcohol film containing pomegranate peel extract and sodium dehydroacetate for use as food packaging. Food Packaging and Shelf Life, 22, 100390

Heras-Mozos, R., Muriel-Galet, V., López-Carballo, G., Catalá, R., Hernández-Muñoz, P., \& Gavara, R. (2019). Development and optimization of antifungal packaging for sliced pan loaf based on garlic as active agent and bread aroma as aroma corrector. International Journal of Food Microbiology, 290, 42-48.

Hernández-López, S. H., Rodríguez-Carpena, J. G., Lemus-Flores, C., Galindo-García, J., \& Estévez, M. (2016). Antioxidant protection of proteins and lipids in processed pork loin chops through feed supplementation with avocado. Journal of Food Science and Technology, 53(6), 2788-2796.

Homaeigohar, S., Davoudpour, Y., Habibi, Y., \& Elbahri, M. (2017). The electrospun ceramic hollow nanofibers. Nanomaterials (Basel, Switzerland), 7(11), 383

Hwang, T. H., Lee, Y. M., Kong, B.-S., Seo, J.-S., \& Choi, J. W. (2012). Electrospun core-shell fibers for robust silicon nanoparticle-based lithium ion battery anodes. Nano Letters, 12(2), 802-807.

I. S. Arvanitoyannis, G. O. (2012). Active and intelligent packaging. In I. S. Arvanitoyannis (Ed.), Modified atmosphere and active packaging technologies (pp. 628-654). Boca Raton, Florida, U.S.A.: CRC Press.

Ignatova, M., Manolova, N., \& Rashkov, I. (2013). Electrospun antibacterial chitosan-based fibers. Macromolecular Bioscience, 13(7), 860-872.

Jaworek, A. (2007). Micro- and nanoparticle production by electrospraying. Powder Technology, 176(1), 18-35.

Jenab, A., Roghanian, R., Emtiazi, G., \& Ghaedi, K. (2017). Manufacturing and structural analysis of antimicrobial kefiran/polyethylene oxide nanofibers for food packaging. Iranian Polymer Journal, 26(1), 31-39. 
Jiang, S., Wang, H., Chu, C., Ma, X., Sun, M., \& Jiang, S. (2015). Synthesis of antimicrobial Nisin-phosphorylated soybean protein isolate/poly(l-lactic acid)/ZrO2 membranes. International Journal of Biological Macromolecules, 72, 502-509.

Jun, I., Han, H.-S., Edwards, J. R., \& Jeon, H. (2018). Electrospun fibrous scaffolds for tissue engineering: Viewpoints on architecture and fabrication. International Journal of Molecular Sciences, 19(3), 745.

Kara, H. H., Xiao, F., Sarker, M., Jin, T. Z., Sousa, A. M. M., Liu, C.-K., ... Liu, L. (2016). Antibacterial poly(lactic acid) (PLA) films grafted with electrospun PLA/allyl isothiocyanate fibers for food packaging. Journal of Applied Polymer Science, 133(2).

Katsogiannis, K. A. G., Vladisavljević, G. T., \& Georgiadou, S. (2015). Porous electrospun polycaprolactone (PCL) fibres by phase separation. European Polymer Journal, 69, 284-295.

Kayaci, F., Ertas, Y., \& Uyar, T. (2013). Enhanced thermal stability of eugenol by cyclodextrin inclusion complex encapsulated in electrospun polymeric nanofibers. Journal of Agricultural and Food Chemistry, 61(34), 8156-8165.

Kayaci, F., Sen, H. S., Durgun, E., \& Uyar, T. (2014). Functional electrospun polymeric nanofibers incorporating geraniol-cyclodextrin inclusion complexes: High thermal stability and enhanced durability of geraniol. Food Research International, 62, $424-431$.

Kayaci, F., Umu, O. C. O., Tekinay, T., \& Uyar, T. (2013). Antibacterial electrospun poly(lactic acid) (PLA) nanofibrous webs incorporating triclosan/cyclodextrin inclusion complexes. Journal of Agricultural and Food Chemistry, 61(16), 3901-3908.

Kayaci, F., \& Uyar, T. (2012). Encapsulation of vanillin/cyclodextrin inclusion complex in electrospun polyvinyl alcohol (PVA) nanowebs: Prolonged shelf-life and high temperature stability of vanillin. Food Chemistry, 133(3), 641-649.

Kerry, S. A. H. J. P. (2008). Smart packaging of meat and poultry products. In Kerry, P. B. J. (Ed.), Smart packaging technologies for fast moving consumer goods (pp. 33-59). West Sussex, England: John Wiley \& Sons Ltd.

Korehei, R., \& Kadla, J. (2013). Incorporation of T4 bacteriophage in electrospun fibres. Journal of Applied Microbiology, 114(5), 1425-1434.

Korehei, R., \& Kadla, J. F. (2014). Encapsulation of T4 bacteriophage in electrospun poly(ethylene oxide)/cellulose diacetate fibers. Carbohydrate Polymers, 100, 150-157.

Kuntzler, S. G., Almeida, A. C. A. d., Costa, J. A. V., \& Morais, M. G. d. (2018). Polyhydroxybutyrate and phenolic compounds microalgae electrospun nanofibers: A novel nanomaterial with antibacterial activity. International Journal of Biological Macromolecules, 113, 1008-1014.

Kuntzler, S. G., Costa, J. A. V., \& Morais, M. G. d. (2018). Development of electrospun nanofibers containing chitosan/PEO blend and phenolic compounds with antibacterial activity. International Journal of Biological Macromolecules, 117, 800-806.

Kuswandi, B. (2017). Freshness sensors for food packaging. Reference Module in Food. Science: Elsevier.

Lan, W., Liang, X., Lan, W., Ahmed, S., Liu, Y., \& Qin, W. (2019). Electrospun polyvinyl alcohol/d-limonene fibers prepared by ultrasonic processing for antibacterial active packaging material. Molecules (Basel, Switzerland), 24(4), 767.

Lasprilla-Botero, J., Torres-Giner, S., Pardo-Figuerez, M., Álvarez-Láinez, M., \& M. Lagaron, J. (2018). Superhydrophobic bilayer coating based on annealed electrospun ultrathin poly( $\varepsilon$-caprolactone) fibers and electrosprayed nanostructured silica microparticles for easy emptying packaging applications. Coatings, 8 (5).

Lee, D. S. (2016). Carbon dioxide absorbers for food packaging applications. Trends in Food Science \& Technology, 57, 146-155.

Lee, J.-S., Chang, Y., Lee, E.-S., Song, H.-G., Chang, P.-S., \& Han, J. (2018). Ascorbic acid-based oxygen scavenger in active food packaging system for raw meatloaf. Journal of Food Science, 83(3), 682-688.

Lee, S., \& Obendorf, S. K. (2007). Use of electrospun nanofiber web for protective textile materials as barriers to liquid penetration. Textile Research Journal, 77(9), 696-702.

Leyva Salas, M., Mounier, J., Valence, F., Coton, M., Thierry, A., \& Coton, E. (2017). Antifungal microbial agents for food biopreservation - A review. Microorganisms, 5(3), 37.

Li, L., Wang, H., Chen, M., Jiang, S., Jiang, S., Li, X., \& Wang, Q. (2018). Butylated hydroxyanisole encapsulated in gelatin fiber mats: Volatile release kinetics, functional effectiveness and application to strawberry preservation. Food Chemistry, 269, 142-149.

Lim, L. T. (2011). 4.52 - Active and intelligent packaging materials. In M. Moo-Young (Ed.), Comprehensive Biotechnology (Second Edition) (pp. 629-644). Burlington: Academic Press.

Lim, L. T. (2015). Encapsulation of bioactive compounds using electrospinning and electrospraying technologies. In Nanotechnology and Functional Foods: Effective Delivery of Bioactive Ingredients (pp. 297-317).

Lin, L., Dai, Y., \& Cui, H. (2017). Antibacterial poly(ethylene oxide) electrospun nanofibers containing cinnamon essential oil/beta-cyclodextrin proteoliposomes. Carbohydrate Polymers, 178, 131-140.

Lin, L., Gu, Y., \& Cui, H. (2018). Novel electrospun gelatin-glycerin-e-Poly-lysine nanofibers for controlling Listeria monocytogenes on beef. Food Packaging and Shelf Life, 18, 21-30.

Lin, L., Gu, Y., \& Cui, H. (2019). Moringa oil/chitosan nanoparticles embedded gelatin nanofibers for food packaging against Listeria monocytogenes and Staphylococcus aureus on cheese. Food Packaging and Shelf Life, 19, 86-93.

Lin, L., Mao, X., Sun, Y., Rajivgandhi, G., \& Cui, H. (2019). Antibacterial properties of nanofibers containing chrysanthemum essential oil and their application as beef packaging. International Journal of Food Microbiology, 292, 21-30.

Lin, L., Zhu, Y., \& Cui, H. (2018). Electrospun thyme essential oil/gelatin nanofibers for active packaging against Campylobacter jejuni in chicken. LWT, 97, 711-718.
Lin, X., Fan, X., Li, R., Li, Z., Ren, T., Ren, X., \& Huang, T.-S. (2018). Preparation and characterization of PHB/PBAT-based biodegradable antibacterial hydrophobic nanofibrous membranes. Polymers for Advanced Technologies, 29(1), 481-489.

Lin, X., Yin, M., Liu, Y., Li, L., Ren, X., Sun, Y., \& Huang, T.-S. (2018). Biodegradable polyhydroxybutyrate/poly-e-caprolactone fibrous membranes modified by silica composite hydrol for super hydrophobic and outstanding antibacterial application. Journal of Industrial and Engineering Chemistry, 63, 303-311.

Lin, Y., Yao, Y., Yang, X., Wei, N., Li, X., Gong, P., ... Wu, D. (2008). Preparation of poly(ether sulfone) nanofibers by gas-jet/electrospinning. Journal of Applied Polymer Science, 107(2), 909-917.

Liu, Y., Li, Y., Deng, L., Zou, L., Feng, F., \& Zhang, H. (2018). Hydrophobic ethylcellulose/gelatin nanofibers containing zinc oxide nanoparticles for antimicrobial packaging. Journal of Agricultural and Food Chemistry, 66(36), 9498-9506.

Liu, Y., Liang, X., Wang, S., Qin, W., \& Zhang, Q. (2018). Electrospun antimicrobial polylactic acid/tea polyphenol nanofibers for food-packaging applications. Polymers, 10(5).

Liu, Y., Vincent Edwards, J., Prevost, N., Huang, Y., \& Chen, J. Y. (2018). Physicoand bio-activities of nanoscale regenerated cellulose nonwoven immobilized with lysozyme. Materials Science and Engineering: C, 91, 389-394.

Liu, Y., Wang, S., Lan, W., \& Qin, W. (2019). Fabrication of polylactic acid/carbon nanotubes/chitosan composite fibers by electrospinning for strawberry preservation. International Journal of Biological Macromolecules, 121, 1329-1336.

Liu, Y., Wang, S., Zhang, R., Lan, W., \& Qin, W. (2017). Development of poly(lactic acid)/ chitosan fibers loaded with essential oil for antimicrobial applications. Nanomaterials (Basel, Switzerland), 7(7), 194.

Maftoonazad, N., \& Ramaswamy, H. (2018). Novel techniques in food processing: Bionanocomposites. Current Opinion in Food Science, 23, 49-56.

Malhotra, B., Keshwani, A., \& Kharkwal, H. (2015). Antimicrobial food packaging: potential and pitfalls. Frontiers in Microbiology, 6, 611-611.

Marcos, B., Sárraga, C., Castellari, M., Kappen, F., Schennink, G., \& Arnau, J. (2014). Development of biodegradable films with antioxidant properties based on polyesters containing $\alpha$-tocopherol and olive leaf extract for food packaging applications. Food Packaging and Shelf Life, 1(2), 140-150.

María José Fabra, A. L.-R., \& Lagaron, a. J. M. (2016). Nanostructured multilayers for food packaging by electrohydrodynamic processing. In Miguel Ângelo Parente Ribeiro Cerqueira, Ricardo Nuno Correia Pereira, Óscar Leandro da Silva Ramos, José António Couto Teixeira \& A. A. Vicente (Eds.), Edible Food Packaging - Materials and Processing Technologies. Boca Raton: CRC Press - Taylor \& Francis Group.

Marsh, K., \& Bugusu, B. (2007). Food packaging-roles, materials, and environmental issues. Journal of Food Science, 72(3), R39-R55.

Mascheroni, E., Fuenmayor, C. A., Cosio, M. S., Di Silvestro, G., Piergiovanni, L., Mannino, S., \& Schiraldi, A. (2013). Encapsulation of volatiles in nanofibrous polysaccharide membranes for humidity-triggered release. Carbohydrate Polymers, 98(1), 17-25.

Melendez-Rodriguez, B., Figueroa-Lopez, K. J., Bernardos, A., Martínez-Máñez, R., Cabedo, L., Torres-Giner, S., \& Lagaron, J. M. (2019). Electrospun antimicrobial films of poly(3-hydroxybutyrate-co-3-hydroxyvalerate) containing eugenol essential oil encapsulated in mesoporous silica nanoparticles. Nanomaterials (Basel, Switzerland), 9(2), 227.

Miller, K. S., \& Krochta, J. M. (1997). Oxygen and aroma barrier properties of edible films: A review. Trends in Food Science \& Technology, 8(7), 228-237.

Mills, A. (2009). Oxygen indicators in food packaging. In Baraton, M.-I. (Ed.), Sensors for Environment, Health and Security (pp. 371-388). Dordrecht: Springer, Netherlands.

Moreira, J. B., Lim, L.-T., Zavareze, E. d. R., Dias, A. R. G., Costa, J. A. V., \& Morais, M. G. d. (2018). Microalgae protein heating in acid/basic solution for nanofibers production by free surface electrospinning. Journal of Food Engineering, 230, 49-54.

Moreira, J. B., Lim, L.-T., Zavareze, E. d. R., Dias, A. R. G., Costa, J. A. V., \& Morais, M. G. d. (2019). Antioxidant ultrafine fibers developed with microalga compounds using a free surface electrospinning. Food Hydrocolloids, 93, 131-136.

Moreira, J. B., Morais, M. G. d., Morais, E. G. d., Vaz, B. d. S., \& Costa, J. A. V. (2018). Chapter 14 - Electrospun polymeric nanofibers in food packaging. In A. M. Grumezescu \& A. M. Holban (Eds.), Impact of Nanoscience in the Food Industry (pp. 387-417): Academic Press.

Moreira, J. B., Terra, A. L. M., Costa, J. A. V., \& Morais, M. G. d. (2018). Development of $\mathrm{pH}$ indicator from PLA/PEO ultrafine fibers containing pigment of microalgae origin. International Journal of Biological Macromolecules, 118, 1855-1862.

Moreno, M. A., Orqueda, M. E., Gómez-Mascaraque, L. G., Isla, M. I. \& López-Rubio, A. (2019). Crosslinked electrospun zein-based food packaging coatings containing bioactive chilto fruit extracts. Food Hydrocolloids, 95, 496-505.

Mousavi Khaneghah, A., Hashemi, S. M. B., \& Limbo, S. (2018). Antimicrobial agents and packaging systems in antimicrobial active food packaging: An overview of approaches and interactions. Food and Bioproducts Processing, 111, 1-19.

Müller, P., \& Schmid, M. (2019). Intelligent packaging in the food sector: A brief overview. Foods (Basel, Switzerland), 8(1), 16.

Munteanu, B. S., Aytac, Z., Pricope, G. M., Uyar, T., \& Vasile, C. (2014). Polylactic acid (PLA)/Silver-NP/VitaminE bionanocomposite electrospun nanofibers with antibacterial and antioxidant activity. Journal of Nanoparticle Research, 16(10), 2643.

Nazari, M., Majdi, H., Milani, M., Abbaspour-Ravasjani, S., Hamishehkar, H., \& Lim, L. T. (2019). Cinnamon nanophytosomes embedded electrospun nanofiber: Its effects on microbial quality and shelf-life of shrimp as a novel packaging. Food Packaging and Shelf Life, 21.

Nedovic, V., Kalusevic, A., Manojlovic, V., Levic, S., \& Bugarski, B. (2011). An overview of encapsulation technologies for food applications. Procedia Food Science, 1, $1806-1815$. 
Neo, Y. P., Ray, S., \& Perera, C. O. (2018). Chapter 4 - Fabrication of functional electrospun nanostructures for food applications. In Grumezescu, A. M., \& Holban, A. M. (Eds.), Role of Materials Science in Food Bioengineering (pp. 109-146). Academic Press.

Neo, Y. P., Swift, S., Ray, S., Gizdavic-Nikolaidis, M., Jin, J., \& Perera, C. O. (2013). Evaluation of gallic acid loaded zein sub-micron electrospun fibre mats as novel active packaging materials. Food Chemistry, 141(3), 3192-3200.

Neoh, T. L., Ariyanto, H. D., Menéndez Galvan, P., \& Yoshii, H. (2017). Controlled release of 1-methylcyclopropene from its functionalised electrospun fibres under constant and linearly ramped humidity. Food Additives \& Contaminants: Part A, 34(10), 1690-1702.

Nguyen Van Long, N., Joly, C., \& Dantigny, P. (2016). Active packaging with antifungal activities. International Journal of Food Microbiology, 220, 73-90.

Niu, B., Zhan, L., Shao, P., Xiang, N., Sun, P., Chen, H., \& Gao, H. (2019). Electrospinning of zein-ethyl cellulose hybrid nanofibers with improved water resistance for food preservation. International Journal of Biological. Macromolecules.

Noruzi, M. (2016). Electrospun nanofibres in agriculture and the food industry: A review. Journal of the Science of Food and Agriculture, 96(14), 4663-4678.

Ozdemir, M., \& Floros, J. D. (2004). Active food packaging technologies. Critical Reviews in Food Science and Nutrition, 44(3), 185-193.

Padrão, J., Machado, R., Casal, M., Lanceros-Méndez, S., Rodrigues, L. R., Dourado, F., \& Sencadas, V. (2015). Antibacterial performance of bovine lactoferrin-fish gelatine electrospun membranes. International Journal of Biological Macromolecules, 81, 608-614.

Pan, J., Ai, F., Shao, P., Chen, H., \& Gao, H. (2019). Development of polyvinyl alcohol/ $\beta$-cyclodextrin antimicrobial nanofibers for fresh mushroom packaging. Food Chemistry, 300, 125249.

Park, H. J., \& Chinnan, M. S. (1995). Gas and water vapor barrier properties of edible films from protein and cellulosic materials. Journal of Food Engineering, 25(4), 497-507.

Paster, N., Juven, B. J., Shaaya, E., Menasherov, M., Nitzan, R., Weisslowicz, H., \& Ravid, U. (1990). Inhibitory effect of oregano and thyme essential oils on moulds and foodborne bacteria. Letters in Applied Microbiology, 11(1), 33-37.

Peng, H., Liu, Y., \& Ramakrishna, S. (2017). Recent development of centrifugal electrospinning. Journal of Applied Polymer Science, 134(10)

Perera, C. O., Balchin, L., Baldwin, E., Stanley, R., \& Tian, M. (2003). Effect of 1-methylcyclopropene on the quality of fresh-cut apple slices. Journal of Food Science, 68(6), 1910-1914.

Pérez-Masiá, R., López-Rubio, A., \& Lagarón, J. M. (2013). Development of zein-based heat-management structures for smart food packaging. Food Hydrocolloids, 30(1), $182-191$.

Pittarate, C., Yoovidhya, T., Srichumpuang, W., Intasanta, N., \& Wongsasulak, S. (2011). Effects of poly(ethylene oxide) and $\mathrm{ZnO}$ nanoparticles on the morphology, tensile and thermal properties of cellulose acetate nanocomposite fibrous film. Polymer Journal, $43,978$.

Pizzimenti, S., Ciamporcero, E., Daga, M., Pettazzoni, P., Arcaro, A., Cetrangolo, G., Minelli, R., Dianzani, C., Lepore, A., Gentile, F., \& Barrera, G. (2013). Interaction of aldehydes derived from lipid peroxidation and membrane proteins. Frontiers in Physiology, 4, 242-242.

Powers, E. M., \& Berkowitz, D. (1990). Efficacy of an oxygen scavenger to modify the atmosphere and prevent mold growth on meal, ready-to-eat pouched bread. Journal of Food Protection, 53(9), 767-771.

Puligundla, P., Jung, J., \& Ko, S. (2012). Carbon dioxide sensors for intelligent food packaging applications. Food Control, 25(1), 328-333.

Radusin, T., Torres-Giner, S., Stupar, A., Ristic, I., Miletic, A., Novakovic, A., \& Lagaron, J. M. (2019). Preparation, characterization and antimicrobial properties of electrospun polylactide films containing Allium ursinum L. extract.. Food Packaging and Shelf Life, 21, 100357.

Realini, C. E., \& Marcos, B. (2014). Active and intelligent packaging systems for a modern society. Meat Science, 98(3), 404-419.

Robertson, G. L. (2006). Food Packaging: Princible and Practice Second Edition (2nd ed.). Boca Raton, FL: Taylor \& Francis.

Robertson, G. L. (2014). Food Packaging. In Van Alfen, N. K. (Ed.), Encyclopedia of Agriculture and Food Systems (pp. 232-249). Oxford: Academic Press.

Rokbani, H., Daigle, F., \& Ajji, A. (2018). Combined effect of ultrasound stimulations and autoclaving on the enhancement of antibacterial activity of $\mathrm{ZnO}$ and $\mathrm{SiO}_{2} / \mathrm{ZnO}$ nanoparticles. Nanomaterials (Basel, Switzerland), 8(3), 129.

Rooney, M. L. (1995). Overview of active food packaging. In Rooney, M. L. (Ed.), Active Food Packaging (pp. 1-37). Boston, MA: Springer, US.

Rooney, M. L. (2005). 5 - Introduction to active food packaging technologies. In Han, J. H. (Ed.), Innovations in Food Packaging (pp. 63-79). London: Academic Press.

Salević, A., Prieto, C., Cabedo, L., Nedović, V., \& Lagaron, J. M. (2019). Physicochemi$\mathrm{cal}$, antioxidant and antimicrobial properties of electrospun poly( $\varepsilon$-caprolactone) films containing a solid dispersion of sage (Salvia officinalis L.) extract. Nanomaterials, 2, 270.

Samanta, A., Takkar, S., Kulshreshtha, R., Nandan, B., \& Srivastava, R. K. (2016). Electrospun composite matrices of poly( $\varepsilon$-caprolactone)-montmorillonite made using tenside free Pickering emulsions. Materials Science and Engineering: C, 69, 685-691.

Schmatz, D. A., Costa, J. A. V., \& Morais, M. G. d. (2019). A novel nanocomposite for food packaging developed by electrospinning and electrospraying. Food Packaging and Shelf Life, 20, 100314

Senthil Muthu Kumar, T., Senthil Kumar, K., Rajini, N., Siengchin, S., Ayrilmis, N., \& Varada Rajulu, A. (2019a). A comprehensive review of electrospun nanofibers: Food and packaging perspective. Composites Part B: Engineering, 175, 107074.
Senthil Muthu Kumar, T., Senthil Kumar, K., Rajini, N., Siengchin, S., Ayrilmis, N., \& Varada Rajulu, A. (2019b). A comprehensive review of electrospun nanofibers: Food and packaging perspective. Composites Part B: Engineering, 175.

Shao, P., Liu, Y., Ritzoulis, C., \& Niu, B. (2019). Preparation of zein nanofibers with cinnamaldehyde encapsulated in surfactants at critical micelle concentration for active food packaging. Food Packaging and Shelf Life, 22, 100385

Shao, P., Niu, B., Chen, H., \& Sun, P. (2018). Fabrication and characterization of tea polyphenols loaded pullulan-CMC electrospun nanofiber for fruit preservation. International Journal of Biological Macromolecules, 107, 1908-1914.

Shao, P., Yan, Z., Chen, H., \& Xiao, J. (2018). Electrospun poly(vinyl alcohol)/permutite fibrous film loaded with cinnamaldehyde for active food packaging. Journal of Applied Polymer Science, 135(16), 46117.

Sharif, N., Golmakani, M.-T., Niakousari, M., Hosseini, S. M. H., Ghorani, B., \& Lopez-Rubio, A. (2018). Active food packaging coatings based on hybrid electrospun gliadin nanofibers containing ferulic acid/hydroxypropyl-beta-cyclodextrin inclusion complexes. Nanomaterials (Basel, Switzerland), 8(11), 919.

Silva, F. T. d., Cunha, K. F. d., Fonseca, L. M., Antunes, M. D., Halal, S. L. M. E., Fiorentini, Â. M., Zavareze, E. d. R., \& Dias, A. R. G. (2018). Action of ginger essential oil (Zingiber officinale) encapsulated in proteins ultrafine fibers on the antimicrobial control in situ. International Journal of Biological Macromolecules, 118, 107-115.

Siracusa, V., Rocculi, P., Romani, S., \& Rosa, M. D. (2008). Biodegradable polymers for food packaging: A review. Trends in Food Science \& Technology, 19(12), 634-643.

Sisler, E. C., Dupille, E., \& Serek, M. (1996). Effect of 1-methylcyclopropene and methylenecyclopropane on ethylene binding and ethylene action on cut carnations. In A. R. Smith, A. W. Berry, N. V. J. Harpham, I. E. Moshkov, G. V. Novikova, O. N. Kulaeva \& M. A. Hall (Eds.), Plant Hormone Signal Perception and Transduction: Proceedings of the International Symposium on Plant Hormone Signal Perception and Transduction, Moscow, Russia, September 4-10, 1994 (pp. 127-134). Dordrecht: Springer Netherlands.

Sundaray, B., Subramanian, V., Natarajan, T. S., Xiang, R.-Z., Chang, C.-C., \& Fann, W.-S (2004). Electrospinning of continuous aligned polymer fibers. Applied Physics Letters, 84(7), 1222-1224

Uyar, T. Kny, E. (2017). Electrospun Materials for Tissue Engineering and Biomedical Applications: Research, Design and Commercialization. 1st ed.: 2017. Woodhead Publishing (Elsevier)

Tang, Y., Zhou, Y., Lan, X., Huang, D., Luo, T., Ji, J., ... Wang, W. (2019). Electrospun gelatin nanofibers encapsulated with peppermint and chamomile essential oils as potential edible packaging. Journal of Agricultural and Food Chemistry, 67(8), 2227-2234.

Tavakoli, H., Rastegar, H., Taherian, M., Samadi, M., \& Rostami, H. (2017). The effect of nano-silver packaging in increasing the shelf life of nuts: An in vitro model. Italian journal of food safety, 6 (4), 6874-6874.

Tian, J., Deng, H., Huang, M., Liu, R., Yi, Y., \& Dong, X. (2019). Chapter 15 - Electrospun nanofibers for food and food packaging technology. In Ding, B., Wang, X, \& Yu, J. (Eds.), Electrospinning: Nanofabrication and Applications (pp. 455-516). William Andrew Publishing.

Tian, J., Tu, H., Shi, X., Wang, X., Deng, H., Li, B., \& Du, Y. (2016). Antimicrobial application of nanofibrous mats self-assembled with chitosan and epigallocatechin gallate. Colloids and Surfaces B: Biointerfaces, 145, 643-652.

Tomasula, P. M., Sousa, A. M. M., Liou, S. C., Li, R., Bonnaillie, L. M., \& Liu, L. S. (2016) Short communication: Electrospinning of casein/pullulan blends for food-grade applications1. Journal of Dairy Science, 99(3), 1837-1845.

Topuz, F., Satilmis, B., \& Uyar, T. (2019). Electrospinning of uniform nanofibers of Poly mers of Intrinsic Microporosity (PIM-1): The influence of solution conductivity and relative humidity. Polymer, 178, 121610.

Topuz, F., \& Uyar, T. (2017). Electrospinning of gelatin with tunable fiber morphology from round to flat/ribbon. Materials Science and Engineering: C, 80, 371-378.

Topuz, F., \& Uyar, T. (2018). Electrospinning of cyclodextrin functional nanofibers for drug delivery applications. Pharmaceutics, 11(1).

Topuz, F., \& Uyar, T. (2018). Influence of hydrogen-bonding additives on electrospinning of cyclodextrin nanofibers. ACS Omega, 3(12), 18311-18322.

Topuz, F., \& Uyar, T. (2019). Electrospinning of nanocomposite nanofibers from cyclodextrin and laponite. Composites Communications, 12, 33-38.

Torres-Giner, S. (2011). Electrospun nanofibers for food packaging applications. In Lagarón, J.-M. (Ed.), Multifunctional and Nanoreinforced Polymers for Food Packaging (pp. 108-125). Woodhead Publishing.

Torres-Giner, S., Busolo, M., Cherpinski, A., \& Lagaron, J. M. (2018). Chapter 10 Electrospinning in the Packaging Industry. In Electrospinning: From Basic Research to Commercialization (pp. 238-260): The Royal Society of Chemistry.

Torres-Giner, S., Echegoyen, Y., Teruel-Juanes, R., Badia, J. D., Ribes-Greus, A., \& Lagaron, J. M. (2018). Electrospun poly(ethylene-co-vinyl alcohol)/graphene nanoplatelets composites of interest in intelligent food packaging applications. Nanomaterials (Basel, Switzerland), 8(10), 745.

Vanderroost, M., Ragaert, P., Devlieghere, F., \& De Meulenaer, B. (2014). Intelligent food packaging: The next generation. Trends in Food Science \& Technology, 39(1), 47-62.

Vellora Thekkae Padil, V., Nguyen, N. H. A., Sevcu, A., Cernik, M. (2015). Fabrication, characterization, and antibacterial properties of electrospun membrane composed of gum karaya, polyvinyl alcohol, and silver nanoparticles. Journal of Nanomaterials, 2015, 10.

Vergis, J., Gokulakrishnan, P., Agarwal, R. K., \& Kumar, A. (2015). Essential oils as natural food antimicrobial agents: A review. Critical Reviews in Food Science and Nutrition, 55(10), 1320-1323.

Wang, H., Hao, L., Wang, P., Chen, M., Jiang, S., \& Jiang, S. (2017). Release kinetics and antibacterial activity of curcumin loaded zein fibers. Food Hydrocolloids, 63, $437-446$. 
Wang, H., She, Y., Chu, C., Liu, H., Jiang, S., Sun, M., \& Jiang, S. (2015). Preparation, antimicrobial and release behaviors of nisin-poly (vinyl alcohol)/wheat gluten/ZrO2 nanofibrous membranes. Journal of Materials Science, 50(14), 5068-5078.

Wang, L., Liu, F., Jiang, Y., Chai, Z., Li, P., Cheng, Y., ... Leng, X. (2011). Synergistic antimicrobial activities of natural essential oils with chitosan films. Journal of Agricultural and Food Chemistry, 59(23), 12411-12419.

Wang, L., Mu, R.-J., Li, Y., Lin, L., Lin, Z., \& Pang, J. (2019). Characterization and antibacterial activity evaluation of curcumin loaded konjac glucomannan and zein nanofibril films. LWT, 113, 108293.

Wang, P., Wang, H., Liu, J., Wang, P., Jiang, S., Li, X., \& Jiang, S. (2018). Montmorillonite@chitosan-poly (ethylene oxide) nanofibrous membrane enhancing poly (vinyl alcohol-co-ethylene) composite film. Carbohydrate Polymers, 181, 885-892.

Wang, X., Yang, T., Li, X., \& Jiao, K. (2011). Three-step electrodeposition synthesis of self-doped polyaniline nanofiber-supported flower-like Au microspheres for high-performance biosensing of DNA hybridization recognition. Biosensors and Bioelectronics, 26(6), 2953-2959.

Wang, Z.-H., He, H.-W., Liu, G.-S., Yan, X., Ning, X., \& Long, Y.-Z. (2019). A newly reaction curing mechanism in conjugate electrospinning process. Materials Letters, 254, 5-8.

Wei, L., Sun, R., Liu, C., Xiong, J., \& Qin, X. (2019). Mass production of nanofibers from needleless electrospinning by a novel annular spinneret. Materials \& Design, 179, 107885.

Weiss, J., Kanjanapongkul, K., Wongsasulak, S., \& Yoovidhya, T. (2012). 13 - Electrospun fibers: Fabrication, functionalities and potential food industry applications. In Huang, Q. (Ed.), Nanotechnology in the Food, Beverage and Nutraceutical Industries (pp. 362-397). Woodhead Publishing.

Wen, P., Zhu, D.-H., Feng, K., Liu, F.-J., Lou, W.-Y., Li, N., ... Wu, H. (2016). Fabrication of electrospun polylactic acid nanofilm incorporating cinnamon essential oil/ $\beta$-cyclodextrin inclusion complex for antimicrobial packaging. Food Chemistry, 196, 996-1004.

Wen, P., Zhu, D.-H., Wu, H., Zong, M.-H., Jing, Y.-R., \& Han, S.-Y. (2016). Encapsulation of cinnamon essential oil in electrospun nanofibrous film for active food packaging. Food Control, 59, 366-376

Wen, Y., Li, Y., Si, Y., Wang, X., Li, F., Yu, J., \& Ding, B. (2015). Ready-to-use strip for l-ascorbic acid visual detection based on polyaniline/polyamide 66 nano-fibers/nets membranes. Talanta, 144, 1146-1154.

Xin, S., Li, X., Ma, Z., Lei, Z., Zhao, J., Pan, S., ... Deng, H. (2013). Cytotoxicity and antibacterial ability of scaffolds immobilized by polysaccharide/layered silicate composites. Carbohydrate Polymers, 92(2), 1880-1886.

Xue, J., Wu, T., Dai, Y., \& Xia, Y. (2019). Electrospinning and electrospun nanofibers: Methods, materials, and applications. Chemical Reviews, 119(8), 5298-5415.

Xue, J., Xie, J., Liu, W., \& Xia, Y. (2017). Electrospun nanofibers: New concepts, materials, and applications. Accounts of Chemical Research, 50(8), 1976-1987.

Xu, J., Liu, X., Zhang, Z., Wang, L., Tan, R., \& Zhang, D. (2019). Controllable generation of nanofibers through a magnetic-field-assisted electrospinning design. Materials Letters, $247,19-24$.

Yang, R., He, J., Xu, L., \& Yu, J. (2009). Bubble-electrospinning for fabricating nanofibers. Polymer, 50(24), 5846-5850.
Yang, Y., Li, W., Yu, D.-G., Wang, G., Williams, G. R., \& Zhang, Z. (2019). Tunable drug release from nanofibers coated with blank cellulose acetate layers fabricated using tri-axial electrospinning. Carbohydrate Polymers, 203, 228-237.

Yao, J., Zhang, S., Lim, L.-T., \& Chen, X. (2017). Investigation of isothiocyanate release from electrospun modified poly(L-lactic acid)/mustard powder composite fibers. Polymer Journal, 49, 449.

Yao, Z.-C., Chang, M.-W., Ahmad, Z., \& Li, J.-S. (2016). Encapsulation of rose hip seed oil into fibrous zein films for ambient and on demand food preservation via coaxial electrospinning. Journal of Food Engineering, 191, 115-123.

Yao, Z.-C., Chen, S.-C., Ahmad, Z., Huang, J., Chang, M.-W., \& Li, J.-S. (2017). Essential oil bioactive fibrous membranes prepared via coaxial electrospinning. Journal of Food Science, 82(6), 1412-1422.

Yildirim, S., Röcker, B., Pettersen, M. K., Nilsen-Nygaard, J., Ayhan, Z., Rutkaite, R., .. Coma, V. (2018). Active packaging applications for food. Comprehensive Reviews in Food Science and Food Safety, 17(1), 165-199.

Yilmaz, A., Bozkurt, F., Cicek, P. K., Dertli, E., Durak, M. Z., \& Yilmaz, M. T. (2016). A novel antifungal surface-coating application to limit postharvest decay on coated apples: Molecular, thermal and morphological properties of electrospun zein-nanofiber mats loaded with curcumin. Innovative Food Science \& Emerging Technologies, 37, 74-83.

Yousefi, H., Su, H.-M., Imani, S. M., Alkhaldi, K., M. Filipe, C. D., \& Didar, T. F. (2019). Intelligent food packaging: A review of smart sensing technologies for monitoring food quality. ACS Sensors, 4 (4), 808-821.

Zehetmeyer, G., Meira, S. M. M., Scheibel, J. M., de Brito da Silva, C., Rodembusch, F. S., Brandelli, A., \& Soares, R. M. D. (2017). Biodegradable and antimicrobial films based on poly(butylene adipate-co-terephthalate) electrospun fibers. Polymer Bulletin, 74 (8), 3243-3268.

Zhang, C., Feng, F., \& Zhang, H. (2018). Emulsion electrospinning: Fundamentals, food applications and prospects. Trends in Food Science \& Technology, 80, 175-186.

Zhang, W., Ronca, S., \& Mele, E. (2017). Electrospun nanofibres containing antimicrobial plant extracts. Nanomaterials (Basel, Switzerland), 7(2), 42.

Zhang, Z., Jin, F., Wu, Z., Jin, J., Li, F., Wang, Y., ... Wang, Y. (2017). O-acylation of chitosan nanofibers by short-chain and long-chain fatty acids. Carbohydrate Polymers, 177, 203-209.

Zhijiang, C., Cong, Z., Ping, X., \& Yunming, Q. (2018). Preparation, characterization and antibacterial activity of biodegradable polyindole/bacterial cellulose conductive nanocomposite fiber membrane. Materials Letters, 222, 146-149.

Zhong, T., Oporto, G. S., \& Jaczynski, J. (2017). 19 - Antimicrobial food packaging with cellulose-copper nanoparticles embedded in thermoplastic resins. In A. M. Grumezescu (Ed.), Food Preservation (pp. 671-702): Academic Press.

Zhou, X., Ma, Q., Dong, X., Wang, J., Yu, W., \& Liu, G. (2015). Flexible Janus nanofibers: A feasible route to realize simultaneously tuned magnetism and enhanced color-tunable luminescence bifunctionality. RSC Advances, 5(45), 35948-35957.

Zhu, L., Zaarour, B., \& Jin, X. (2019). Fabrication of perfect CMCS/PVA nanofibers for keeping food fresh via an in situ mixing electrospinning. Materials Research Express, 6(12), 125001

Zhu, Y., Cui, H., Li, C., \& Lin, L. (2019). A novel polyethylene oxide/Dendrobium officinale nanofiber: Preparation, characterization and application in pork packaging. Food Packaging and Shelf Life, 21, 100329. 